University of South Florida

DIGITAL COMMONS

@ UNIVERSITY OF SOUTH FLORIDA
Digital Commons @ University of

South Florida

Integrative Biology

\title{
Echinoids of the Indian Museum at Calcutta. II. Clypeasteroids and Cassiduloids: A Translation of Échinides de Musée Indien à Calcutta. II. Clypeastridés et Cassidulidés
}

René Koehler

John M. Lawrence

University of South Florida, lawr@usf.edu

\section{Recommended Citation}

Koehler, R. (2020). Echinoids of the Indian Museum at Calcutta. II. Clypeasteroids and Cassiduloids: A Translation of Échinides de Musée Indien à Calcutta. II. Clypeastridés et Cassidulidés (J. M. Lawrence, Trans.). Herizos Press, Tampa.

This Book is brought to you for free and open access by the Integrative Biology at Digital Commons @ University of South Florida. It has been accepted for inclusion in Integrative Biology Books by an authorized administrator of Digital Commons @ University of South Florida. For more information, please contact digitalcommons@usf.edu. 


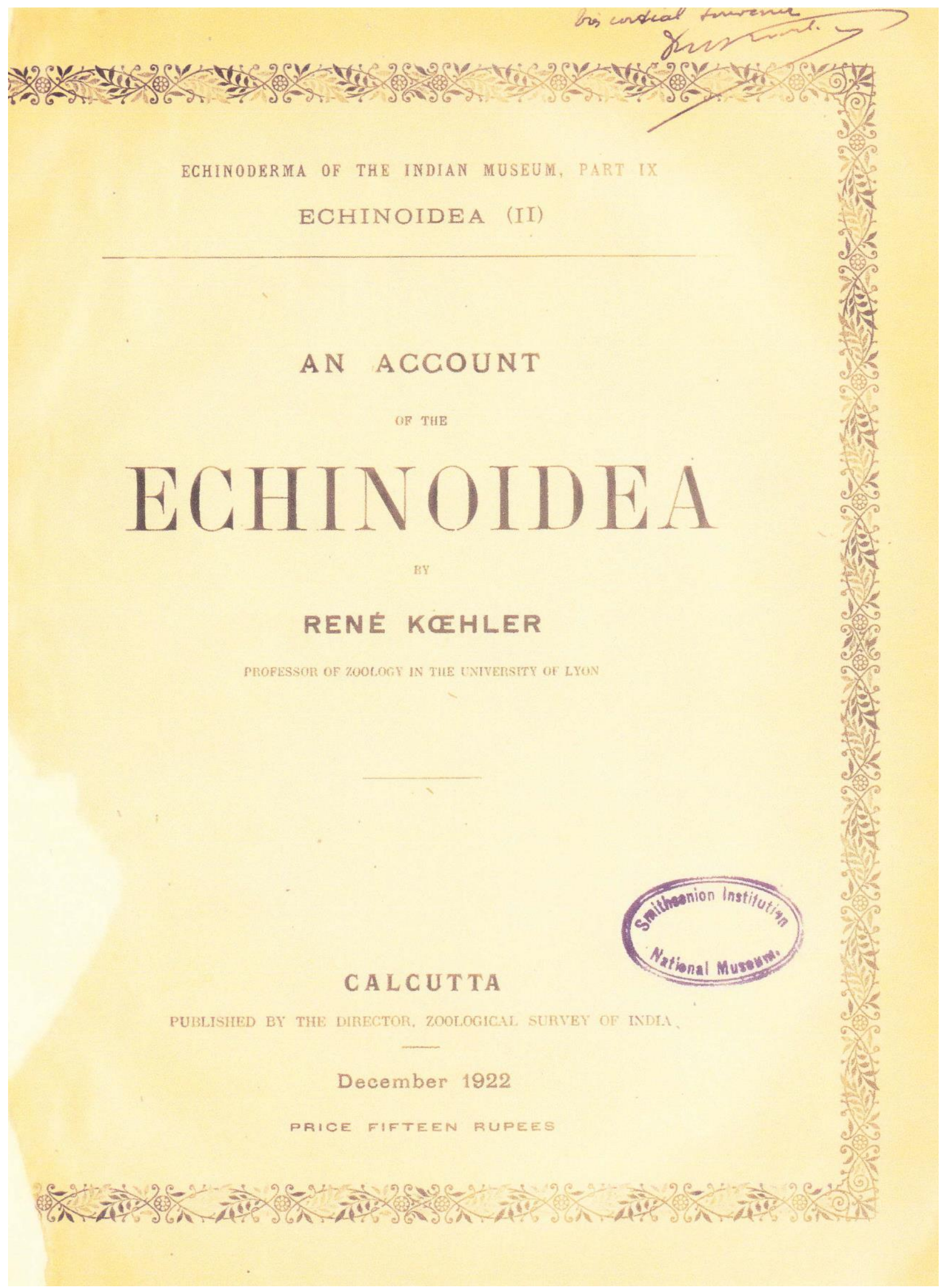




\section{B(IIIVITIES}

\section{MUSE I IUIEN \\ A CALCUTTA \\ RENE KEHLER}

II. Clypeastridés et Cassidulidés

OAIOUIIA

December 1922 
Kœhler, R. 1922. Echinoids of the Indian Museum at Calcutta. II. Clypeasteroids and Cassiduloids. Translated by John M. Lawrence.

(C) John M. Lawrence. Herizos Press, Tampa, Florida. 
Translator's notes:

Original grammar, punctuation, and spelling (even seemingly typographical errors) have been preserved.

p. 110. "Peronella decagonalis var. pallida. Pfeffer, 1181, p. 60." This probably should be "1881". p. 124. "Le plus grand exemplaire provient de "l'a côte de Ganjam et sa largeur, qui égale à peu près la longueur, dépasse 11.5 millimètres." This probably should be "The largest specimen comes from the coast of Ganjam and its width, nearly equal to its length, exceeds 115 millimeters."

Sometimes in station information, the greater depth precedes the shallower depth. E.g., " $6{ }^{\circ} 02^{\prime}$ N. $81^{\circ} 29^{\prime}$ E. $68-52$ fms." I have not changed these.

I have not changed the spelling of geographical names to current ones. E.g., p. 127, "Tavoy" has not been changed to "Dawei". 


\title{
ECHINOIDS
}

OF THE

\section{INDIAN MUSEUM AT CALCUTTA}

\author{
II. Clypeasteroids and Cassiduloids
}

This memoir follows the one I published in 1914 titled Echinoderma of the Indian Museum. Part VIII. Echinoidea. I. Spatangoidea. I had left to finish the study of the subclass of irregular echinoids to occupy myself with the Clypeasteroidea Gregory and of the Cassiduloidea Agassiz. The latter are very poorly represented in the collections of the Indian Museum and they contain only two species of Echinolampas, E. Alexandri and ovatus. I shall report, in addition, in this memoir, some dead tests of Echinoneus cyclostomus. The clypeasteroids are much more numerous and constitute a very important collection. As there are very numerous specimens of some species, it appeared interesting to me to dissect some to recognize, when the state of the specimens was suitable, the arrangement of internal organs. I have principally placed my attention on the digestive system. The anatomy of Clypeaster is, in fact, very poorly known. Whoever would have the happy chance to study living animals such as the large Clypeaster of the Antilles, the Red Sea or the Pacific, would certainly have the opportunity to observe very important new facts. In preserved animals, whose state of preservation - it is necessary to acknowledge — is far from satisfactory, investigations have been necessarily very limited. For some organs, it has not been possible to pursue these studies very far, still less to make histological investigations.

I mainly proposed to make some anatomical observations to investigate the relations that could exist between the internal structure and the systematic position of these echinoderms. As I was able to note various interesting particularities of their internal organization, I thought that there was reason to point them out here, despite the many gaps that remain to be filled, if only to invite zoologists, who may have at their disposal live animals or animals in good condition, to investigate the general anatomy for information likely to supplement those that can be provided by purely external characters for the determination or establishment of families, genera and species

Among the most interesting anatomical characters that I have seen in clypeasteroids, I shall report most particularly the presence of a distinct gland, an appendage of the digestive tube whose 
existence had never been suspected until now. This gland, elongated and applied against the first part of the ventral intestinal circumference, is located in the anterior part of the body of the urchin. It nearly follows the anterior radius III. It evidently produces secretions related to the digestion of food. It has the composition of a true gland. It has distinct acini, forming a compact mass and comparable to the diverticulum that we know in spatangoids, a hollow and sacciform organ attached to the first part of the ventral intestinal caecum. This gland, which I propose to call simply the intestinal gland, is found in all species of the genus Clypeaster s. lat. that I have studied, including Rhaphidoclypus reticulatus. I have found it in Arachnoides placenta. But very curiously it is completely missing in all other clypeasteroids. It thus exists in those where the auricles are separate and distinct and missing in those where the auricles are fused into a single piece in an interambulacral location. Here, the study of the anatomy of the digestive tube provides one more argument to zoologists that the arrangement of the auricles separate the clypeasteroids into two distinct groups.

I have also observed some variations in the arrangement of the intestinal siphon that depends on the family considered. We know that in regular echinoids, the entire length of the siphon is applied against the internal border of the ventral intestine, but that in spatangoids, it leaves the intestine immediately after its proximal opening and follows a direct path to find a little further the edge of the of the ventral intestine. Now, we find in clypeasteroids, depending on the group considered, one or the other of these arrangements. In the genera Clypeaster and Rhaphidoclypus, the siphon that originates toward the end of the esophagus, remains attached for its entire length against the internal edge of the loop of the ventral intestine. The same arrangement is found in Arachnoides placenta. This also occurs in scutellids, at least in the three genera I have studied, Echinodiscus, Echinarachnius and Rotula. To the contrary, the arrangement changes in the two other families. We have already seen that, in Echinocyamus pusillus, the siphon follows a direct and nearly transverse path to connect immediately the esophagus and the corresponding region of the loop of the ventral intestine. Now, I find the same arrangement, with variations, in another Echinocyamus from the Indian Ocean, as well as in the genus Fibularia and in all the family Langanidæ.

It is not only from the point of view of the variation of the organs, such as the digestive tube, that the study of the internal organs of clypeasteroids is interesting. I have no need to recall here the importance of the internal skeleton in animals, i.e., this ensemble of partitions and pillars that, in most of the clypeasteroids, extends from the dorsal surface to the ventral surface of the test and forms a very developed endoskeleton. The importance of this endoskeleton in classification does not need to be demonstrated. Authors have frequently used its characters. However, I think the importance of the endoskeleton has been often misunderstood and that we have too often neglected its study. The development of the internal calcareous pillars of the test, their form and arrangement can, in fact, furnish systematics with information of the first order. This information is of two kinds. It is appropriate to consider, on one hand, the character of the calcareous pillars themselves and, on the other hand, the relation of these pillars with the internal organs. It is especially the latter than appear to me to have too often been neglected. In fact, there is a relation of greatest importance between the endoskeleton and the development of the different internal organs, notably the digestive tube, to take as an example that is most striking. Compare, for example, in the genus Laganum, the endoskeleton of a species such as L. Bonani (Pl. IX, fig. 4), where the very reduced calcareous pillars are strictly localized in the periphery of the test, to that of L. decagonale (Pl. XI, fig. 3) in which the calcareous pillars have taken a considerable increase in width and at the same time that a more complicated arrangement, and where they fill more than half the general cavity, 
greatly reducing the space available for the digestive tube. We can ask ourselves if two species having characters do different can remain in the same genus. It would be appropriate evidently to revise the species of the genus Laganum to investigate if they can be separated into two groups, one of which would have an internal skeleton conforming to the type of L. Bonani and the others conforming to the type of $L$. decagonale. I unfortunately have not been able to examine a sufficiently large number of Laganum to undertake this investigation and I can for the moment only indicate an interest. The same remark applies to the genus Peronella.

We know that in the family Fibularidæ, the reduced internal partitions exist in the genus Echinocyamus and are missing in the genus Fibularia. I shall indicate later the differences that are present in the digestive tube of these two genera, differences that are correlated with the differences of the endoskeleton. In the genus Clypeaster s. lat, the internal partitions have very variable characters and differences. They are divided into peripheral pillars that occupy the borders of the test and form a more or less important border that more or less restricts the general cavity, and in central pillars developed especially in the interradial regions (Pl. III, fig. 1, 4 and 5, Pl. V, fig. 1, 2, 5 and 6 etc.). The arrangement of three pillars varies with the species. In the species formerly called Clypeaster reticulatus (Linnaeus) or scutiformis Lamarck (Pl VI, fig. 3 and 4), these marginal pillars are completely missing. The general cavity, which is not narrowed at its periphery, is very large. The digestive tube, which is not restricted in its development, comes to be located in the outermost part of the test. It fills the very border of that is relatively taller. The arrangement of the internal organs is thus completely different from that we know in other species of Clypeaster. I suggest it is impossible to leave $C l$. reticulatus in the latter genus. This is why I shall adopt the term Rhaphidoclypus, proposed by A. Agassiz, which he did not use.

Examination of the internal skeleton of clypeasteroids thus shows, for classification, a very great importance that is very often neglected. In addition, authors often have not taken into account the indications that it provides. This is because, at least in part, study of the internal skeleton requires dissection that destroys the specimens. We hesitate to do this when we do not have many specimens available. In some cases, when it involves small specimens with a flat body and a weakly pigmented integument, examination by transparency provides some information on the internal structure, less on the arrangement of the endoskeleton itself and the path of the digestive tube. We can examine the individual taken from alcohol, but it is often advantageous to clear them first in balm. I have thus obtained very good preparations of the digestive tube of Echnodiscus auritus, Laganum decagonale etc. But there is another process that permits recognition of the arrangement of internal columns and often of the digestive tube without submitting the specimens to the least preparation, without removing the least part of the test. Radiography is sufficient for this. Radiography permits, in fact, to obtain photographs in which is the internal skeleton is shown in the most perfect, best defined way, showing the finest ramifications that the pillars can form. Even better, the digestive tube generally can be recognized in the clearest way in the radiographs. I am surprised this technique has not been widely used up to now — not only in echinoderms but in many other animals. ${ }^{1}$ We can do this by examining some radiographs that I reproduce here (Pl. VIII, fig. 6, Pl. XIII, etc.). It is possible to obtain interesting results. It is necessary naturally to operate properly and to choose carefully the tubes producing X-rays. I recommend, to obtain the clearest and greatest finest in contours and details, to use very "soft" tubes. Naturally, direct study of specimens in which one of the surfaces of the body has been removed more or less completely

\footnotetext{
${ }^{1}$ It is necessary to cite the work of R. N. Wolfenden: Radiography in Marine Zoology. The British Echinodermata. Supplement to the Arhiv Rœntgen Ray. In 1, 6 p., 15 pl. 1897.
} 
will give still more precise information than radiography. But, I repeat, the latter process gives immediately and without the least effort for the zoologist, without the least damage to the specimens documentation of the first order.

\section{Clypeasteroids}

The collection of the INVESTIGATOR contains twenty-two species of clypeasteroids. Here is the list.

\section{CLYPEASTRID雨.}

Clypeaster Annandalei nov. sp.

Clypeaster destinatus nov. sp.

Clypeaster fervens nov. sp.

Clypeaster rarispinus Meijere.

Raphidoclypus reticulatus (Linné).

ARACHNOIDID $\bar{Æ}$.

Arachnoïdes placenta (Linné).

10

LAGANID $\bar{Æ}$.

Laganmn bonani Klein.

Laganum decayonale de Blainville.

Laganum depressum Lesson.

Laganum retinens nov. sp.

Laganum Rullandi nov. sp.

Laganum versatile nov. sp.

Peronella Lesueuri (L. Agassiz).

Peronella macroproctes nov. sp.

Peronella merguiensis nov. sp.

SCUTELLIDǢ.

Echinodiscus auritus Leske.

Echinodiscus bisperforatus Leske.

FIBULARIID $\bar{\AA}$

Echinocyamus sollers nov. sp.

Echinocyphus crispus Mazelli.

Fibularia craniolaris (Leske).

Fibularia cribellum Meijere.

Fibularia volva L. Agassiz. 
Among these twenty-two species, thirteen are already known and nine are new. These are in bold characters in the above list.

I also take advantage of the happy circumstance that permitted me to study some clypeasteroids from the Indian Ocean in order to describe and represent two new forms in the Jardin des Plantes. One is a Clypeaster very remarkable for its size and for the flatness of its body and that is represented by only a single dry specimen. The other is a Laganum close to Laganum tonganense coming from Mozambique and represented by two specimens.

\section{Clypeastridæ Agassiz}

\section{The family Clypeastridæ}

The family Clypeatridæ represents a group that we consider willingly as very homogeneous and in which it is not easy to make sections. In his work of 1914, H. L. Clark has recognized only two genera, Clypeaster, which contains all known species except one, in which the poriferous zones of the petals are more or less convex and the anus ventral, and the genus Anomalanthus, in which the poriferous zones are divergent and the anus marginal. This has only a single species, represented, it seems up to now, by a unique specimens whose origin itself is uncertain.

Authors who have most recently studied Clypeaster, H. L. Clark and Lambert, have undertood the genus Clypeaster in a very different way. H. L. Clark gives to the term Clypeaster a very vast extension. He has not sought to establish subdivisions in the genus or to use previously proposed subdivisions. He recognizes nineteen species among the living clypeasters, unfortunately without discussing the value of their characters or the synonymy of most of them. These are the following species, which I group according to their geographical distribution.

Cl. rosaceus (Linné), pallidus H. L. Clark, Ravenelii (A. Agassiz), subdepressus (Gray), lamprus H. L. Clark (= C. latissimus Agassiz 1883) and prostratus Ravenel, frorm the Antilles and the Atlantic coast of North America.;

Cl. ochrus H. L. Clark, speciosus Verrill, europacificus H. L. Clark, rotundus, A. Agassiz from the Pacific coast of America;

Cl. japonicus Dôderlein and virescens Dôderlein, from Japan;

Cl. leptostracon Agassiz and H. L. Clark, lytopetalus Agassiz and H. L. Clark, from the Hawaiian Islands;

Cl. Audouini Fourteau, humilis (Leske), from the Indian Ocean;

Cl. reticulatus (Linné), from the Indian and Pacific Oceans;

Cl. australasice Gray, from the southeast coast of Australia;

Cl. rarispinus Meijere, from the Sunda Islands.

In 1914, in his memoir on the synonymy of the living species of clypeasters, Lambert recognizes, among the former species, Cl. rosaceus, subdepressus, latissimus, Joubini Lambert (= Cl. ambigenus Michelin non Lamarck); ravenelii from the Antilles and the Atlantic:

Cl. reticulatus, humilis, productus and australasia Gray (the last synonym of $\mathrm{Cl}$. ambigenus Lamarck) from the Indian Ocean;

Cl. rotundus and speciosus from the Pacific. 
He added $\mathrm{Cl}$. Audouini and rarispinius, but considered them as purely nominal species, lacking sufficient description and figures; $C l$. clypeus, excelsior, japonicus and virescens of Dôderlein; $C l$. leptostracon and lytopetalus of Agassiz and H. L. Clark and $\mathrm{Cl}$. rotundus of'A. Agassiz.

Since the publication of the memoir of Lambert, $\mathrm{Cl}$. clypeus and excelsior have been transferred to $\mathrm{Cl}$. japonicus, and $\mathrm{Cl}$. japonicus, virescens, leptostracon and lytopetalus have been described and figured in a very satisfactory way by Clark.

If we compare the two lists above with each other, we see that Lambert cites a species that $\mathrm{H}$. L. Clark does not mention. It is $\mathrm{Cl}$. productus Gray of the Indian Ocean. This Cl productus appears to be a young form and perhaps a young $C l$. humilis. Clark does not mention it anywhere, not even among the synonyms of $\mathrm{Cl}$. humilis. $\mathrm{Cl}$. ambigenus Lamarck is considered by Lambert as synonymous with $\mathrm{Cl}$. testidunarius A. Agassiz and synonymous also with $\mathrm{Cl}$. australasiae Gray. Clark accepts part of the synonymy but he believes the species to which he reserves the name australasice is restricted to the southeast coast of Australia. Cl. ambigenus figured by Michelen is very different. Lambert proposes to call it $\mathrm{Cl}$. Joubini. On the other hand, Clark considers $\mathrm{Cl}$. prostratus Ravenel from Carolina as distinct from $\mathrm{Cl}$. subdepressus from the Antilles. The latter has, among others, tetradactyl pedicellariae. Lambert unites the two species. The two authors agree on the subject of $\mathrm{Cl}$. rosaceus, Ravenelii, Audouin, rarispinus, speciosus, reticulatus, humilis, rotundis, latissimus that Clark calls lamprus. ${ }^{2}$ The other species cited by Clark, Cl. pallidus, europacificus, ochrus, japonicus, virescens, leptostracon and lytopetalus were described and figured by him. Their validity appears to me beyond question and I think this should also be the opinion of Lambert now.

In summary, the genus Clypeaster should be given a very broad meaning, at least twenty-one living species that are the following: seven from the Antilles or the Atlantic (Cl. rosaceus, pallidus, Ravenelii, subdepressus, lamprus or latissimus, prostratus, Joubini); four from the Pacific $(\mathrm{Cl}$. ochrus, speciosus, europacificus, rotundus): two from Japan ( $\mathrm{Cl}$. japonicus, virescens); two from the Hawaiian Islands (Cl. lytopetalus. leptostracon); five from the Indian and Pacific Oceans $(\mathrm{Cl}$. reticulatus, .Audouini, humilis, rarispinus and australasiae) (the latter is synonymous with $\mathrm{Cl}$. testidunarius Agassiz); and one from Australia, Cl. telurus, recently described by H. L. Glark.

I have encountered, in the collections of the INVESTIGATOR very numerous $C l$. rarispinus and some $\mathrm{Cl}$. reticulatus, three new species of Clypeaster, of which one is remarkable for its elevated test, and which I describe under the names of $\mathrm{Cl}$. Annandalei, dispositus and fervens. In addition, I describe a new Clypeaster ( $\mathrm{Cl}$. amplificatus) belonging to the Jardin des Plantes and remarkable for its large size, coming from the Red Sea. The number of living species of Clypeaster is thus found to be twenty-five.

Before studying these diverse species, I would like to say some words about the classification of forms attributed to the genus Clypeaster s. lat. The number of the living species presently known is relatively low. The genus contains especially fossil species that have a variety and a richness of very remarkable forms. Zoologists have not been much concerned so far in sub-dividing the genus Clypeaster as they consider it, perhaps wrongly, as making a very homogeneous ensemble. But paleontologists who have had to examine a quantity of species have sought to divide them into a number of groups of unequal value and that do not appear to have even the value of sub-genera. It is worthwhile to investigate if the presently living forms can and should be placed in the groups accepted by the paleontologists, and if there is reason to continue to use the term Clypeaster in the broad sense indicated above and generally adopted in zoology.

\footnotetext{
${ }^{2}$ H. L. Clark has believed it necessary to replace the term latissimus with that of lamprus because the latissimus described by Agassiz in 1883 is not the same as that to which he attributed this name in 1872-1874.
} 
Lambert, in 1912, discussed the characters of sections previous established by authors, and in his work published in the Mémoires de la Société Paléontologique Suisse, vol. XXXVIII, he classified Clypeaster in two large categories, according to whether the lower surface of the test was concave or not. He proposed to place in the first category the genera Clypeaster, *Paleanthus ${ }^{3}$, Plesianthus, Rhaphidoclypus and *Dactylanthus; in the second group the genera *Bunactis, *Pliophyna, *Oxypleura. *Enryplcura, *Platypleura, * Laganidea and Stolonochjpus.

This classification has been modified in a very profound way in the work of Lambert and Thiéry, published in 1914 (p. 298-309). These authors notably proposed to establish various genera, among which I shall cite only the following that are of interest to living forms.

CLYPEASTER. - Test oval, of average size with the slightly projecting petals and often sickle-shaped poriferous zones. Lower surface largely concave, sometimes deepening into an infundibulum with five conspicuous ambulacra. The type is $\mathrm{Cl}$. rosaceus. Lambert and Thiéry add $\mathrm{Cl}$. ambigenenus Lamarck. I think there is reason to place in this section $\mathrm{Cl}$. pallidus, austalasice and japonicus.

CORONANTHUS. - Test of very large size, very depressed, oral surface with an infundibulum. Among the living forms, Lambert and Thiéry cite Cl. latissimus, rarispimis and Ravenelii. However, if, as Lambert and Thiéry indicate, Cl. rarispinus is in Coronanthus, it is necessary to remove from the diagnosis proposed by these authors the words "very large size" because $\mathrm{Cl}$. rarispinus is always fairly small.

STOLONOCLYPUS. - Test depressed without sharp edges; closed petals, slightlly projecting, internal pillars grouped into partitions dividing the general cavity. The type is $C I$. humilis. Lambert and Thiéry place in this section $\mathrm{Cl}$. Andouini, rotundus and subdepressus. We can also include $\mathrm{Cl}$. prostratus and telurus.

PARATINANTHUS. - Test oblong, upper surface convext, oblong, swollen test with convex upper surface, swollen under the petals; margin more or less extended, oral surface flat with a conspicuous peristomial infundibulum, moderately thick borders; petals half open. Lambert and Thiéry place in this section $\mathrm{Cl}$. Joubini and speciosis. I propose to add $\mathrm{Cl}$. ochrus and europacificus.

RHAPHIDOCLYPUS. - Test depressed, langaniform above; lower surface concave; swollen borrs, free interiorally; central pillars branched. The type is $\mathrm{Cl}$. reticulatus (Linné) $(=\mathrm{Cl}$. scutiformis A. Agassiz); There is place in this same genus for Cl. lytopetalus H. L. Clark.

The other sections of clypeasteroids are known only as fossils.

In his memoir of 1914, H. L. Clark suggested that instead of leaving all recent species of the family Clypeastridæ in the genus Clypeaster, with the exception of the single Australian form forming the type of the genus Anomalanthus. After havng studied most of the living forms, he was convinced, he said, that there are all the possible intermediaries in the form of the structure of the test.

${ }^{3}$ Genera marked with an asterisk are fossils. 
I do not completely agree with the opinion of the American scholar. I agree, like him, that most of the presently living clypeasters have, in their structure, a very great uniformity and we see that their internal organization likewise has very constant characters. Also we would attribute the values of true genera to the divisions established by paleontologists, so that Clypeaster s. str., Coronanthus, Stolonoclypus and Paratinanthus. At most, we could retain these terms as sections in which it is useful to distribute the various species of the genus Clypeaster. But it not the same, in my opinion, with Rhaphidoclypus that I consider a true genus, having the same value as the genus Clypeaster s. lat. and that I believe must be preserved. This genus was originally established by Agassiz in 1863. But it was not maintained by this author. Lambert and Thiéry have, correctly, re-established it in 1914. Among the characters that these authors attributed to it in their diagnosis, I call particularly attention to these words: "internally free swollen borders". In fact, while, as we shall see, in most presently living Clypeaster, the marginal region of the test is more or less filled interiorly by calcareous pillars that restricts the general cavity. In Rh. reticulatus, the borders of the test are free interiorly. We can be assured of this by comparing the photograph that I reproduce here of a Rh. reticulatus opened by the ventral surface (Pl. VI, fig. 4), to show the internal partitions and the digestive tube of the various species of Clypeaster that I have studied: Cl. Annandalei (PI. II, fig. 1), humilis (PI. III, fig. 1 and 4), destinatus (PI. V, fig. 6), (PI. V, fig. 1 and 2). In all these species, the digestive tube does not reach the border of the test itself, but remains more or less distant, the entire peripheral region being completely filled by branched and anastomosing calcareous pillars that fill this region. In Rh. reticulatus, to the contrary, the digestive tube occupies, in the general cavity, an absolutely marginal location. This arrangement is made possible by the complete absence of calcareous pillars in the peripheral part of this cavity. The pillars appear only in the intestinal loops. A similar arrangement is found in a species described by H. L. Clark under the name $\mathrm{Cl}$. lytopetalus, at least judging from the figure this scholar published in 1914 (Pl. CLXXXVIII, fig. 2).g

It seems impossible to me to leave in the same genus, species whose internal organization has such remarkable differences. This is why I suggest it is appropriate to maintain the genus Rhaphidoclypus in contrast to the genus Clypeaster that I preserve in giving it an extended meaning. The internal structure appears to have in all the species of this latter genus a very great uniformity. However, the pillars have incontestably a very variable development. It is appropriate to note with great care their arrangement and their development by using either open tests or radiographic views. It is also to be regretted that the information that we have on this subject from living forms is not more complete. It hardly permits us to use them for classification.

The digestive tube, which never reaches the marginal part of the body in the genus Clypeaster has the same characters everywhere. It comprises, as usual, a first loop or circumvolution after the esophagus and corresponding to the ventral loop of other irregular urchins and a recurrent loop corresponding to the dorsal loop of the latter. It is preferable not to use the names ventral and dorsal because, in clypeasteroids, whose body is flat, the two intestinal loops are nearly in the same plane. The loop called dorsal remains alone inside the preceding. It is preferable to use, to designate them, the words direct loop and recurrent loop, or even first loop and second loop (or circumvolution). I reported above a very remarkable character of the clypeasteroids, I want to speak of the gland attached to the first intestinal loop and is found toward the unpaired radius III. The intestinal siphon has a fairly short path. In all the family, it remains attached its entire length to the internal border of the first intestinal loop. It never becomes free any point. The Aristotle's lantern does not appear to have any very important variations. At most, it is appropriate to note its dimensions, either absolute or relative to the dimensions of the test. 
The pedicellariae of the Clypeastridæ are generally fairly numerous. They have three different forms, tridactyl, trifoliate and ophiocephalous. They always have three valves. Most characteristic are the triactyles. They reach fairly large sizes. The tube feet have always in the disks a calcareous rosette, but whose characters scarcely vary from one species to another.

\section{Clypeaster Annandalei nov. sp.}

(PI. I, fig. 1 to 7; PI. II, fig. 1 to 11; PI. III. fig. 6 to 9; PI. V, fig. 3; PL X, fig. 7; PI. XIV, fig. 1)

Station 130. Delta of the Godavoy, 281-258 fms. Nine specimens.

Station 360. 13³6' N.; 47 "32' E. 130 fms. About twenty specimens.

Some other specimens are found in jars without any label.

The specimens are usually in fairly good state of preservation, but in most, the test has some abrasion that has removed most of the spines. The specimens reach a fairly great size. In most of them, the length is between 70 and 80 millimeters. It can be greater because in the two largest specimens of the collection, it is 105 millimeters. In the smallest, the length is 61 millimeters. Here are the principal dimensions that I have noted for some specimens that I designate respectively by the letters A to $\mathrm{H}$ :

\begin{tabular}{|c|c|c|c|c|c|c|c|c|}
\hline & \multicolumn{7}{|c|}{ Specimens } & \multirow[b]{2}{*}{$\begin{array}{l}\mathrm{H} \\
\mathrm{m} / \mathrm{m}\end{array}$} \\
\hline & $\begin{array}{l}\mathrm{A} \\
\mathrm{m} / \mathrm{m}\end{array}$ & $\begin{array}{l}\mathrm{B} \\
\mathrm{m} / \mathrm{m}\end{array}$ & $\begin{array}{l}\mathrm{C} \\
\mathrm{m} / \mathrm{m}\end{array}$ & $\begin{array}{l}\mathrm{D} \\
\mathrm{m} / \mathrm{m}\end{array}$ & $\begin{array}{l}\mathrm{E} \\
\mathrm{m} / \mathrm{m}\end{array}$ & $\begin{array}{l}\mathrm{F} \\
\mathrm{m} / \mathrm{m}\end{array}$ & $\begin{array}{l}\mathrm{G} \\
\mathrm{m} / \mathrm{m}\end{array}$ & \\
\hline Length of test & 105 & 101 & 79 & 82 & 81 & 77 & 61 & 90 \\
\hline $\begin{array}{l}\text { Width between ends of radii II } \\
\text { and IV }\end{array}$ & 97 & 95 & 76 & 77 & 77 & 73 & 66 & 64 \\
\hline $\begin{array}{l}\text { Width between ends of radii I and } \\
\mathrm{V}\end{array}$ & 78 & 77 & 65 & 64 & 76 & 66 & 47 & 66 \\
\hline Width at the peristome & 93 & 92 & 72 & 72 & 65 & 70 & 49 & 80 \\
\hline Height & 34 & 30 & 28 & 22.5 & 35 & 24 & 20 & 32 \\
\hline $\begin{array}{l}\text { Length of the unpaired anterior } \\
\text { petal }\end{array}$ & 45 & 43 & 34 & 32 & 39 & 31 & 25 & 42 \\
\hline Length of the anterior petals & 43 & 44 & 30 & 32 & 39 & 31 & 25 & 42 \\
\hline Length of the posterior petals & 46 & 44 & 31 & 32 & 41 & 31 & 24.5 & 45 \\
\hline $\begin{array}{l}\text { Maximum width of the unpaired } \\
\text { anterior petal }\end{array}$ & 25.5 & 19 & 15.5 & 17 & 19 & 14 & 24.5 & 22 \\
\hline $\begin{array}{l}\text { Maximum width of the anterior } \\
\text { petals }\end{array}$ & 19 & 16 & 13 & 15 & 16 & 12.5 & 12 & 18 \\
\hline $\begin{array}{l}\text { Maximum width of the posterior } \\
\text { petals }\end{array}$ & 20 & 17 & 13 & 15 & 16 & 12.5 & 11 & 19 \\
\hline \multirow{2}{*}{$\begin{array}{l}\text { Maximum width of the } \\
\text { interporiferous zone of the } \\
\text { anterior petal }\end{array}$} & 11 & 9 & 7 & 8.4 & 10 & 5.5 & 11 & 11 \\
\hline & 18 & 13 & 13 & 11 & 14 & 11 & 5.5 & 13 \\
\hline
\end{tabular}




\begin{tabular}{|c|c|c|c|c|c|c|c|c|}
\hline $\begin{array}{l}\text { Distance between the end of the } \\
\text { unpaired anterior petals and the } \\
\text { border of the test }\end{array}$ & 14 & 13 & 13 & 11 & 10 & 12 & 11 & 11 \\
\hline $\begin{array}{l}\text { Distance between the end of one } \\
\text { of the anterior petals and the } \\
\text { border of the test }\end{array}$ & 16 & 14 & 12 & 11 & 12 & 11 & 11 & 12 \\
\hline $\begin{array}{l}\text { Distance between the end of one } \\
\text { of the posterior petals and the } \\
\text { border of the test }\end{array}$ & 13 & 7 & 6.5 & 8 & 7.5 & 7.4 & 11 & 11 \\
\hline $\begin{array}{l}\text { Difference between the last pores } \\
\text { of the unpaired anterior petal }\end{array}$ & 4 & 1.3 & 1.3 & 1.5 & 1.8 & 1.6 & 4 & 1.5 \\
\hline $\begin{array}{l}\text { Difference between the last pores } \\
\text { of the anterior petals }\end{array}$ & 5 & 3 & 1 & 1.5 & 2 & 2 & 1 & 2 \\
\hline $\begin{array}{l}\text { Difference between the last pores } \\
\text { of the posterior petals }\end{array}$ & $5 \times 3$ & $\begin{array}{c}5 \\
3.5 \mathrm{x}\end{array}$ & $\begin{array}{c}5 \\
3 \times 2\end{array}$ & $\begin{array}{c}5 \\
3 \times 3\end{array}$ & $\begin{array}{c}6 \\
3.5 \times 3\end{array}$ & $\begin{array}{c}4 \\
3.5 \mathrm{x}\end{array}$ & $\begin{array}{c}1 \\
5.3 \times 2\end{array}$ & $\begin{array}{c}5 \\
4 \times 3\end{array}$ \\
\hline $\begin{array}{l}\text { Diameter of the peristome } \\
\text { Width and length of the periproct } \\
\text { Ratio between the length and } \\
\text { height of the test }\end{array}$ & 3.08 & 33 & 2.8 & 3.65 & 2.3 & 3.2 & $\begin{array}{c}.8 \\
3\end{array}$ & 2.8 \\
\hline
\end{tabular}

We see that the test is in principle very high and the ratio between length and height varies ordinarily between 3.65 and 2.3, or, if one prefers, the height can vary between 46.6 and $33 \%$ of the length.

The contour of the body varies fairly little. Seen from the dorsal surface, the test has the form of a fairly regular pentagon, very slightly longer than wide with the corners fairly widely rounded and the sides slightly concave. This is especially evident in specimens of medium size. It is less evident in large individuals in which it sometimes happens that the two anterior sides are very slightly convex. The posterior border is also less concave than the four others. It can become nearly straight. The corner that correspond to the radial regions is fairly widely rounded so that the parts of the periphery of the test that border them are more important than the intermediate concave parts. For example, in a specimen in which the sides strictly speaking are each $15 \mathrm{~mm}$ in length, I measure 28 millimeters between the two extreme points of the curve that limits each of the corners. The test reaches its maximum width a little behind the ends of radius II and IV on a line that passes near the anterior gonopores, toward the posterior region of the two latero-anterior corners, which is a little more prominent than the anterior region of these same corners. This line is found a little before the middle of the length of the body. The two latero-posterior corners are a little narrower than the two latero-anterior corners and their anterior end is more projecting than the posterior end.

The ventral surface is nearly flat for the greatest part of its extent. It becomes depressed fairly rapidly near the peristome that is a little sunken. The five ambulacra that leave the latter are very conspicuous but very narrow. They disappear a short distance from the periphery of the test. The peristome is slightly further from the anterior border than the posterior border of the body. It does not correspond at all to the apical plate, but is found a little behind it. The periproct, sensibly wider than long, is near the posterior border of the test. It is separated from it by 2.5 to 3 millimeters in the individuals 80 millimeters in length. The border of the test is thick but not swollen. The dorsal surface is remarkably convex, much more elevated than in all the other known living clypeasters. The profile has a contour that we can better compare to that of a hat (Pl. II, fig 5 to 10). In general, 
the test is first elevated obliquely to the end of the petals. Then it becomes a little less oblique on the external fourth of it. It then elevates again to some distance from the apical plate where it follows the curve with the greater radius so that the top of the body is very rounded. In some specimens, like those that I represented in Pl II, fig 8 and 9, the top is more or less pointed and the form of the test is more like a shallow cone. Moreover, as I said above, the test itself varies rather greatly according to the individual.

The apical plate (Pl. I, fig. 3), of moderate size, is about 3 millimeters in diameter in a specimen 80 millimeters in length. It is pentagonal with indentations from the ocellar plates that are very small and whose openings are widened transversally. It has over its entire surface fine and irregularly distributed pores. Between them are some small secondary tubercles. The gonopores are in general small and sometimes even difficult to see. They are longer than wide.

The petals are very developed. They are elongated and fairly wide. They cover a good part of the dorsal surface of the test. They remain however separated from each other in the proximal region. The two rows of ambulacral plates that separate them at this level are always perfectly distinct. Thee petals are found absolutely flush with the test. They are not elevated above the surface of the test, neither in the interporiferous zones nor in the poriferous zones. They widen progressively for two thirds or three-fourths of their length. Then they narrow fairly rapidly. The unpaired anterior petal always remains very widely open at its distal end. The others are nearly completely closed. Also, the two lines that form the successive internal pores of each row can remain nearly exactly straight in the anterior petal in the large specimens where the lines diverge to the end of the petal. In smaller specimens, the two internal rows of pores approach each other in the last quarter of the petal. But they always remain very widely open at the end. In the paired petals, the two lines of internal pores, after separating from each other over three-fourths or even four-fifths the length of the petal, quickly approach each other and meet at the distal end. The pores of the same pair are very far apart from each other, especially in the widest part of the petal where the poriferous zone always remains narrower than the interporiferous zone. The pores are relatively large in each row, but especially those of the external row that are very widened transversely, three times wider than long, with the corner and the borders rounded, of irregular form and, moreover, a little unequal. The alignment is less regular than that of the internal pores that are small and very regularly rounded. A very conspicuous groove unites the two pores of each pair and the small rib that separates successive pairs has a very regular row of four to six primary, very separated tubercles. Outside them are some miliary tubercles.

The interporiferous zone of the anterior petal is rather wide. It widens progressively up to the distal end of the petal that is, we know, widely open. At its end, the width is 7 millimeters in specimen F. The width of this zone is, in general, greater than of the poriferous zone at the same level. Each plate has, on each side of the median suture, some widely separated primary tubercles of rather reduced dimensions. The number is usually not greater than three in the most enlarged part of the petal, with a large number of miliary tubercles (P1. II, fig. 11). In the lateral petals, the interporiferous zone widens progressively to about four-fifths the length of the petal. Then it narrows rapidly at approximately the fifth or sixth last pore pairs of each side. The petal does not absolutely close and the last two pores remain often separated by a space of 2 or 3 millimeters. This interporiferous zone is not as wide as on the unpaired anterior petal. In the widest part of the lateral petal, its width is in general hardly greater than that of the poriferous zone at the same level. However, this is in this regard, variation in the various specimens. The primary tubercles are naturally less numerous on the lateral petals than on the anterior petal. 
In specimen E, I count forty pore pairs on each side of the unpaired anterior petal. The first seven or eight are extremely small and irregular. There are thirty-nine on the latero-anterior petals and forty-two on the latero-posterior petals. The first six are always extremely small. In specimen F, I count thirty-three pore pairs on the anterior petals and thirty-four on the latero-posterior petals. The first five pore pairs are always very small. Toward the end of the petals we can encounter some irregular pores, sometimes isolated, sometimes arranged in pairs that are located outside the regular alignment of pores making up the petal strictly speaking. In specimen $\mathrm{C}$, for example, we can see such pores in the series IIIb, IIa, Ia, and Vb. These supplementary pairs are sometimes a little smaller than the normal pores, sometimes they have the same size.

After the petals, the ambulacral plates of each row rapidly have a great development. We can still count three up to the periphery of the test. They have rather small primary tubercles, not prominent and fairly widely separated, identical moreover to those of the interporiferous zones. They are often arranged in more or less apparent concentric zones, five or six per plate. Between thee primary tubercle are slightly projecting and very spaced miliary tubercles.

The interradial regions of the dorsal surface of the test are greatly narrowed up to the apical plate. Its tubercles have the same characters as in the ambulacral zones (Pl. V, fig. 3). However, the primary tubercles become slightly more projecting and notably denser in approaching the apical system. Near it, the width of each interradius decreases progressively to only 1 millimeter. But, as I have already said, the two rows of plates remain distinct up to the apical plate.

The ventral surface has the arrangement usually known in the genus Clypeaster. The ambulacral plates are much larger than the interambulacrals. At the periphery, these plates are four times wider than long. Each plate is nearly three times wider than the corresponding interambulacral. The primary tubercles are very regularly arranged on the entire ventral surface. They are a little larger and more numerous than on the dorsal surface. The scrobicular circles are also more conspicuous. The primary tubercles are likewise more projecting. The primary tubercles, arranged irregularly on the plates in the area of the peristome, are in concentric rows that are more or less apparent approaching the periphery of the test.

The ambulacral grooves are fine but conspicuous and fairly deep. They continue to the periphery of the test, but greatly attenuate one centimeter from the border.

Reaching the area of the peristome, the interambulacral and ambulacral zones abruptly sink, but we cannot say that there is a true infundibulum and the peristome is not very sunken, 3 to 4 millimeters in average. It is small, a little oval and widened transversally. The periproct is irregularly oval and notably wider than long. It is covered with numerous small plates that have some spines.

The large primary spines (Pl. XIV, fig. 1e) have in their second half some very fine small teeth, at first low and spaced. They come closer together near the end. The smaller primary spines have small teeth that are more numerous, denser and more pointed in the second third of their length that reaches 2 millimeter. The miliary spines (fig. 1f) are 07 to 1 millimeter in length. They have in the two-thirds of three-fourths of their length some teeth that are inconspicuous in the basal part and that develop progressive at the same time that they become denser. These teeth are conical, very pointed and directed obliquely. Then, in the terminal part, i.e., in the approximate third of their length, the spine sensibly enlarges and the teeth come closer together. This increase in size is more or less marked and can be enough to make the spines a little claviform.

The rosettes of the tube feet (fig. 1e) are 0.07 to 0.08 millimeters in diameter. Their structure recalls that figured for $\mathrm{Cl}$. rosaceus by Meijere in 1904 (pl. XVIII, fig. 553), with a single circle 
of perforations and a peripheral row of twenty to twenty-five slightly swollen and rounded lobes at the end.

I have encountered only two kinds of pedicellariae, tridactyles of two different forms, some fairly large and the others smaller, and trifoliate.

In the large tridactyls, the head is 0.5 millimeters in length. The basal part of the valves is very widened (Pl. XIV, fig. 1a), wider than long and its length exceeds a third of the total length of the valve. It is a little higher than wide and triangular. It remains at first wide in the first half, then narrows much more rapidly and is continuous with the narrow base of the blade. This gradually widens into a spoon of moderate width but elongated. It narrows fairly rapidly toward its end. Its borders have teeth at first extremely fine that become a little larger in the second half while always remaining low and fairly obtuse. The perforations of the blade are fairly large and arranged fairly regularly, small and denser than in the basal part. The lower arcs are moderately developed.

In the area of the peristome, these pedicellariae are sometimes a little shorter than usual, while their basal part is wider.

The small tridactyl pedicellariae (fig. 1b) are two times shorter than the preceding, and their head hardly exceeds 0.25 millimeter in length. Their structure is similar, but the width is greater in relation to the width. The blade forms a very wide spoon, round at the end. The length equals half the total length of the valve. The teeth are short, conical and a little pointed.

The valves of the trifoliate pedicellariae are scarcely 0.08 millimeter in length (fig. Id). The blade is very wide, round, nearly as wide as long and even sometime a little wider than long. It has extremely fine and very pointed teeth and separated from the basal part by a very narrow neck that remains very short. These pedicellariae are very abundant.

The color of the specimens in alcohol is a deep gray, sometimes purplish, sometimes greenish or brown.

$C l$. Annandale $i$ is represented in the collections of the INVESTIGATOR by numerous specimens. I have believed I could sacrifice some in order to study the internal organization that shows several interesting peculiarities. The anatomy of $\mathrm{Cl}$. Annandalei can moreover serve as a type for the anatomy in general of the genus Clypeaster.

Before beginning the study of the internal organs, I must first indicate an important character of $\mathrm{Cl}$. Annandalei that immediately hits the eye when we open a specimen. It is the remarkable thinness of the wall of the test. We are completely surprised at how little developed these walls are and the weak resistance they have. The dorsal surface is slightly thicker than the ventral surface, but the thickness does not exceed 0.9 millimeters in the area of the petals and is hardly 0.7 millimeters on the ventral surface. Toward the border of the test, the thickness of the wall increases a little. As a result of this, the test of $\mathrm{Cl}$. Annandale $i$ is very fragile. The ventral surface in particular is crushed and broken in many specimens.

The photograph in Pl. II, fig 1 gives a very good idea of the internal organs of $\mathrm{Cl}$. Annandalei. The animal being opened by the ventral surface, we can see, after having removed the Aristotle's lantern, that a good part of the general cavity is absolutely empty. The digestive system, not important as a whole, is completely in the outer third of the test radius. At some distance inside the border, the gonads do not form a very important mass, at least in the various specimens that I have opened. They hardly extend to the dorsal region of the body. The latter contains in its center the very narrow axial apparatus that is directed toward the apical plate and occupies the vertical axis of the body. This entire central region lacks calcareous pillars. They hardly appear except in the gonads, and even there they are not very developed. They become more numerous and denser 
outside the ventral intestinal loop, between this loop and the periphery of the test. We see the section of these pillars in the individuals whose ventral surface was removed as shown in Pl. II, fig 1. But we have a better understanding of their arrangement in the vertical sections, as I have represented in Pl. II, fig. 4 and 5. These pillars are dense and fairly numerous in the marginal region the test, but they exist only in a band whose width dos not exceed 6 millimeters on average. After this region comes a part absolutely lacking in pillars and filled with the digestive tube. Inside it, we encounter in the interradius some isolated pillars extending vertically from the dorsal surface to the ventral surface, only three to six in each interradius. These pillars cross the tissue of the gonads. The ambulacral regions are absolutely lacking in pillars, as is the case more over in the other Clypeaster, but what is especially striking in $\mathrm{Cl}$. Annandalei is the small number and little development of the pillars. They are thin, flattened in the radial direction. They break very easily. If one compares the vertical section of $\mathrm{Cl}$. Annandalei to that of another Clypeaster of the Indian Ocean, such as $\mathrm{Cl}$. humilis, we can see some differences exist in the number, development and thickness of the calcareous pillars, likewise also in the thickness of the wall of the test in the two species. The photographs that I reproduce here in Pl. I, fig 4 and 5 on one hand, and Pl. III, fig 5 on the other hand, show these differences. Immediately outside the sutural line that follows the middle of the unpaired anterior ambulacral III on the dorsal surface of the test, and to the right of this line when we look at the urchin opened by the ventral surface, we can see a series of small apophyses on the plates of series IIIa that are hardly 2 millimeters in high over a nearly equal length. These six to eight apophyses, which are flattened in the radial sense, follow each other on the internal surface of the test from the distal end of the petal about three-fifths of its length and stop a fairly great distance from the apical system, in which opens a similar apophysis, but smaller, on the edge of the madreporite (see Pl. I, fig. 5). These apopohyses function for the insertion of the mesenterial strands that attach the first portion of the intestinal loop to the test directed along radius III. Toward the end of the petals, we note two or three small similar apophyses. Finally the entire internal surface of the test is bristly with a considerable number of very fine needles that leave from the ventral surface and extend vertically for some distance. These needles occur also on the dorsal surface of the test but are less numerous there. They are composed of a hyaline calcareous tissue. They break very easily. See Pl. I, fig. 4, Pl. III, fig. 8.

The Aristotle's lantern is relatively little developed. In a specimen whose length is 80 millimeters, the length of the lantern in direction III-5 is 9 millimeters. I represent here the dorsal and ventral surface of the Aristotle's lantern (Pl. II, fig. 3 and 4) as well as various lateral views (Pl. III, fig 7 and 8), and finally a lateral view of an isolated jaw (Pl. III, fig. 6).

The pharynx enclosed in the Aristotle's lantern is thus extremely short and very narrow. The esophagus that follows it is short and flattened in the antero-posterior direction, i.e., following III 5. It is directed first obliquely in relation to the antero-posterior axis, but it curves very quickly in the direction of radius II and thus is flattened horizontally. I think it is preferable to keep the name esophagus for the part of the digestive tube flattened in antero-posterior direction and to fix the origin of the first loop at the point where the direction of flattening of the digestive tube changes by $90^{\circ}$. We shall see moreover that at this level appears glandular formations that permits fixing a very clear anatomical limit and to which I shall return later.

The first ventral intestinal loop, which corresponds to the ventral loop of other echinoids and that follows the esophagus, thus continues directly toward the anterior end of the body and nears the ventral side. It is in the middle of the unpaired ambulacrum III between the two rows of internal pores of the anterior petal. I have said that this intestinal loop was at its origin flattened in the 
horizontal direction and that it kept this form nearly all its path. Its surface is nearly smooth and it is rare that it has accentuated folds.

The esophagus is held in place by a vertical mesenterial strand that extends the length of its posterior border and that is located exactly in a vertical plane. This bade, triangular in form, is attached to the test following the median line of ambulacrum III by successive beams that run the length of one of its sides, while its third side runs the length of the axial gland that it supports that is moreover very small. After a path along the unpaired ambulacrum III, the intestine curves very rapidly toward interradius 3 , i.e., toward the right, the animal always being seen by the ventral surface, in describing an angle less than $90^{\circ}$ but widely rounded. It passes successively by radii IV, V, I and II to return to radius III while always remaining exactly in the same horizontal plane. Thus is determined the first loop of the digestive system or the ventral loop. The loop always passes a little the middle of ambulacrum II. It reaches the point where the first loop near its beginning had curved to the side. These two ends of the first intestinal loop are connected to each other by a mesenterial strand attached to the internal surface of the test by its external border. This continues the length of the external border of the first intestinal loop, but it is apparent only as single narrow and isolated strands. Some millimeters beyond the median line of radius III, the intestine, conforming to that which exists in all echinoids, changes direction abruptly in order to form the second intestinal loop or recurrent loop that corresponds to the dorsal loop of regular urchins and spatangoids. This takes place a little above but especially within the first loop. It is visible on nearly all its path when we look at the animal from the ventral side. At the posterior interradius 5 , it curves following a right angle to continue by a very short rectum.

The part of the digestive tube that follows the esophagus is first extremely narrow, but it enlarges rapidly during its entire path along radius III. The first intestinal loop reaches its maximum width, only about 5 millimeters, at the point where, having passed radius III, it abruptly curves at a right angle. It has the form of a tube with an extremely thin wall. It remains perfect flat in a horizontal plane. This first loop keeps nearly the same width or it very slightly widens to radius $1 \mathrm{~V}$. Then it narrows again and has a new enlargement at radius $\mathrm{V}$, in order to narrow again near interradiuis 5. Up to this moment, the digestive tube is still perfectly flat. I add that in all the specimens that I have opened, it is absolutely empty. But, after the posterior interradius 5, its diameter increases regularly. At the same time it becomes cylindrical. Its diameter decreases a little to 4 , sometimes even to 3 millimeters. We begin to see mud in the in the interior of the intestine. This change occurs toward the posterior interradius 5 . We see further that this is the point where the intestinal siphon opens. The diameter of the intestine remains fairly regular.

We shall examine more closely the various particularities of the digestive tube. It is very interesting and even unexpected.

From the point of view of the mesenterial attachments that support it, we note first that the triangular strand that I reported above and that connects to the posterior border of the esophagus at the dorsal surface of the test and to the axial gland, passes on both sides of the esophagus that it completely envelops and rejoins the internal border of the first intestinal loop along which it forms a mesenterial strand first free of any attachment on its internal border and is free in the liquid of the general cavity. This lamella has its maximum width in the part that corresponds to the point where the first ventral intestinal loop, after having passed radius II, recurves at a nearly right angle. Throughout its path, the mesenterial lamella has no attachment the length of its internal border, but the first intestinal loop is help in place very sufficiently by the calcareous pillars and needles of the test that surround the internal organs. In the posterior interradius 5, the internal mesenterial lamella has some attachments with the corresponding gonad. Beyond, it is connected to the 
external border of the second intestinal loop, attaching thus the latter to the corresponding part of the first loop. This same lamella likewise attaches to the two left gonads. Then, in anterior radius III, it connects to the external border of the first intestinal loop at its beginning.

As for the external border of the first intestinal loop, it is attached to the internal surface of the test by connective tissue strands, triangular and very thin, contiguous at the base, that pass between the calcareous pillars and are attached likewise to portions of the gonads that are extended through the calcareous pillars to the periphery of the test. The second intestinal loop, or recurrent loop, is closely applied against the second part of the first intestinal loop and, as I have said, it is connected to it by an extremely narrow mesenterial strand.

We shall now study more closely the gland related to the beginning of the intestine that I reported above. This gland begins at the end of the esophagus in the form of a thin, elongated mass that is developed along the internal border of the digestive tube located in the unpaired anterior radius III, i.e., up to the point where it curves with a right angle. The gland enlarges a little as it approaches the anterior end of the body. In the specimen represented in Pl. II, the gland is about 18 millimeters in length, its width is 2 millimeters in the posterior region and 3 millimeters in the anterior region. The gland has clusters of isolated acini that we can see with a magnifying glass. Its aspect recalls that of the gonads, but we distinguish easily the nearby gonads by its finer acini and its light brown color while these glands are grayer and darker.

Histological examination of the intestinal glands has not given me very interesting information on its structure because of the bad state of preservation of the pieces. The preparations have shown me numerous nuclei in the midst of connective tissue and cellular debris, recalling images from profoundly altered tissues.

This gland is closely associated with the intestine. However, I cannot affirm that it directly empties its secretory products into the digestive tube itself. It has not been possible for me to discover communications between the latter and the gland. But, in contrast, it is easy to confirm there is a close relation between the tissue of the gland and the intestinal absorbing system, and that the external marginal lacuna sends very numerous branches into the thickness of the issue. Or, if we prefer, the gland has channels that go into the external marginal lacuna. Examination of preparations clarified in baum containing both the gland and the adjacent region of the intestine shows these branches most clearly. The gland evidentlyt plays an important role in the digestion of our Clypeaster. I propose to give it simply the name intestinal gland.

This is the first time that a gland of this nature, and forming an organ very distinct of the intestine itself, has been observed in an echinoderm. Is it necessary to see in this gland a formation similar to a glandular apparatus annexed to the digestive tube of spatangoids and that we call the intestinal diverticulum, in the walls of which are seen, as we know, numerous branches of the intestinal absorbing system and that always form a large mass? The diverticulum that normally develops in the area of the anterior radius III has the form of a hollow sac that spreads especially in the dorsal region of the body and whose glandular wall secretes a liquid that goes into the first intestinal loop near radius III. But this glandular apparatus is very different in its location, form and relations to the intestinal gland of Clypeaster. I recall also that I have reported previously, in spatangoids of the Mediterranean, of true glands located in the very thickness of the walls of the first intestinal loop, exactly at the beginning of this loop and in the area at the point where the intestinal siphon begins. These glands, whose existence was doubted by Cuénot, have been found by other zoologists in other species. The presence of a perfectly differentiated glandular organ in Clypeaster should not thus surprise us. It is evidently in the beginning of the first intestinal loop that phenomena of the greatest importance in the digestion should occur. I.e., in this region the 
intestine is subject to a special situation thanks to the presence of the intestinal siphon that isolates it from the rest of the digestive tube.

The intestinal absorbing system contains, as in the other echinoids, two marginal lacunae, one eternal and the other internal. These marginal lacunae are not very apparent in $\mathrm{Cl}$. Annandalei because their color of a brownish gray is not very different from the color of the intestine itself or that of the mesenteries that accompany it. But they are much more apparent in other species, notably in $\mathrm{Cl}$. rarispinus of which I shall speak later. Their path is nearly the same, while staying a little simpler. Whatever it is, the internal marginal lacuna follows the anterior border of the esophagus and is applied against the free border of the mesenterial lamella that extends the length of the internal border of the first intestinal loop. It is accompanied outside by the intestinal siphon that is attached to it and that we shall return to later. These two canals remain thus first located some distance from the intestine itself. But they approach it little by little. They become bound to it toward interradius 4, to separate again a little in radius $\mathrm{V}$ and finally come together in a definitive way in interradius 5. The distal opening of the siphon is easily recognizable. As for the internal marginal lacuna, it continues its path beyond this opening along the second portion of the first intestinal loop, narrowing progressively. Up to here, these arrangements have nothing peculiar. But if we consider to the contrary this lacuna toward the beginning of the first intestinal loop, we note that it is bifurcated into two branches of unequal size. One, smaller, continues along the free border of the intestine, and then on the anterior border, likewise free, of the esophagus outside of the siphon to join the corresponding oral ring conforming to the general rule. The other larger branch is directed nearly transversally in relation to the antero-posterior axis of the body, completely to the beginning of the first intestinal loop. It crosses obliquely, closed applied on the ventral surface of this loop after having formed a small loop made up of two very short and nearly perpendicular although rounded corners. This marginal lacuna remains tightly applied to the ventral surface of the intestine where it is easy to distinguish - we recognize it very clearly in my photograph (Pl. II, fig. 1), thanks to its white color — and it reaches the external border (or radial) along which it is applied to the intestinal gland that we studied above. There this transverse branch divides again into two diametrically opposite branches and between the gland and the intestine. One of these branches, more important, goes toward the anterior end of the body, along the external border of the digestive tube, following the curve. It is the external marginal lacuna that extends along the entire length of the first intestinal loop. The other branch is directed toward the posterior end of the body, i.e., from the side of the Aristotle's lantern. But it narrows very rapidly and disappears at the esophagus. It is at these two longitudinal branches, running in opposite directions, which we can see end, and very probably open there, the numerous small branches that leave from the tissue of the intestinal gland that I reported above.

We thus see that the intestinal gland accompanies the first portion of the digestive tube for most of its path the length of the anterior system. It is in very intimate relation with the absorbing system. Moreover, the internal marginal lacuna communicates directly with the eternal marginal lacuna by the intermediary of a branch that crosses nearly transversely the path of the intestine on its very surface. I have found similar arrangements in the various species of Clypeaster of the Indian Ocean that I have studied, i.e., Cl. humilis, rarispinus as well as in the new species that I shall describe below under the name of $\mathrm{Cl}$. destinatus. These various species have the same intestinal gland as $\mathrm{Cl}$. Annandalei, in general a little less developed but having constantly the same relations.

We have generally accepted that the intestinal siphon is lacking in the clypeasteroids. Now this organ exists perfectly as we have just seen. It is seen not only in the genus Clypeaster but also, as 
we shall have the occasion to state later, in all the families known as clypeasteroids. The siphon has its origin, in $\mathrm{Cl}$. Annandalei, toward the point where the esophagus ceases and is continued as the digestive tube strictly speaking. The proximal opening is found there. From this point the siphon ascends and slightly enlarges toward the anterior end of the body in which the internal marginal lacuna crosses above the transverse branch that this lacuna sends toward the intestinal gland, and follows the curve of the intestine to the area of the posterior interradius where it opens by its distal opening. Here, the wall of the intestine abruptly becomes dark. But this change is not very apparent in $\mathrm{Cl}$. Annandalei because of the general deep color of all the internal organs. We see in the other species that this difference in color is much more conspicuous, notably in $\mathrm{Cl}$. rarispinus where the color of the digestive tube is a very light brownish yellow in the first part of its path between the Aristotle's lantern and the region corresponding to the distal opening of the siphon. There it abruptly takes a deep gray color beyond this opening. The internal and external marginal lacuna have a deep purple color while the siphon is usually whitish.

The gonads form in general in $\mathrm{Cl}$. Annandalei five very distinct and independent masses. They occupy the interradial regions at the level of the digestive tube, i.e., very near the ventral surface. In the specimens that I have opened, the principal part of each gland is a mass that, seen by the ventral surface, has a generally triangular form, with the base turned toward the periphery and a top protruding freely in the general cavity. This principal mass is crossed, as I have already had the occasion to say, by relatively few and little developed central calcareous pillars. Then the gonads extend on one hand, toward the top of the body, progressively narrowing as they near halfway or two-thirds of the height of the test and continue as very apparent gonoducts. The principal masses formed by the gonads are very distinct from each other in the specimens I have opened. But it is possible that at the moment of sexual maturity, these masses more or less merge with each other. We can see in the specimen whose photograph I reproduce here (Pl. II, fig. 2) that the two gonads 1 and 2 are connected to each other inside the digestive tube. On the other hand, the gonads are developed horizontally outside the digestive tube and go between the marginal calcareous pillars to the periphery of the test. The reticulated tissue that they form extend both into the ambulacral areas and the interambulacral areas. They are a spongy mass that fills all the intervals left between the pillars. The color of the gonads is a deep gray identical to that of the other internal organs.

Although the arrangement of the internal calcareous pillars can be easily recognized in the opened specimens, as I have represented in Pl. II, fig. 1, it is not without interest however to examine the radiography of entire individuals and to compare the images thus obtained with the direct preparation. I reproduce in Pl. X, fig. 7 the reduced radiograph of a specimen in which we recognize with the greatest ease the peripheral pillars and the central pillar. These are very reduced in number and development. The peripheral pillars form, together, a relatively thin border, a little thicker in the peripheral half than in the anterior half of the body.

SIMILARITIES AND DIFFERENCES - $\mathrm{Cl}$. Annandale $i$ is characterized essential by the contour of the pentagonal test with very rounded corners and nearly as long as wide in the adult, by the very elevated form of the test, by the extremely thin wall and by the weak development of the internal pillars. We are very surprised to encounter in a Clypeaster of such great size and very elevated test, the remarkable thinness of its wall and small number of internal calcareous pillars. When we would expect to find rather thick and solid walls at the same time as very developed pillars in relation to the height of the test. The living species that Ch. Annandalei is closest by its exterior form at least is $\mathrm{Cl}$. europacificus, described recently by $\mathrm{H}$. L. Clark after specimens found by the 
ALBATROSS at the Galapagos Islands, at Panama and on the coasts of California between 29 and $56 \mathrm{fms}$. But the form of the petals is completely different in the two species. They are in fact much wider with more separated pore pairs and the lateral petals are more completely closed in $\mathrm{Cl}$. Annandalei than in Cl. europacificus, To the contrary, the petals are less enlarged in $\mathrm{Cl}$. Annandalei than in other large species of Clypeaster such as $\mathrm{Cl}$. japonicus Dôderlein, virescens Dôderlein, australasiæ (Gray) and speciosus Verrill, from which it is completely separated, moreover, by its other characters.

Among the various divisions, genera or sub-genera, that authors have proposed to establish in the genus Clypeaster s. lat., there is none where $\mathrm{Cl}$. Annandalei can find its place. I think it is appropriate to establish for it a particular section to which I propose to give the name Leptoclypus ${ }^{4}$. It would be characterized essentially by the slightly elongated form, the flat ventral surface, the peristome not preceded by an infundibulum, the very elevated profile, the petals flush with the test and not joined together, wide poriferous zones, the unpaired anterior petal open and the lateral petals closed, the extremely thin and fragile test, very weak development of both the central and peripheral the internal calcareous pillars.

We shall see further on that a second species, likewise encountered by the INVESTIGATOR, could be placed in this same section of Leptoclypus. I have sent one of the specimens of $\mathrm{Cl}$. Annandalei to Lambert, asking him to indicate to me the fossil forms that could be attached. Here is the information that this echinoderm scholar had the kindness to communicate to me. $\mathrm{Cl}$. Annandalei has completely the form of some species of the sections Pliophyna and Oxyclypeina. They approach particularly $\mathrm{Cl}$. agyptiacus Wright from the Pliocene, but it differs by the absence of a true infundibulum while $\mathrm{Cl}$. altus. agyptiacus and other species of this section have without doubt a narrow infundibulum, but deep and perfectly characterized.

We find, it is true, flat lower surfaces, nearly lacking an infundibulum in the section Oxyclypeina, for example in $\mathrm{Cl}$. petasus Pomel and doma Pomel whose ventral surface recalls exactly that of $\mathrm{Cl}$. Annandalei. The latter, from the point of view of the former, thus approaches especially these Miocene species. But the similarities are limited. $\mathrm{Cl}$. Annandalei remains very different by its closed petals, with rows of very separated pores, by the thin test and the rarity of its tubercles, three or four only ono the ridges of the poriferous zones.

In summary, despite a general form that recalls some Oxyclypeina from the Miocene (Langhien and Hellvetian), $\mathrm{Cl}$. Annandalei has characteristics very different that do not permit us to related it to the Oxyclypeina group. It is a separate type that without doubt derive from this latter group but by still unknown intermediaries. As for the relative height of the individuals, it is very variable in the various Clypeaster. $\mathrm{Cl}$. Annandalei does not differ from the others in this relation. Although in $\mathrm{Cl}$. argyptiacus, the height is on average thirty-five hundredths of the length. But in some individuals, it decreases to $28 \%$ while it increases in others to $40 \%$ without other appreciable differences.

On the other hand, my excellent colleague, F. A. Bather of the British Museum has kindly indicated to me of a superficial resemblance that he found between $\mathrm{Cl}$. Annandalei and $\mathrm{Cl}$. suffarcinatus Duncan and Sladen (Paleontologica indica, series XIV, vol. I, part 3, vol. VI, 1886). This latter species comes from the Pleiocene of the coasts of Belouchistan and the Persian Gulf. It is not quite as tall as $\mathrm{Cl}$ Annandalei. It especially different in the closed petals and the convex interporiferous areas that are remarkably flat in $\mathrm{Cl}$. Annandalei.

\footnotetext{
${ }^{4}$ To recall the thinness of the wall of the test, $\lambda \dot{\varepsilon} \pi \tau 0 \sigma$, thin.
} 
I ask N. Annandale, Director of the Indian Museum, to kindly accept the dedication of this new species, in memory of the excellent relations that I have always had with him.

\section{Clypeaster destinatus nov. sp.}

(PL IV, fig. 1 to 7 and 10 to 13; PI. V, fig. 4 to 6; PI. XIV, fig. 3)

Station 146. $-11^{\circ} 05^{\prime} 45^{\prime \prime}$ N. $75^{\circ} 04^{\prime} 08^{\prime \prime} ; 36 \mathrm{fms}$. About fifteen specimens.

Station $246 .-11^{\circ} 14^{\prime} 30^{\prime \prime}$ N. $74^{\circ} 57^{\prime} 15^{\prime \prime}$ S. 68-148 fms. Three dry specimens.

East of Terribles; $13 \mathrm{fms}$. Two specimens.

The specimens are all much smaller than the preceding species, but it has a great resemblance to it that is also shown both in the exterior characters and in the internal structure, to the point that one can ask if $\mathrm{Cl}$. destinatus is only the young form of $\mathrm{Cl}$. Annandalei. I do not believe, however, that this supposition is correct because the exterior form of $\mathrm{Cl}$. destinatus does not conform exactly to that of $\mathrm{Cl}$. Annandalei. The test is comparably shorter and more elongated and I observe in the arrangement of the calcareous pillars, in the characters of the digestive tube as well as in the form of the pedicellaiae, more or less marked differences that do not permit referring the specimens of stations 146 and 246 and of Terribles to $C l$. Annandalei.

The body does not reach even an average size for a Clypeaster. It remains rather small. In the largest individuals, the length is not greater than 57 millimeters and in several, the length varies around 50 millimeters. In some it even is 40 millimeters. In a general way, the length is greater than the width, but sometimes the contour is regularly oval, sometimes it is pentagonal with rounded corners. In the first case, the maximum width is seen toward the middle of the length and the anterior region of the body is a little then. In the second case, the maximum with is at the end of the anterior petals. The specimen I have represented here (Pl. IV, fig. 1 and 4) and that I have designated by the letter $\mathrm{A}$, is moreover the largest of the collection. It is polygonal. The corners are very round, the lateral borders are not concave but straight or even slightly convex. The posterior border is a little rounded. In individual B (fig. 3), the contour is regularly oval with a slight narrowing in the anterior region of the body. I indicate in the following table the principal measurements that I have taken on the two specimens A and B and on two others a little smaller that I designat by the letters $\mathrm{C}$ and $\mathrm{D}$. Individual $\mathrm{C}$ has a contour nearly oval with, however, a slight tendency to take a slightly pentagonal form, while in D the pentagonal form is a little better marked. I designate by the letter E a fifth individual (Pl. IV, fig. 6 and 7) that shows a curious anomaly of which I shall speak later.

Length of test

Maximum width

Height at the apical plate

Length and width of the unpaired anterior petal

Length and width of the latero-anterior petals

\begin{tabular}{lllll}
\multicolumn{5}{c}{ Specimens } \\
\multicolumn{1}{c}{$\mathrm{A}$} & \multicolumn{1}{c}{$\mathrm{B}$} & \multicolumn{1}{c}{$\mathrm{C}$} & \multicolumn{1}{c}{$\mathrm{D}$} & \multicolumn{1}{c}{$\mathrm{E}$} \\
$\mathrm{m} / \mathrm{m}$ & $\mathrm{m} / \mathrm{m}$ & $\mathrm{m} / \mathrm{m}$ & $\mathrm{m} / \mathrm{m}$ & $\mathrm{m} / \mathrm{m}$ \\
57 & 57 & 52 & 44.5 & 40 \\
52 & 51 & 40 & 41 & 40 \\
13.7 & 11.5 & 12 & 10 & 9 \\
& & & & \\
$20.5 \times 11$ & $23 \times 12$ & $13.5 \times 10.5$ & $20 \times 9$ & $11 \times 8$ \\
$20 \times 9.5$ & $22 \times 11$ & $10.5 \times 9$ & $17 \times 8$ & $15 \times 5$
\end{tabular}


Length and width of the latero-posterior petals

Distance between the end of the unpaired anterior petal and the border of the test

Distance between the end of latero-anterior petals and the border of the test

Distance between the end of the lateroposterior petals and the border of the test Ratio of the length and height of the test

$\begin{array}{ccccc}21 \times 9 & 23 \times 10 & 18 \times 9 & 19 \times 8 & 13 \times 7.2 \\ 9.5 & 7.2 & 8 & 5.3 & 7.8 \\ 18.5 & 6.2 & 7 & 5 & 7.2 \\ 9 & 7.5 & 8 & 6.2 & 9.3 \\ 4.14 & 4.9 & 4.33 & 4.45 & 5.1\end{array}$

The test is fairly elevated. But, as we see by the numbers above, this height is not very great and the ratio between the length and height of the test varies between 4.14 and 5.1. The height gradually decreases up to the end of the petals, and then much more slowly. The borders are fairly thick and rounded.

The ventral surface is flat. But it is slightly depressed at some distance from the peristome that is a little sunken.

The apical plate is pentagonal with slightly concave sides (Pl. IV, fig. 11). Its slightly convex surface has numerous, irregularly arranged pores. The five gonopores are small and rounded. Each ocular pore forms a small slit, narrow and slightly curved.

The petals are not appreciably raised above the surface of the body. Their poriferous zones like their interporiferous zones are exactly flush with the test. The anterior petal is always a little more elongated than the others. If also is a little wider. It is widely open forward and, as a general rule, less in adult specimens. The interporiferous zone widens gradually toward the end of the petal. The line formed by the series of successive internal pores is usually a little straight, while the external border of the petal is convex. As a result, at the distal end of the petal the five or six last pores become closer and closer to the internal pores. The latter are small and round, while the larger external pores are transversely widened and wider outside than inside. The maximum width of the petal is toward three-fourths its length. It then decreases as it approaches the distal end. This is not the result of the poriferous zones coming closer together but from each of them becoming narrower. In the large specimen A, I count twenty-nine pore pairs on each side of the anterior petal. The first five are very small. The width of the interporiferous zone at the end of the petal is 6 millimeters and the maximum width of the poriferous zone is 4 millimeters. Their plates have a small number of primary tubercles. The intercalated miliary tubercles are very separated from each other. The two pores of each pair are connected by a small transverse furrow. The space between successive pairs has two or three primary tubercles in general with some miliary tubercles.

The lateral petals differ from the anterior petals in that they are always nearly completely closed at their distal end. They are obovate but relatively narrow and elongated. They are very strongly narrowed at their distal end. The maximum width is always toward the middle of the length or a little beyond. They then narrow both by the poriferous zones of each side coming closer together and by the line of pores of each zone coming closer together. The two posterior petals are a little more elongated than the two anterior petals. The structure of these petals is the same as that of the unpaired anterior petal. But the interporiferous zone is always narrower and its maximum width is a little beyond the middle of the length. In specimen A, the maximum is 3.8 millimeters on the anterior petal and 4 millimeter on the posterior petals. It is slightly greater than the width of 
the interporiferous zone. I count twenty-nine pore pairs on each side in the anterior petals and thirty-two in the posteriors, the first four or five pore pairs being always strongly reduced.

Each small projecting ridges that separate the successive pore pairs usually have three primary tubercles, regularly aligned and of small size. In the interporiferous zone, the primary tubercles are larger but they are neither very numerous nor dense. They are distributed very irregularly (Pl. IV, fig. 12). The miliary tubercles are very fine and sparse.

It can happen that outside the regular pores of the petals, we see some abnormal pairs in the ambulacral zones, and even sometimes in the interambulacral zones. In specimen A, these supplementary pairs are arranged in the following way. At the end of the unpaired anterior petal, a pair of pores appears first in series IIIb near the normal pairs while series III has two pairs of pores. None exist in radius II, but in radius I, I found a pair in Ib located well outside the petal, and another in Ia, but nearer the petal. The test has not been brushed on the other side and I cannot distinguish the supplementary pore. Moreover, the arrangement of these small supplementary pores does not follow any regular law, no more than in $\mathrm{Cl}$. Annandalei. It varies with the specimen.

After the petals, the ambulacral zones abruptly widen and we observe first two plates, very tall although wider than long. Then a pair of plates much shorter whose external border nearly corresponds to the periphery of the test. All these plates have primary tubercles, more separated than those of the interporiferous zones of the petals and of the same dimensions as the latter. The intercalated miliary tubercles are likewise not dense. In passing to the ventral surface, the plates progressively narrow as they approach the peristome. The primary tubercles appear a little denser than on the dorsal surface. They are also a little larger in the external region of the plates. But in the area of the ambulcral groove, they become much smaller. The miliary tubercles are close but not contiguous. In the immediate area of the peristome, the primary tubercles are denser but also a little smaller.

The interambulacral regions of the dorsal surface have the same characters as the interporiferous zones of the petals from the point of view of the arrangement of the tubercles. But in the area of the periphery of the test, and and on all the flat marginal part of the dorsal surface, these tubercles are a little denser. The interambulacral tubers have the same arrangement as those of the ambulacral zones.

The ambulacral grooves on the ventral surface are very clearly marked on all their length. But they become much deeper as they approach the peristome. The interambulacral regions of the dorsal surface have the same characters as the interporiferous zones of the petals from the point of view of the arrangement of the tubercles. But in the peripheral region of the test, and on all the flat marginal part of the dorsal surface, these tubercles are a little denser. The interambulacral tubercles have the same arrangement as those of the ambulacral zone.

The peristome, located at the base of a small, very shallow infundibulum is pentagonal in form. The periproct is small with a slightly irregular contour, a little widened transversally. It is covered with fairly large plates with very small spines. It is very near the posterior border of the test. Its length is scarcely equal to the distance that separates this edge from its posterior border.

The primary spines of the ventral and dorsal surfaces are cylindrical and can attain 2 millimeters in length ( $\mathrm{Pl}$. XIV, fig. 3b). They are smooth or with very short teeth, fine and sparse. On the ventral surface in the immediate area of the peristome, the spines enlarge more or less clearly, especially toward their end. They take a slightly spatulate form. The teeth become stronger and closer together on the widest part. In the smallest primary spines, the length can be less than one millimeter. The length of the miliary spines varies between 0.6 and 0.8 millimeters. These 
spines are slightly enlarged in the terminal quarter. The very fine teeth that they have on all the preceding part becomes stronger and closer together (fig. 3a).

The tube feet rosettes (fig. $3 \mathrm{c}$ ) are 0.07 in diameter. They recall those of $\mathrm{Cl}$. humilis that Meijere figured in 1904 (Pl. XVIII, fig. 353). There are twenty-four to twenty-five marginal teeth. Outside the regular internal circle of perforations, we find fairly numerous smaller perforations, but never forming a complete circle.

The pedicellariae are of three kinds, tridactyl, trifoliate and ophiocephaous. There is first large tridactyl pedicellariae in which the head attains a length of 0.5 to 0.6 millimeters (Pl. XIV, fig. 3d). The basal part of the valve is triangular, nearly as wide as long, or a little longer than wide the perforations are fairly large and the border has some low, large teeth. The apophysis is projecting and sinuous, but does not have teeth strictly speaking. The blade, at first very narrow, widens rapidly and progressively on about half its length to form a spoon that never reaches a great width. It narrows little by little to end in a round point. It thus has the form of an elongated lozenge. Teeth appear on the borders after the most widened region. They are first very fine and low, then they develop more, especially at a short distance from the end where they become much stronger, conical and pointed. The perforations are fairly large. The lower arcs are very apparent but fairly short. The pedicellariae are distributed on the entire surface of the test. They are notably fairly abundant in the area of the peristome. They greatly recall those of $\mathrm{Cl}$. Annandalei, but their basal part is generally higher with a more projecting apophysis. The blade is a little narrower.

There are tridactyl pedicellariae of a second form that are much smaller than the preceding. Their head is only 0.25 millimeters in length on average (fig. 3e). The basal part is comparatively higher than in the large pedicellariae. It is also a little wider than long. The perforations are fairly large. The stalk, wider at its origin, enlarges rapidly and forms an elongated spoon that occupies nearly all its length. It ends in a round border. Fine teeth, which become stronger toward the end, appear over the entire length of the spoon. The perforations are fairly large and arranged regularly. The lower arcs are little developed.

The head of the trifoliate pedicellariae is 0.12 to 0.15 millimeters in length. The blade has first a narrow fairly elongated part that continues into an oval spoon, longer than wide. It narrows toward the widely rounded end (fig. 3g). The borders have conical and obtuse teeth. The perforations are fairly numerous.

The head of the ophhiocephalous pedicellariae are 0.4 millimeters in length. The valves (fig. 3f) are similar to those of $\mathrm{Cl}$. humilus that Meijere has figured (Pl. XVIII, fig. 352). But they are a little shorter and wider. The lower arcs are also a little shorter. The teeth are very strong, a little stronger and less numerous than in $\mathrm{Cl}$. humillis. The perforations are fairly small.

The color of the specimens in alcohol is generally very deep: brown, yellowish brown or a slightly violet brown.

As for the internal structure of $\mathrm{Cl}$. destinatus, I can note the following characters (Pl. V, fig. 5 and 6). The test is thin and very fragile, first because of the very thinness of the walls but also from the weak development of the central calcareous pillars. The walls are, however, a little thicker comparatively than in $\mathrm{Cl}$. Annandalei. The ventral surface is also thinner than the dorsal surface. The peripheral calcareous pillars are developed in a zone wider than in the latter species. They widen parallel to the periphery of the test and are arranged in a fairly regular manner in concentric circles that are often four in number. They also have a tendency to unite and are joined by the borders. In the intervals that are free between the pillars are extensions of the gonads. The digestive tube is distinguished from that of $\mathrm{Cl}$. Annandalei by a much greater width of the first intestinal loop at its origin and by the gradual increase that we see after the esophagus, by the folds that it 
has on a good part of its length, by the difference in color of the walls that is first very light, and finally by the different relations of the siphon and the internal marginal lacuna with the intestine. In fact, the siphon and the internal marginal lacuna remain applied directly against the internal border of the first intestinal loop, from their beginning, while in $\mathrm{Cl}$. Annandalei, they are separated from the intestine by all the width of the mesenterial lamella that is developed here. Finally, the two successive loops of the digestive tube are more separated from the border of the body in $\mathrm{Cl}$. Annandalei because of the greater thickness of the peripheral calcareous pillars. These differences appear clearly when we compare the respective photographs that I reproduce here of $\mathrm{Cl}$. Annandalei (Pl. II, fig. 1) and of Cl. destinatus (Pl. V, fig. 5 and 6). The intestinal gland is thin and elongated. It follows exactly the middle of radius III. It has a very llight yellow color. The portion of the internal marginal lacuna that crosses the first part of the ventral intestinal loop, in the direction of the gland, is simply oblique without have the sinuosity that it has in $\mathrm{Cl}$. Annandalei when it reaches the digestive tube. The siphon opens as in this latter species a little after interradius 5. But the marginal lacuna continues beyond this point for a greater length and we can recognize it up to the area of the end of the first intestinal loop.

The gonads have nearly the same characters as in $\mathrm{Cl}$. Annandalei. But they are connected to each other by more or less important portion inside the digestive tube.

In a specimen that is 56x49 millimeters, like that whose photograph I reproduce in $\mathrm{Pl}$. V, fig. 5, the Aristotle's lantern is 15 millimeters in its greatest length, i.e., in the direction III-5. This length is about 13.5 to 14 millimeters in the other directions. The posterior border is nearly straight and the other sides are fairly strongly concave. In $\mathrm{Cl}$. Annandalei, the dimensions of the Aristotle's lantern vary little in the different directions and the posterior border more strongly concave. In relation to the size of the body, the dimensions of the Aristotle's lantern remain the same in the two spcies. If we compare, to the contrary, to that of species whose exterior form recalls more $\mathrm{Cl}$. destinatus, such as $\mathrm{Cl}$. humilis, we see that in the latter, as shown in the photographs reproduced in Pl. II, fig. 1 and 2, the lantern is much more developed and at the same time more elongated in the antero-posterior direction. $40 \mathrm{In}$ a specimen that measures $65 \times 53 \mathrm{~mm}$, the length of the lantern is 26 millilmeters following the direction III-5.

The central pillars are not numerous, but fairly thick. They remain simple and are localized in the masses of the gonads. We can count about a dozen in each interradius. They are slightly more developed in $\mathrm{Cl}$. Annandalei, but sensibly less strongly and less numerous than in $\mathrm{Cl}$. humilis.

The digestive tube has an esophagus and, at the beginning of the first intestinal loop, a very light brown color with transparent walls. These walls have some folds that are not very conspicuous at first. The aspect changes after radius IV. The color becomes progressively deeper and olive and the folds are much more accentuated up to the posterior interradius 5 or a little beyond. This first portion of the intestinal loop is, as in $\mathrm{Cl}$. Annandalei, completely flat. The width of the digestive tube increases very rapidly and very regularly from the beginning of the esophagus. It attains its maximum a little beyond radius III at the point where the tube curves. This width, 9 millimeters, is comparatively greater than in $\mathrm{Cl}$. Annandale $i$ where it is hardly 5 millimeters in a specimen whose length of body is 80 millimeters. It is to be noted, moreover, that here this width of the ventral intestinal loop at its beginning is acquired gradually in $\mathrm{Cl}$. destinatus, and less abruptly than in $\mathrm{Cl}$. Annandalei, and that the internal border of the intestine follows a curve much more regular than in this latter species. In the posterior interradius 5 , the width of the intestine, that has diminished fairly rapidly, is no more than 4 millimeters. The intestine is still fairly flat, but it becomes progressively nearly cylindrical. Its diameter does not exceed 2 millimeters at the point where the first intestinal loop is continuous with the second dorsal, or recurrent, loop that keeps 
nearly the same diameter throughout its length. We can note, in comparing the photographs I reproduce here (Pl. V, fig. 5 and 6) of the internal organization of $\mathrm{Cl}$. destinatus to that of $\mathrm{Cl}$. Annandalei (Pl. II, fig. 1), that the passage of the first intestinal loop to the second is done in the former a little further from radius II than in $\mathrm{Cl}$. Annandalei. In other words, this first loop is very slightly longer in $\mathrm{Cl}$. destinatus. We note also that the mesenteries connecting the different parts of the digestive tube, either among themselves or to the test, are remarkably thin in C. destinatus. In particular, we can be sure that this fairly wide mesenterial blade, that in $\mathrm{Cl}$. Annandalei is developed the length of the internal border of the first intestinal loop at its origin, between radius III and V, and that separates both the siphon and the internal marginal lacuna from the very border of the intestine, is completely missing here, and that the siphon with the internal marginal lacuna remains applied exactly against the internal border of the intestine.

SIMILARITIES AND DIFFERENCES. - Despite a very great difference of size in the exterior form. $\mathrm{Cl}$. destinatus appears to me especially very near $\mathrm{Cl}$. Annandalei that I just described. It differs first by the smaller size of the adult. The largest specimens do not exceed 57 millimeters in length. This lengths varies the most often around 50. The test is in general more elongated than in $\mathrm{Cl}$. Annandale and the height is comparatively less. The smallest specimens of $\mathrm{Cl}$. Annandalei is always very clearly distinguished from $\mathrm{Cl}$. destinatus (it is true that I have not had at my disposal specimens of the first species whose length was less than 61 millimeter). The petals have the same characters in the two species. The anterior petal is widely open at its distal end with the internal poriferous zones straight and parallel. The other petals are nearly closed. These petals do not form an appreciable projection and they remain flush to the test. The primary tubercles are very spaced and they are even less numerous in $\mathrm{Cl}$. destinatus than in $\mathrm{Cl}$. Annandalei.

From the point of the very structure of the test, we can note that it is very thin and fragile in the two species, a little less however in $\mathrm{Cl}$. destinatus, and that the internal pillars are little developed. The central pillars have nearly the same arrangement in the two species, but the peripheral pillars are more numerous and stronger in $\mathrm{Cl}$. destinatus. They cover at the periphery of the test a zone a little wider than in $\mathrm{Cl}$. Annandalei. The arrangement of the internal organs in the two species is equally very close. However, the digestive tube of $\mathrm{Cl}$. destinatus differs from that of $\mathrm{Cl}$. Annandalei by a much greater width of the first intestinal loop at its origin and the progressive increase of the width after the esophagus, by the folds that occur on a good part of its length, by the difference in the color of the walls that are first very light, and by the different relations of the siphon and the internal marginal lacuna with the intestine. These two formations are applied directly against the internal border in $\mathrm{Cl}$ destinatus instead of being separated their entire length by a mesenterial lamella that we note in $\mathrm{Cl}$. Annandalei at the beginning of the first loop. Finally, the digestive tube of $\mathrm{Cl}$. destinatus is separated from the border of the body because of the greater thickness of the peripheral calcareous pillars.

The distinction between the two species will be very easy when we have adult specimens. We will distinguish immediately the test less elevated, borders a little thicker in $\mathrm{Cl}$. destinatus, characters of the pedicellariae that are slightly different, and finally in the arrangement of the internal organs. Perhaps we hesitate between adult $\mathrm{Cl}$. destinatus and very young $\mathrm{Cl}$. Annandalei whose length does not exceed 40 to 50 millimeters. The test in fact should be comparatively lower in the latter and perhaps the distinctive characters of the two species would they not be easy to discover. It may be that it is for these two species as for many others in which it is extremely difficult, and often even impossible to determine the young. 
Because of the resemblance of the two species have between them, I think it is appropriate to place $\mathrm{Cl}$. destinatus beside $\mathrm{Cl}$. Annandalei in the same section of Leptoclypus that I have proposed to establish for the latter.

The distinction of $\mathrm{Cl}$. destinatus from other species of Clypeaster coming from the Indian Ocean does not seem to me to present any difficulty. $C l$. rarispinus has a very flat body, thin petals, fairly elongated, rather pointed and always closed at the end. The length of the test is rarely greater than the width.

Cl. fervens, which I shall describe later, has a relatively more elevated test than $\mathrm{Cl}$. destinatus. The petals are obovate, very widened in their second half, the anterior petal partly open, and petals forming a very conspicuous projection on the surface of the test. The ventral surface is very concave. Finally, the pedicellariae are completely different. The wall of the body is thicker than in $\mathrm{Cl}$. destinatus, judging by the weight of the individuals.

The form of the petals that are all more or less partially open in $\mathrm{Cl}$. australasiae permits distinguishing this species from $C$. destinatus.

$\mathrm{Cl}$. humilis is widely distributed in the Indian Ocean. It reaches in general larger sizes than $\mathrm{Cl}$. destinatus. But it is interesting to compare individuals having nearly the same size. Cl. humilis is distinguished its shorter petals that cover only a very narrow part of the dorsal surface of the test. These petals are widely obovate. The anterior petal, like the other four, is closed at it distal end. The pedicellariae are completely different. From the point of view of the internal structure, we already know that in $\mathrm{Cl}$. humilis, that I shall return to later with some details, has a very thick test, solid and resistant, very developed central pillars, must more numerous and stronger than in $\mathrm{Cl}$. destinatus, a larger Aristotle's lantern etc. There is no resemblance between the species.

One of the individuals from station 246, that I designated above by the letter E, has an extremely interesting anomaly. The contour of the test, instead of being regularly ovalate, is irregular. The greatest length, instead of being in the direction III-5, is in the direction V-2. The body is widened anteriorly between the ends of radii II and IV, while it narrows posteriorly and ends in a very narrow region, forming a small, very slightly rounded border that corresponds to radius $\mathrm{V}$. In addition, we note at the border of the test, exactly at the end of radius I, a small round bulge that not only protrudes outside, but corresponds to the very thickness of the test. At this point, it has a height of 4 millimeters, while elsewhere the height is only 3 millimeters.

This specimen could be consider as being nearly exactly tetramerous on the dorsal surface (Pl. IV, fig. 6), while the ventral surface has nearly normal pentaradiate symmetry (fig. 7). This surface is especially modified in its exterior contour.

On the dorsal surface, petals I, II, III and IV only are normally constituted. Interradius 1, 2, 3 and 4 alone are entire. Petal V is missing. There are sometimes vestiges in the form of a group of small polygonal and unequal plates that make a small group located toward the middle of the region corresponding to interradius 4 and 5 united. These plates are especially recognizable by their pores that are very irregularly arranged. I observe in this small group, two unequal anterior plates, two posterior plates, nearly the same size, and three medium-size plates, of which two are small and one larger than the others. There are twelve pores on these plates. Four form a small anterior row, the external pores appear double. Four other form two medium- sized rows. Finally, the last four form a posterior row. These pores are unequal and have different forms. Some are round like the internal pores of normal poriferous zones. The others are widened like the external pores of these zones. I consider interradial zones 4 and 5 are represented nearly completely and are incomplete only in their proximal region, inside the small group of plates that make up petal $\mathrm{V}$. In fact, the space between the two petals I and IV first have a double row of polygonal plates, 
which one cannot say that they belong to interradius 4 instead of interradius 5 . Then, each side of the group formed by the rudimentary plates of radius $\mathrm{V}$, are in to perfectly distinct series of large, polygonal plate having the usual characters of interradial plates. They continue to the border of the test and then onto the ventral surface. These two rows represent the right (b) series of interradius 4 and that of left (a) of interradius 5. It is to be noted that the two adjacent plates of the small ambulacral group, those of series $b$ in interradius 1 and those of series a in interradius 5, contribute to limit the adjacent pores that encroach a little on their surface. On the other hand, outside this small group of plates that represent the vestige of the left latero-anterior petal, the plates of radius $\mathrm{V}$ have their usual form. There is between this group and the border of the test, three successive pair of plates that are continuous with the corresponding ambulacral plates of radius $\mathrm{V}$ on the ventral surface. Thus we can say that the interradii 4 and 5 and radius $V$ have disappeared more or less completely in their dorsal part and adjacent to the apical system, but they exist for the rest of their length.

The petals themselves, I, II, III and IV, have some slight differences that I shall indicate in a summary fashion. The unpaired anterior ambulacrum III is widely open anteriorly. Its left poriferous zone (b) is more developed and longer than the other. The left latero-anterior petal is longer and wider than its corresponding right, and it posterior poriferous zone (b) is a little wider and more curved the anterior (a). The right posterior petal I, which has no correspondence on the other side of the test, is shorter than the others and has an obovate form. At the distal end of these petals are some supplementary pores. A similar pore exists also outside the right anterior petal. These supplementary pores are likewise encountered outside the petals, in variable number, in normal specimens.

The apical system has five gonopores that are arranged in four corners of a trapezoid. Those that correspond to interradii 1, 2 and 3 are normal. But the two others, unequal, are found very near each other between the proximal regions of petals I and IV. They correspond, respectively, to interradii 4 and 5. The pore of interradius 5, which has the same dimensions as the three first, occupies a normal situation. It is located like them, in the middle of the base of the interradius. The other pore, located beside it, is a little smaller and moved toward radius IV.

The ventral surface has, in its contour, the same deformation the dorsal surface at the level of radius I, but the interradii are complete. The ambulacral grooves extend to the intermediate area of the test borders. The groove of radius I is shorter than the others. It approaches radius V. It is at the point where it reaches the periphery of the test where the small tuberosity I reported above is found. I cannot give any information about the nature of this tuberosity. It encloses perhaps a parasite. But I believe that it is similar to the superficial deformations of the test that I have seen in numerous abnormal echinoids that I have had the opportunity to study that result in more or less marked swellings or depressions 45 (see my memoir presently in press on the Anomalies du test des Échinides).

The arrangements of $\mathrm{Cl}$. destinatus of station 246 are very interesting, especially because anomalies of the test are very rare in clypeasteroids. However, a similar case was described by W. L. Tower in $1901^{5}$ in an Echinarachnius parma.

\section{Clypeaster fervens nov. sp.}

(PL VI, fig. 1, 2 and 6; PI. XIII, fig. 6; PI. XV, fig. 1)

\footnotetext{
${ }^{5}$ An abnormal clypeasteroid echinoid. Zool. Anz. Vol. 24, p. 188.
} 
Southern coast of Ceylon. $-6^{\circ} 02^{\prime}$ N.; $81^{\circ} 29^{\prime \prime}$ E. $68-52$ fms. One specimen.

This Clypeaster from the southern coast of Ceylon differs by several characters from $\mathrm{Cl}$. destinatus and it is closer to $\mathrm{Cl}$. humilis. But it cannot be referred to this species. It is certainly new. It is remarkable for its fairly elongated form with a pentagonal contour clearly concave in the the interradial spaces, by its obovate petals whose end is fairly elongate and very far from the border of the test, by its very wide and convex interporiferous zones, by its nearly entirely closed anterior petal and finally, by its profile that is clearly conical.

Here are the principal dimensions that I have taken of this specimen:

$\begin{array}{ll}\text { Length } & \mathrm{m} / \mathrm{m} \\ \text { Maximum width } & 56 \\ \text { Height at the apical plate } & 51.6 \\ \text { Length and width of the unpaired anterior petal } & 16.5 \\ \text { Length and width of the latero-anterior petals } & 20 \times 11.3 \\ \text { Length and width of the latero-poterior petals } & 1810.3 \\ \text { Distance between the end of the anterior petal and the border of the test } & 20 \times 11.3 \\ \text { Distance between the end of the latero-anterior petals and the border of the test } & 10.5 \\ \text { Distance between the end of the latero-posterior petals and the border of the test } & 10.3 \\ \text { Ratio between the length and width of the test } & 3.4\end{array}$

The test is longer than wide (Pl. VI, fig. 1 and 2), pentagonal in form but with a very sinuous contour. It is formed by a succession of alternating convex and concave lines. The convex parts 46 correspond to the five radial regions and the concave part to the four interradial pairs. The maximum width is at the two latero-anterior radii. The anterior region, limited by a small convex border, is narrow. The much larger posterior border is nearly straight, slightly depressed at interradius 5. The ventral surface is flat in its external half, but it is depressed faiarly strongly toward the peristome that is located at the base of a very accentuated infundibulum. The five ambulacral grooves are very marked. They go to a short distance from the border of the test and disappear in reaching these borders. The dorsal surface is very high and the profile is clearly conical with a round, blunt top (Pl. VI, fig. 6). When we look at the test by the side, we note the profile follows an oblique, nearly straight line going from the apical plate to the border of the test and that it is scarcely depressed at the end of the petals. Seen from the anterior or posterior end, this line is seen slightly depressed at the distal end. Then it is less oblique to the border of the test.

The fairly small apical plate has a little irregular pentagonal contour. It is covered with numerous miliary tubercles. They are fairly large. The water pores are difficult to see between them. The gonopores are small. The two anterior ones are little apparent. The left posterior one is slightly inside and is located on the apical plate itself.

The petals form a conspicuous projection on the dorsal surface of the test, due especially to the convex form of their interporiferous region. The unpaired anterior petal, a little longer than the other, is progressively widened and reaches its maximum width at two-thirds its length. Then it narrows progressively because of the curve of its two poriferous zones. These do not join, however, at the distal end of the petal where they remain separated by a space of about 3 millimeters. The poriferous zones have a convex external border and a concave internal border. These two borders follow nearly the same curve. The interporiferous zone has a maximum width of 6 millimeters. 
The half-width of this zone is thus a little greater than the width of each poriferous zone at the same level. I count forty-one pore pairs on each side. The first ten are very small. The internal pores are, as usual, round and smaller than the externals that are widened transversely but not virguliform. The two pores of each pair are connected by a small furrow and the space that separates them has some primary tubercles. The number of tubercles varies from two to five according to zone. They are interspersed with miliary tubercles. The interporiferous zone has fairly dense primary tubercles. They are usually arranged in a regular manner in small transverse rows of five or six. Between them are very dense miliary tubercles.

The anterior and posterior lateral petals are obovate and closed at the end. The have their maximum width toward four-fifths of their length. Then they narrow and are closed by a curve with a short radius. The two anterior petals are a little shorter than the posteriors. I count thirtynine pore pairs on the anterior petals. The first ten or eleven pairs are very small, I count forty-two on the posterior petals. For the rest, the petals are like the unpaired anterior petal. The poriferous and interporiferous zones are not flush with the test. The petals form a fairly conspicuous ridge, due principally to the convex form of the interporiferous zones, but the poriferous zones themselves are not flat. They are slightly rounded, thus contributing to the convex form of the petal.

I find a pair of supplementary pores at the end of the unpaired anterior petal in the series a and a pair at the end of the posterior petal likewise in series a. Outside the petals, the ambulacral plates have a covering of tubercles identical that of the interporiferous zones, containing sparse primary tubercles between which are dense, contiguous miliary tubercles. The interradial zones of the dorsal surface have first, in their region between the petals, a covering of primary granule, between which the miliary granules are less dense than on the ambulacral zones and not contiguous. But beyond the line that circumscribes the petals, these granules become more numerous and denser than in the ambulacal zones. The same characters are found on the ventral surface.

The ambulacral grooves of the ventral surface are not very conspicuous. They are effaced nearly completely at the periphery of the test.

The peristome, located as I said above, at the bottom of a fairly deep funnel, has a pentagonal form. The periproct is round, but a little wider than long. It is very near the posterior border of the test. The small plates that cover it have numerous spines, dense, short and fairly thin.

The primary spines of the ventral surface are 1.5 to $2 \mathrm{~mm}$ in length. They are cylindrical, a little thinner at the end. Their surface is completely smooth (Pl. XV, fig. 1a). In the area of the peristome, these spines begin to flatten and are enlarged toward the middle of their length, often in the first third, and they become a little fusiform. Their end is never pointed. Sometimes the terminal part of these spins is slightly curved. The miliary spines are fairly thick. Their length varies between 0.5 and 0.6 millimeters (fig 1b). They have fairly conspicuous teeth on nearly all their length. They become denser and a little more developed in the terminal part that is a little enlarged like a club. The primary spines of the dorsal surface resemble those of the ventral surface, but are always shorter.

The rosettes of the tube feet are 0.055 to 0.06 millimeters in diameter (fig. If). They are thinner than those of $\mathrm{Cl}$. destinatus and the number of marginal teeth hardly exceeds twenty. They have a large central opening with generally a single circle of oval perforations.

The tridacytle pedicellariae are, as usual, of two different sizes. The larger are fairly numerous on the ventral surface, especially in the area of the peristome where we can easily recognize them with a magnifying glass. Their head is 0.6 to 0.7 millimeters in length, supported by a fairly short stalk. The valves (Pl. XV, fig. 1e) are notable for the thinness of the blade. The basal part is usually 
short, wider than long. Its length is equal sometimes to a quarter, sometimes to a third of the total length of the valve. The borders are irregular or even with teeth, low and triangular. The apophysis likewise has on its free border some similar teeth. The perforations are small and fairly numerous. The blades first have the form of a very narrow gutter. It very slowly widens on two-thirds and sometimes even three-fourths of its length to form an inconspicuous spoon that narrows progressively to its end whose form varies a little. The borders of the spoon have small teeth, conical, obtuse and dense. They become stronger near the end. The part that forms the gutter of the blade can have two or three extremely low and triangular teeth. The perforations are large and oval. The lower arcs are little developed by are however very apparent.

The tridactyl pedicellariae of the second form are much smaller. The valves are not more than 0.35 millimeters in length (fig. 1d). The basal part is comparatively longer than in the preceding. It exceeds a third of the total length of the valve. The blade has the form of a very elongated and narrow lozenge. It enlarges progressively in the first half to form in the second a triangular spoon that narrows to a round end. Its borders have teeth that are first extremely small. They become much stronger toward the end. The lower arcs are a little more developed than in the preceding form. We can moreover find transitions between the two forms of pedicellariae.

The trifoliate pedicellariae are very small. The length of the valves does not pass 0.07 . The valves (fig. 1e) are very similar to those I have indicated in $\mathrm{Cl}$. destinatus. There is, finally, ophiocephalous pedicellariae whose head is 0.25 millimeters on average. It likewise recalls those of this latter species.

I have not studied the internal structure of $\mathrm{Cl}$. femvis to avoid destroying the only specimen I have in hand. But radiographic examination has shown me that the internal calcareous pillars of the test are not more developed than in $\mathrm{Cl}$. destinatus and that the peripheral pillars are rather less numerous, which permits the digestive tube to come a little nearer the very border of the test.

The specimen in alcohol has a violet brown color, tending to the blackish.

SIIMILARITIES AND DIFFERENCES. - $\mathrm{Cl}$. fervens appears very close to $\mathrm{Cl}$. australasiae that is synonymous with $\mathrm{Cl}$. ambigenus (Lamarck). As we have seen above, this synonymy has been indicated by Lambert, who considers likewise that $\mathrm{Cl}$. testudinarius A. Agassiz is a synonymous form. H. L. Clark cites in $1914 \mathrm{Cl}$. australasiae as a synonym of $\mathrm{Cl}$. testudinarius but does not mention $\mathrm{Cl}$. ambigenus. Whatever it is, we have a good design of $\mathrm{Cl}$. australasiae by Gray (1851, PL. I, fig 2) and different photographs published by Clark in 1914. We can be assured, in comparing the figure to the photographs that I give here of the specimen collected by the INVESTIGATOR, that the exterior form is very similar. There is even a great resemblance in size and in contour between this specimen and that which Gray represented. The resemblance is also very great with the individual whose photograph Clark has reproduced (Pl. CXXXIV, fig. 1) although the latter is much larger. However, I dare not identify the specimen from the INVESTIGATOR with $\mathrm{Cl}$. australiasice because in the latter, the petals are clearly open at the distal end, - they are especially open in the individual of gray and they are a little less in those of Clark - while in the individual of the INVESTIGATOR, the anterior petal alone is slightly open at its distal end and the four others are clearly closed. The test of $\mathrm{Cl}$. fervens appear to me as sensibly higher than that in $\mathrm{Cl}$. australasiae.

It is difficult for me to pursue the comparison between the two species, because the descriptions that we have of $\mathrm{Cl}$. australasiae are very incomplete. It is especially according to the figures and photographs of Gray and Clark that we compare the species. It is possible that the discovery of new specimens coming from the Indian seas comes to show the affinities between the two species 
are greater than I can presently suppose. Perhaps also they will show the contrary. Whatever it is, it appears preferable to me to apply a new name to the species found by the INVESTIGATOR rather than reporting it, incorrectly, as $\mathrm{Cl}$. australasiae. I shall add that, as Clark remarked, $\mathrm{Cl}$. australasiae appears localized to the southeast coast of Australia. It has never been reported in other localities. Moreover, the American naturalist scholar said that the pedicellariae do not show peculiar characters. Now the large tridactyl pedicllariae that I observe in $\mathrm{Cl}$. fervens show to the contrary a completely special form because of the narrowness of their valves.

In 1914, Lambert, citing Cl. japonicus, said: we have a specimen of this species that does not appear to differ sufficiently from $\mathrm{Cl}$. ambigenus (Lamarck) (which is thus synonymous with $\mathrm{Cl}$. australasice Gray). According to the photographs that Clark published in 1914 and according to the observations that I have been able to make on a Clypeaster from Japan that appears to me perfectly identical to $\mathrm{Cl}$. japonicus, I think the two species are distinct. In any case, the Clypeaster of the INVESTIGATOR is not a japonicus. In the latter, the form is very different (see H. L. Clark, Pl. CXXXIV, fig. 2 to 4). The body is more elongated, less high, the contour is not sinuous and the central columns are considerably developed. It is regrettable that Clark, who examined the pedicellariae of $\mathrm{Cl}$. japonicus, was content to say that the tridactyl values varied in length from 0.15 to 1.10 millimeter without describing them.

There is no possible confusion with the other Clypeaster of the Indian Ocean, notably with $\mathrm{Cl}$. humilis. Finally, $\mathrm{Cl}$. fervens differs completely in the form of the petals and the protrusion they make on the surface of the test, by the very height of the body, by the form of the ventral surface and finally by the characters of the pediceellariae ofo the new species hat I have described above under the name of $\mathrm{Cl}$. destinatus and that is found in very near waters.

\section{Clypeaster humilis (Leske)}

(Gray and Al. Agassiz emend.)

(PI. III. fig. 1 to 5 and 12; PI. XIV, fig. 5)

Echinanthus humilis Leske, 1778, pl. XIX, fig. A, B.

Scutella placunaria Lamark, 1816, p. 12.

Echinanthus explanatus Gray, 1851, p. 35, and 1855, p. 7, pl. II, fig. 1.

Echinanthus testidunarius Gray, 1851, p. 35 and 1855, p. 6, pl. I, fig. 1.

Clypeaster placunarius Michelin, 1861, p. 135, pi. XXXV, fig. 2a (non Cl. placunarius Agassiz and Desor) ${ }^{6}$.

Clypeaster Saisseti Michelin, 1861, a, p. 328, pl. IX, fig. 2.

Clypeaster humilis Al. Agassiz, 1872-74. p. 510, pl. XI a.

Clypeaster rosaceus, 1887, Loven, p. 173.

Alexandria magnifica Pfeffer, 1881, p. 66.

Clypeaster rosaceus Meijere, 1904, p. 133. pl. XVIII, fig. 352 and 353.

Clypeaster humilis R. Brown, 1910 a, p. 41.

Clypeaster humilis Lambert, 1914, p. 13, 18, 19, etc.

Stolonoclypus humilis Lambert and Thiéry, 1914, p. 301.

Clypeaster humilis H. L. Clark, 1914, p. 36, pl. CXXIII, fig. 23, and CXXXVIII, fig. 4.

\footnotetext{
${ }^{6}$ According to Lambert, Clypeaster placunarius Agassiz and Desor is synonymous with Cl. ambogenus Lamarck.
} 
The characters of this species are well known. It does not appear useful to me to describe them here again, all the more that it is not represented in the collections of the INVESTIGATOR. But I believe, nevertheless, that it is indispensable to state some of these characters in view of the comparisons that I have had the occasion to make with the new species described above. I shall take as examples some specimens of average size, or even fairly small, for these comparisons. These specimens come from the Red Sea and belong to the Museum.

Here are the principal dimensions that I have taken on four specimens that I shall designate respectively by the letters $\mathrm{A}, \mathrm{B}, \mathrm{C}, \mathrm{D}$ :

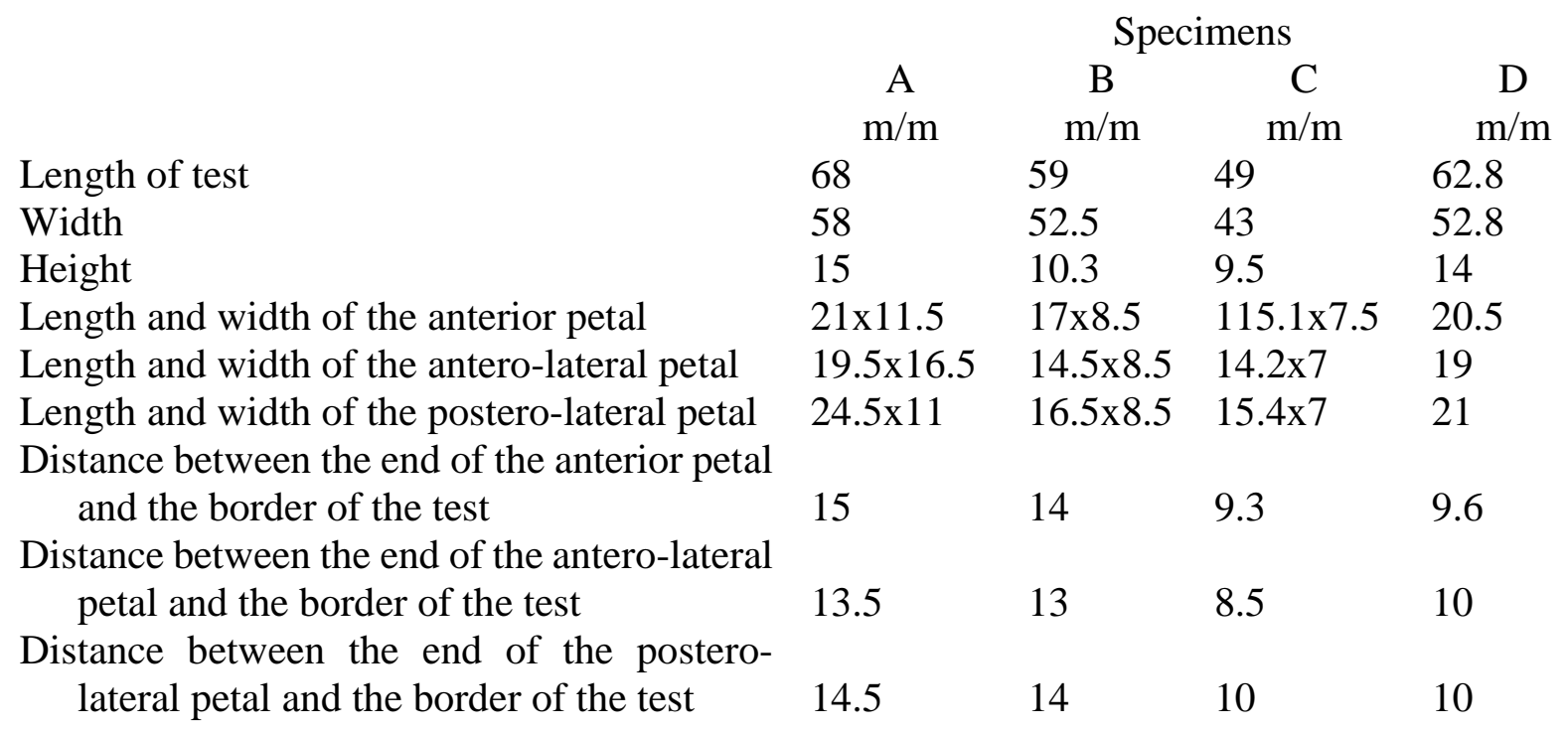

One of the characters that is immediately striking when we examine the dorsal surface of $\mathrm{Cl}$. humilis, a character that is seen in the numbers above and that we can verify in the photographs I have reproduced in Pl. III, fig. 2 and 3 as well as those of H. L. Clark, is the relative shortness of the petals and the large interval that separates their very round distal end from the corresponding border of the test. We know that the five petals of $\mathrm{Cl}$. humilis have a more or less ovulate form and the maximum width is beyond half their length. On the other hand, the petals forming the dorsal surface of the test are a very apparent protrusion. The interporiferous zone in particular is more or less strongly convex. The poriferous zones are also very convex. The interporiferous zones are covered with numerous, dense primary granules. Between them, the miliary tubercles are not abundant. The poriferous zones have, between the successive pores, a row of primary tubercles, likewise very dense. The characters given by the form of the petals and their length in relation to the width of the test are completely constant in Cl. humilis.

The pedicellariae of $\mathrm{Cl}$. humilis are very poorly known. Meijere has observed the tridactyls and ophiocephalous. But he was content to say that they had no particular characters and he showed one valve of the ophiocephalous pedicellaria. Now, I have observed, in the specimens I have in hand, two different kinds of tridactyl pedicellariae that have some characters that can be used to establish differences between $\mathrm{Cl}$. humilis and various other species of the genus. The tridactyl pedicellariae of the first form have a large and wide head (Pl. XIV, fig. 5e) and the valves are 0.8 millimeter in length (fig. 5a). Their basal region is fairly high and the length is a third of the total 
length. This region is nearly as long as wide. Its borders are smooth or with hardly two or three small teeth that are very low and little apparent. The apophysis, a little elevated at its free border, is nearly completely smooth. The blade, at first fairly narrow, enlarges gradually into a spoon that is not very wide and occupies hardy a fourth of the total length. It ends in a very convex border. It has teeth, at first small and conical, but which rapidly become strong and elongated toward the round end of the valve. The perforations are not very large. They are round and not dense. There is an indication of very short lower arcs. These pedicellariae are fairly widespread. The other tridactyls, which are much more abundant than the preceding, are in contrast much smaller. Their head is only about 0.25 millimeters in length (fig. $5 \mathrm{~d}$ ). The basal part of the valves is relatively more developed that in the pedicellariae of the first form. Its length is more than a third of the total length. The blade is strongly narrowed at its base. It widens very rapidly into a spoon relatively wider than in the large pedicellariae. It has a triangular form. It narrows very rapidly to a fairly pointed end. Its borders have teeth arranged as the large pediceellariae. The perforations are large and oval. There are also rudiments of the lower arcs.

The trifoliate pedicellarie are fairly abundant. The valves are 0.10 to 0.12 millimeters in length (fig. 5b). The blade that begins by an extremely short neck widens very rapidly into a spoon a little longer than wide, sometimes round at the end, sometimes more pointed and with teeth that are close together on its border. The ophiocephalous, which are not very widespread, have already been figured by Meijere (Pl. XVII, fig. 352). Their valves are about 0.15 millimeters in length.

H. L. Clark (1914, p. 37) thought the pedicellariae were very rare because he found on a specimen only one ophiocephalous and no tridactyl, while on another he found some tridactyls and no ophiocephalous. This is not what I have observed in my specimens where the pedicellariae are in principle fairly abundant, except we find the ophiocephalous more rarely.

The rosettes of the disks of the tube feet are 0.015 millimeters in diameter (fig. $5 \mathrm{c}$ ). They have only a single circle of perforations.

Here, on the other hand, the particularities that I have been able to obtain on the internal anatomy of a $\mathrm{Cl}$. humilis. The test is notable for its very considerable thickness of the wall that makes dissection of this species very difficult. The very strong marginal pillars ae sometimes cylindrical, sometimes widened parallel to the border of the test. They form six or seven more or less regular concentric circles, at least in the region between interradius 3 and interradius 5. The other pillars, located inside the intestinal loops are likewise very developed. They form a fairly important compact mass. But it remains localized to the regions with the gonads and leaves completely free the central and raised part of the test (Pl. III, fig. 5).

The lantern is very developed. Agassiz has published several photographs either of the entire lantern or of different isolated pieces $(1874, \mathrm{Pl}$. XIa). In a specimen whose photograph I reproduce in Pl. III, fig. 1 and 4, in which the length is 64 millimeters and the maximum width is 54 millimeters, the length of the lantern is 25 millimeters between the anterior end and the middle of the posterior border and 30 millimeters between the ends of the jaws of radii III and V (fig. 1 and 2).

The first intestinal loop is a very deep greenish gray, a little reddish in its part between radii III and V. Then it becomes progressively greenish to its end. This tint differs from the light brown color in the first portion of the ventral intestinal loop of $\mathrm{Cl}$. rarispinus and that, in this species, is abruptly replaced by greenish color in posterior interradius 5. The dorsal loop is yellowish gray. In the specimen I represent here in Pl. III, fig 1 and 4, the width of the first intestinal loop at its origin is a little more than 5 millimeters. Then this width falls nearly immediately to 4 millimeters. It is 3 millimeters in interradius 5 and only 2 where it become the second loop, whose width 
remains 2 millimeters its entire length. The passage from the first to the second loop is between radius III and interradius 3 , a little near the second and consequently a little before the point where the change of direct occurs in $\mathrm{Cl}$. rarispinus, which occurs in interradius 3 itself.

The intestinal gland, a little lighter in color than the intestine to which it is attached, has a length of 11 millimeters and a width of 2 millimeters in the individual in fig. 4. It is very distinct. Its acini ae fairly fine, finer than in $\mathrm{Cl}$. rarispinus of a smaller size. They marginal vessels have nearly the same color as the ventral intestinal loop. They are only a little deeper.

The gonads do not form very considerable masses, at least in the individual I have opened. They undoubtedly are larger 55 when they are mature, but I have nothing to say about this. In any case, the gonads are far from forming masses as developed as in $\mathrm{Cl}$. rarispinus where they extend to a short distance from the center of the body, like the numberous calcareous pillars that support them.

\title{
Clypeaster rarispinus (Meijere)
}

\author{
(PI. V, fig. 1, 2 and 7; PI. VI. fig. 7 to 11; PI. XIV, fig. 9)
}

Clypeaster rarispinus Meijere, 1904, p. 134; pl V. fig. 55 and 56; pl. XVIII, fig. 354 to 361; pl. XIX, flg. 362.

Clypeaster rarispinus H. L. Clark, 1914, p. 30.

Alexandria magnifica Loriol, 1891, p. 20 (non Pfeffer, 1881).

Station 85. - Coast of Ganjam. - 30-31 fms. - Ten specimens.

Station 90. - Coast of Ganjam. - 28-30 fms. - Four specimens.

Station 94. - Coast of Vizagapatam. - 15-17 fms. - Ten specimens.

Station 95. - Coast of Ganjam. - 15-26 fms. - Three specimens.

Station 138. - $14^{\circ} 25^{\prime}$ N.; $80^{\circ} 15^{\prime} 45^{\prime \prime}$ E. -12 fms. - Four specimens.

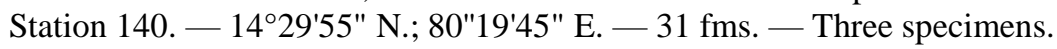

Station 146. — Laccadive Islands. - $11^{\circ} 5^{\prime} 45^{\prime \prime}$ N.; $75^{\circ} 48^{\prime}$ E. — $36 \mathrm{fms}$. — Five specimens.

Station 467. - Coast of Iravan 'ore. - $9^{\circ} 55^{\prime}$ N.; $75^{\circ} 41^{\prime}$ E. - 42-75 fms. - Two small specimens.

26 miles W. S. W. of Honawar. - 28 fms. - Numerous specimens.

8 miles S. of Puri. - $13 \mathrm{fms}$. - Numerous specimens.

Coast of Ganjam. - 18 fms. - Two specimens.

Coast of Ganjam. - $28 \mathrm{fms}$. - Several specimens.

Coast of Ganjam. - $35 \mathrm{fms}$. - Five specimens.

W. of Mangalore. - 16-31 fms. - Numerous small specimens.

$6^{\circ} 01^{\prime}$ N.; 81 $16^{\prime}$ E. - 34 fms. - One specimen.

Santapalii, Madras Presidency. _ "Golden Crown", 1909. — Three small specimens.

Mouth of the Hugli. — "Golden Crown" 10 Feb. 1909. - Several specimens.

Gopalpore. - "Golden Crown". — Two specimens.

The characters of $\mathrm{Cl}$. rarispinus have been indicated in a very sufficient manner by Meijere and I can only confirm his description that has, moreover, been reviewed by H. L. Clark. However, I must note that Meijere has not reported an important character of $\mathrm{Cl}$. rarispinus, a character that we recognize in a more or less clear manner in the specimen that he has reproduced the photograph in his pl. VI, fig. 56. I want to speak of the flattening of the interporiferous zones of the petals, an arrangement that recalls that which I reported above in $\mathrm{Cl}$. Annandalei. I have always seen in the very numerous $\mathrm{Cl}$. rarispinus collected by the INVESTIGATOR that these zones remain flush with the test and that, even in the large specimens, they follow the general curve of the body without forming an appreciable protrusion. I shall add that the test itself is always very depressed and that 
its border is very thin. Its contour is susceptible to show some variations that are not of great importance. The sides can be more or less concave and the corners more are less marked. The ratio of the length and the width can also slight increase or decrease. Thus I represent here (Pl. VI, fig. 8 and 9), two relatively large individuals in which the length is nearly equal to the width, and that can be regarded as corresponding to the most common form. In one, the sides are nearly straight (fig. 8) while in the other, they are fairly strongly concave (fig. 9). A third individual, to the contrary, (fig. 7) is more elongated than the average. I likewise observe some variations in the form of the petals that, in principle, are thin and elongated, as we see for example in fig. 8 but that can be a little widened (fig. 9), or is widened more in their first half to become narrower at the end (fig. 7). There are not regular rows of primary tubercles between the successive pore pairs. At the most, we observe here and there, especially in the external half of the petal, a primary tubercle nearer the internal border of the poriferous border than the external border. As for the interporiferous zone that is narrow, it has unequal primary tubercles, not dense and very irregularly arranged. The smallest have the size of the tubercles of the poriferous zones. The others are a little larger (Pl. V, fig. 7).

The pedicellariae that I observe recall, with some difference however, thoe that Meijere has represented in 1904 (pl. XVIII, fig. 354 to 361). The tridactyl pedicellariae are of two kinds. One is fairly large and the length of the head can be 0.4 to 0.45 millimeters (Pl. XIV, fig. 9). These are without doubt the pedicellariae that Meijere has represented in fig. 359 and 360. But I note in the larger that the blade of the valve is stronger in this group than in the figure given by this author, and that it has along its entire length, very fine and closely spaced teeth that are more numerous and less strong than those Meijere has represented. The teeth can be completely missing however. The blade widens rapidly in the last quarter into a very short spoon, shorter than wide, round at the end and with fairly low and fine teeth on its border. The pedicellariae of the second form are smaller and their valves are at most 0.3 millimeters in length. Their form is nearer to that represented by Meijere, but the narrow basal part of the blade has a perfectly smooth border.

I have also encountered ophiocephalous pedicellariae that Meijere has not indicated. They are very small and the length of the head is no greater than 0.06 to 0.07 millimeters. Finally, there are trifoliate pedicellariae that have already been reported by H. L. Clark, whose valves are only 0.07 $\mathrm{mm}$ in height. The blade forms a nearly half-circular spoon with fine teeth, a little elongated, that is connected to the basal region by a narrow part a little longer than the basal part itself. I have not encountered pedicellariae similar to those that Meijere represents in fig. 361. I do not know if the author wanted to represent a trifoliate pedicellaria. In any case, the form is very different from those that I just described.

The characters of the spines have already been indicated by Meijere. The length of the miliary spines varies between 0.35 and 0.45 millimeters. These spines gradually enlarge toward their end.

The internal organs in $\mathrm{Cl}$. rarispinus are very distinct, which makes their study easier than in the other species. The calcareous pillars of the periphery of the disk are more or less widened tranversely in some specimens (Pl. V, fig. 1 and 2). They form, especially near the border, elongated, fairly exactly concentric arcs. I can count up to six to seven of these arcs. In other individuals, the pillars remain more isolated and are arranged in a more irregular manner. In some individuals whose length is from 40 to 42 millimeters, like those I represent here, the pillars are developed in a peripheral band about 5 millimeters of average thickness, widening a little in the radial regions and narrowing in the interradial parts. Inside the intestinal loops, numerous isolated pillars extend from the dorsal surface to the ventral surface of the disk, through the gonads up to a short distance from the center of the body. 
When we remove one of the surfaces of the test (Pl. V, fig. 1 and 2), the largest part of the digestive tubes appear with all the desirable clearness. Its color contrasts with the other organs. After a very short esophagus, the intestine is directed, as usual, toward the anterior end of the test and widens rapidly. Its external border follows near the middle of ambulacrum III. Then it abruptly curves to the left (the animal being seen by its dorsal side as in fig. 2). The external border makes a nearly right angle but very rounded at the top with the preceding part, while the internal border follows a regularly concave curve. Between the round top and the base of the opposite concavity, the intestinal tube has its maximum width, about 6 millimeters. The width decreases rapidly and falls to 3 millimeters, a width it keeps up to the left posterior interradius. The intestine remains flat and empty on this half-circumference, but beyond interradius 5, it tends to become circiular at the same time that it narrows. At the end of the first loop, its width does not exceed 2 millimeters. This intestinal loop describes thus more than one entire circumference because its end largely passes ambulacrum III and nearly reaches interradius 3 before recurving to form the second dorsal loop that we can observe, at the anterior end of the body, three successive portions of the body, contiguous for a small part of their length. The second intestinal loop that begins thus toward interradius 3 follows for more than a half circumference, the external border of the ventral loop, outside of which it remains exactly located. It is visible both by the dorsal surface and the ventral surface up to the point where it recurves at a right angle into posterior interradius 5 to reach the anus.

From the beginning of the esophagus and on the first half of the ventral loop, the digestive tube has a very uniform color of very bright light brown. It is all the more conspicuous in general because the tube is completely empty. Then, a little before interradius 5 , at the place where the siphon ends and where the branches of the intestinal lacunae open into the internal marginal lacuna, the intestine becomes a deeper shade of purple. But this color changes abruptly to a very deep gray, sometimes greenish or yellowish, that is due in large part to the very contents of the intestine. We note, in fact, that after this region, the digestive tube is filled with mud that we see by transparency across the wall of the intestine.

The gland that accompanies the first part of the intestine along ambulacrum III appears in $\mathrm{Cl}$. rarispinus with great clarity thanks to its color that is deeper than that of the portion of the digestive tube to which it is attached and that is a more or less deep purple. This gland narrows behind and widens slightly in the anterior region in encroaching a little onto the ventral surface of the intestine. Its anterior end is 2 millimeters behind the round angle formed by the external border of the first intestinal loop. The acini that constitute it are relatively large and round. They appear as small bright grains.

The two internal and external marginal lacunae are remarkably distinct because of their color of deep purple, especially marked on the external lacuna that is narrower than the internal. Its color tends rather to deep brown. Forward, this lacuna has the arrangements we know. It crosses a little obliquely the beginning of the digestive tube on the ventral surface. Then it bifurcates upon reaching the external border into two branches, anterior and posterior. It had already given a narrow branch that will go up along the esophagus. All these arrangements are clearer here and they are seen by simple inspection of the animal opened by the ventral surface. Beyond the posterior interradius 5, the dimensions of the internal marginal lacuna decrease. But this lacuna still remains $\mathrm{k}$ distinct and we can more or less follow it toward anterior ambulacra III. As for the external marginal lacuna, it also remains very distinct up to interradius 5 . Then it decrease in size and gradually disappears before reaching the end of the first intestinal loop. 
The siphon sometimes is white that makes its path very apparent. Its distal opening is located, as I have said above, in interradius 5 at the point where the color of the loop is abruptly modified.

The gonads are very light yellow of greyish yellow. They are generally confluent and form a kind of very wide ring that is interrupted on in ambulacrum III. In the individuals I have opened, the free spaces between the peripheral pillars do not contain extensions of the gonads, or at least the portions that enter them are insignificant.

Meijere compared his $\mathrm{Cl}$. rarispinus only with Alexandria magnifica Pfeffer. He concluded that the two species are different. We know moreover that $A$. magnifica Pfeffer is only $C l$. humilis. On the other hand, Loriol had given in 1891 the name Alexandria magnifica to two specimens from New Caledonia that, according to the information furnished by this author, cannot be related to the latter species. I must say on this subject that I had the opportunity to examine these two specimens, at the home of the late de Loriol himself. I have convinced myself that they are really two $C l$. rarispinus. De Loriol, to whom I have shown authentic specimens of $C l$. rarispinus, recognized his error of determination. I do not believe that $\mathrm{Cl}$. rarispinius can be confused with other Clypeaster.

There is a very great resemblance between $\mathrm{Cl}$. rarispinus and $\mathrm{Cl}$. Audouini Fourteau, except for the fact that the first is known only by small specimens, while the second reaches a large size. However, H. L. Clark, who has had the two species in his hands, considers them as distinct. The test is fairly elevated in $\mathrm{Cl}$. Audouini where the petaloid area reaches more than 0.6 of the length of the body, while in $\mathrm{Cl}$. rarispinius, where the test is fairly low, the petaloid area is only 0.45 to 0.55 of the length. We can think, it is true, that this difference is due to the difference in size. The question must be answered by studying specimens of the same size. On the other hand, the two species do not appear to have the same geographical range. $C l$. Audouini is known in the Red Sea and the east coast of Africa to Natal. Cl. rarispinus has been reported especially in the Sunda Islands and in the Bay of Bengal. Whatever it is, the individuals of the Indian Museum are absolutely in conformity with those of the Sunda Islands described by Meijere. I believe it necessary to apply the same name to them.

\title{
Clypeaster amplificatus uov. sp.
}

\author{
(PI. III, fig. 10 and 11; VII, fig. 1 and 2; PI. XIII, fig. 1)
}

A single specimen, labeled "Massaonah".

The specimen is not part of the collection of the Indian Museum, but belongs to the Jardin des Planes. However, as it comes from a region near those providing the clypeasteroids that are the object of this memoir, it seems to me useful to describe it here, all the more because it has some very remarkable characters.

The individual is first of all remarkable for its large size and its very flat test. But it was subjected to a mutilation of the peripheral part of the test between radii I and III that was an appreciable loss of material and making its contour irregular. It is very probable that this mutilation resulted in some changes in the position of the apical system and the peristome, as well as inequalities in the petals and an irregularity in the arrangement of the plates of the unpaired posterior interradius. Judging from the intact part of the test, the body is slightly longer than wide. It is narrowed in its anterior part. It reaches its greatest width at the end of the posterior petals. The individual is completely lacking in spines. 
Here are the principal measures I have taken (for some of them, the numbers that I indicate correspond to half the intact body).

Length (measured between the ends of radius III and interradius $5 \ldots \ldots . . . .2190$

Half width at the level of the end of the apical system, 81, is for the total width 168

Half width at the end of petal V: 87, is for the total width ................ 174

Height ............................................................. 23

Length of anterior petal III ......................................, 56

Length of left anterior petal IV ......................................... 48

Length of right anterior petal II ..................................... 47

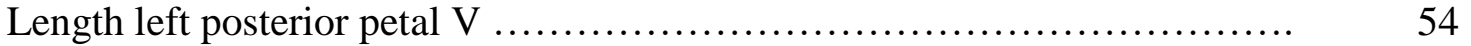

Length right posterior petal I ......................................... 57

Maximum width of anterior petal .................................... 28

Maximum width of left and right anterior lateral petals ................... 27 and 29

Maximum width of left and right posterior lateral petals $\quad 30$ and 27

Distance between end of anterior petal and border of the test ................ 24

Distance between end of left anterior lateral petal and border of the test ....... 35

Distance between end of the left posterior lateral petal and border of the test .. $\quad 46$

Distance between the middle of the apical system and the anterior border of the test ............................................................ 90

Distance between the middle of the apical system and posterior border ......... $103^{7}$

Distance between the center of the peristome and the anterior border of the test 85

Distance between the center of the peristome and the posterior border .......... 105

Diameter of the peristome ............................................ $\quad 9.5$

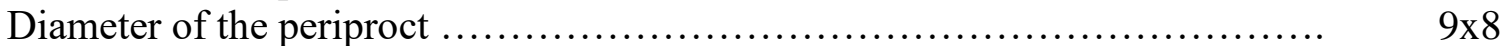

Distance between the centers of the peristome and the periproct ................ 95

Distance been the posterior border of the periproct and the posterior border of the

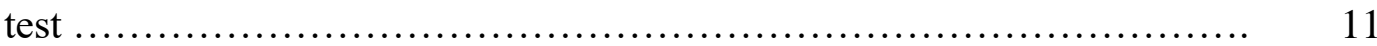

Length of radius $\mathrm{V}$ measured between the center of the peristome and the border of the test ........................................................... 96

Length of radius I .......................................................... 101

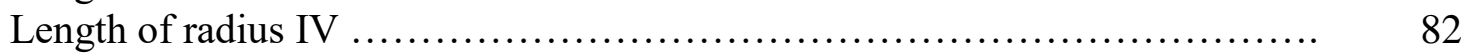

Length of radius II .................................................. 79

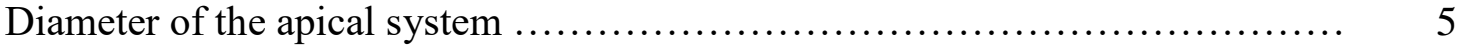

The test is sensibly longer than wide in the specimen than it actually is. But if we double the number that represents half the greatest width at the level of the posterior petal V, we obtain 174 millimeters for the normal width of the test at this level, which is slightly less than the length that is only 190 millimeters. Seen from the dorsal surface, the anterior border of the test is very widely rounded, then it follows a very regular contour on the left up to the level of interradius 4 where it is slightly curved. From there it widens again to reach its maximum width at the height of the left posterior petal. Then the width decreases gradually and the border of the test follows a very regular

\footnotetext{
7 These two numbers are together 193 and not 190, the number indicated for the length of the body measured on the ventral surface. On the dorsal surface, the numbers make a slightly larger total because of the unevenness of the test produced by the protrusion of the apical system.
} 
curve with a very large radius. The posterior region of the test is notably wider than the anterior region (Pl. VII, fig. 1).

The dorsal surface is a little swollen. It remains nearly flat in the peripheral half and more swollen in the central half. The interporiferous area of the petals is slightly protruding. The apical system is nearer the anterior border than the posterior border of the test. On the ventral surface, the five radial grooves are very marked and narrow. The peristome scarcely sunken. It is rather small, nearly exactly circular, very slightly wider than long and nearer the anterior border than the posterior border of the test (fig. 2). The periproct, fairly distant from the posterior border, is a little longer than wide. The edges of the test are very thin and round. They are about 3 millimeters in height.

The apical system, rather small, is covered with very fine and separated granules. Between them are the extremely small openings of the madreporite (Pl. III, fig. 10). The gonopores are slightly elongate in the interradial direction. The ocular pores are, to the contrary, transversely widened. The petals are extremely developed and are a little unequal in the specimen of the Museum. The anterior petal is longer than the other four. Both posteriors are without doubt more elongated than the anterior petals. But, because of the malformation of the test, the right anterior petal is a little more elongated than the opposite petal. And likewise the right posterior petal is notably longer than the left. It has nearly the same length as the unpaired anterior petal. The right anterior petal is the shortest, but it is slightly wider than the left anterior petal. This difference can be seen easily in the photography I reproduce here in Pl. VII, fig. 1 and it is not necessary to insist on it.

The petals are all very wide. They are flush with the test and are nearly closed. They are remarkable for the extreme width of the interporiferous area that keeps nearly the same dimensions up to the area of the apical system, while the poriferous zones abruptly narrow in their proximal region and become nearly linear. They are then separated from the adjacent petal for a length of about 15 millimeters only by an extremely narrow interradial band, a little wider however than the poriferous zone itself. This arrangement gives a very particular character to the petals of our species. From this extremely thin proximal region, the poriferous zones widen rapidly. They reach a width of 5 millimeters that they keep then for nearly all their length. The internal row of pores forms a nearly straight line. The external row forms a convex line. The two zones approach each other toward the distal end of the petals at the same time that the two poriferous rows of each side curve toward each other and tend to approach it. I say that they "tend" to approach because they can only touch in the lateral petals, mainly in the left petal that is really the only one we can say is closed. The right anterior petal is nearly closed, although the last pores are not absolutely contiguous. The left posterior petal is nearly open, but it has at its end numerous small supplementary pores that nearly totally close the end. The unpaired anterior petal as well as the right posterior are both clearly open. The poriferous zones are separated from each other by about 5 millimeters at the end of each of these petals.

The poriferous zones themselves are very marked, very wide except on the first fifth of their length. The pore pairs are very near other and very dense. The external pores are larger and transversely widened. The internal pores are much smaller, cylindrical and punctiform. The pores of each row are connected to the corresponding pores by regular furrows, separated from each other by fine ridges each having a very regular row of about a dozen very dense fine granules on each side. The dimensions of these granules is a little less than those that cover the interporiferous zone. The poriferous zones are rather slightly sunken. As for the interporiferous zones, they are remarkably large and very wide. They narrow, as I said above, in a very abrupt way at their 
proximal end. They are covered with very fine, very dense primary tubercles in the middle region of the zone, while on the sides they tend to form small, very regular transverse rows (Pl. III, fig. $11)$.

Outside the regular pores that form the poriferous zones, we note some irregular pores especially toward the distal end of the petals. These pores are especially numerous at the end of the left posterior and unpaired anterior petals. They are less numerous and smaller at the end of the other petals and especially of the right anterior petal. In addition to these supplementary pores that touch the petals in some way, there are some others located some distance from the petals, forming small inconstant and unequal groups. One of these small groups has four pores and is very apparent outside the left posterior petal. It is separated from it by 17 to 18 millimeters. A similar group having on one side four pores very close to the petal and on the other side, two pores more separated is seen outside the right posterior petal. Finally, outside the left anterior petal and on the plates of series IVa, is a small group of two pores. These supplementary pore are missing in the right petal but there are two are three 64 outside the unpaired anterior petal. These are connected to the other pores that incompletely close this petal at its end.

After these petals, the ambulacral plates become very large, reaching a greater width than the plates of the adjacent interambulacral plates. They continue in a variable number up to the border of the test where their width passes 4 centimeters, at least in radii I and V. We can count about seven successive plates in each of these two radii, five in radius IV and three to four in anterior radius III. All these plates are covered with very fine, very dense tubercles, identical to those we observe in the interporiferous zones as well as in the interambulacral zones.

These latter begin outside the apical system in a remarkably narrow region, constricted between the distal region of the extraordinarily close poriferous zones. They keep this extreme thinness for a length of 2 centimeters by having only three rows, incidentally irregular, of successive tubercles. Then these zones abruptly widen and they develop at first largely between the petals, then still more outside them. Outside the petals, the intterambulacral plates are wider, but shorter than the corresponding ambulacral plates. They have, generally, a regularly alternate arrangement, but in the unpaired posterior interradius they have an irregular arrangement that is especially marked to the left that is due to the appearance of a larger number of smaller plates than usual and irregularly polygonal. We see this irregular arrangement in my photograph (Pl. VII, fig. 1).

The tubercles that cover the interambulacral zones keep the same dimensions for all the entire extent of these zones. They are very dense, surrounded by a small scrobicular circle and separated by spaces covered with extremely fine miliary granules, like those incidentally in the ambulacral regions.

The ventral surface is nearly exactly flat. It is slightly depressed in the immediate area of the peristome that is sunken 2 or 3 millimeters. But there is no distinct infundibulum. I have noted above the form of the peristome and the periproct, as well as the respective position of the two openings. The radial grooves, well-marked, are no more than a millimeter in width. They lengthen by narrowing and tapering to the border of the test. They are covered with extremely fine granules, separated from each other, and lacking a scrobicular circle. The ventral interradial areas are uniformly covered with granules larger than on the dorsal surface, each surrounded by a very marked scrobicular circle, non-contiguous and separated by very fine tubercles remaining however a little larger than those of the radial grooves themelves and those of the dorsal surface. 
On the ventral surface, the diameter of the tubercles strictly speak is 0.11 to 0.12 millimeters, and with a scrobicular circle of 0.25 to 0.26 . On the dorsal surface, these diameters are respective 0.9 and 0.16 to 0.17 millimeters.

The individual is completely bare. I can say nothing about the spines or pedicellariae.

Two fragments of the ventral surface of the test had been removed to allow examination of the internal pillars before the specimen was sent to me. They appear to be close, thick, numerous and with very fine needles between them that come both from the dorsal surface and the ventral surface. But the openings are too small to permit an account of the arrangement of the internal pillars that is extremely interesting. A radiograph like that I represent here, Pl. XIII, fig. 1, show with perfect clarity the considerable development of the endoskeleton of $\mathrm{Cl}$. amplificatus. At first, the peripheral pillars form an extremely wide border that reaches a maximum width in radius I and $\mathrm{V}$. It includes ten to twelve partitions, fairly thin but very dense, arranged with great regularity in the radial regions, more irregular, entangled and branched in the interradial regions. The spaced filled by the digestive tube is very recognizable and we can very easily give an account of its path. We recognize in particular that the first intestinal loop does not make exactly a complete circumference and that the passage of this loop to the second occurs a little before radius III. At its extreme posterior, the second loop makes a very pronounced bend before continuing to the rectum. The various portions of the general cavity, inside the digestive tube, are filled with very numerous, irregularly branched pillars that are developed principally in the interradial regions. The arrangement of the pillars is identical in the five interradii. We can see them advancing between the petals. Each interradial mass sends inside two parallel lamellae that are very near each other that stop some millimeters from the center of the test. In the two posterior radii I and V, numerous partitions arranged parallel to each other and mixed with pillars fill the space that remains empty between the digestive tube and the end of the petals. These partitions and pillars encroach onto the external border of each petal. The pillars are much less developed outside petals II and IV due to the more restricted space that remains free between the end of the petals and the digestive tube. However, the pillars exist in radius II and encroach less onto the corresponding petals. We also find these pillars are scarcely indicated at the end of petal IV and radius III.

The walls of the test are fairly thick and solid.

One is truly surprised to find in a Clypeaster with an extremely thick body in which the two dorsal and ventral walls are very near each other and fairly thick, such a luxury of supports and struts. Perhaps, it is true, the role of the endoskeleton is still more than that of an apparatus of support. Whatever it is, this formidable development of calcareous pillars in a Clypeaster with a very flat body contrasts singularly with the reduction of these pillars in a Clypeaster with a very elevated test and very fragile walls such as $\mathrm{Cl}$. Annandalei.

SIMILARITIES AND DIFFERENCES. - By its large dimensions, by its very depressed test not raised at the petals, by its flat ventral surface without a well characterized infundibulum, it seems necessary that the species of the Red Sea must be placed in the section Coronanthus. This Clypeaster recalls a little some large individuals of Clypeaster humilis. But the similarities are limited to the size and general form. The enormous development of the closed petals that remain flush with the test, so wide that the interambulacal regions become linear well before reaching the apical system, opposes any relationship with $\mathrm{Cl}$. humilis, which belongs moreover to another section. The species approaches more $\mathrm{Cl}$. subdepressus of the Atlantic, but the latter has, according to Agassiz, a well characterized peristomial infundibulum. Like $\mathrm{Cl}$. humilis, it belongs to the section Stolonoclypus. 
As for the species of the Coronanthus section itself, none of them approach $\mathrm{Cl}$. amplificuus.

\section{Genus Rhaphidoclypus (A. Agassiz)}

The genus Rhaphidoclypus was created in 1863 by A. Agassiz for a Clypeaster called scutiformis, attributed incorrectly to Gmelin, and which is nothing other than the Clypeaster reticulatus of Linnaeus. But this genus is purely nominal, A. Agassiz having never published the diagnosis. More importantly, in his "Revision", Agassiz described the species under the name Clypeaster scutiformis. Lambert and Thiéry are the only authors who, in 1914, reprised the name proposed by Agassiz. I recall they characterized the genus Rhaphidoclypus in the following manner: test depressed, laganiform above; lower surface concave; swollen border free interiorly, branched central pillars.

I consider the genus Rhaphidoclypus as being perfectly valid and not as a simple sub-genus of Clypeaster, having the value of a simple section such as Stolonoclypus, Coronanthus, Laubeanthus etc. I suggest, moreover, that the diagnosis of Lambert and Thiéry should be extended and defined as I shall indicate later. When, in fact, one works with Rhaphidoclypus reticulatus, one is struck by the arrangement both in the internal calcareous pillars and the digestive tube. These arrangements are very different from those we see in the genus Clypeaster. The characters of the internal calcareous pillars has already been indicated by A. Agassiz, who published two photographs of them under the name of Clypeaster scutiformis in his "Revision: (pl. XIII, fig. 3 and 4). The peripheral pillars or partitions that exist in the genus Clypeaster and that form more or less developed dense concentric circles fill all the marginal part of the test and separate the digestive tube from the test where it is completely missing. The pillars only appear at some distance from the border. They remain more or less isolated from one another. They are moreover not numerous. They are grouped in a way to form radial or interradial rows of which the largest are more external. As we can see from the photographs of Agassiz (pl. XIII, fig. 3), the pillars closest to the periphery stop completely at some distance from the edge, forming a very regular circle in the border. Thus is produced a kind of peripheral ring that is free of all calcareous formations and that is occupied by the digestive tube. The only calcareous formation that touches the periphery of the test is a kind of arc developed at the periproct. The rectum passes under the arc, separated from the first ventral intestinal loop. I shall also recall that the ventral surface of the test has some very fine needles, most of which do not reach the dorsal surface. The digestive tube is not absolutely attached to the internal surface of the marginal region of the test. It is separated by a space that is extremely narrow and nearly virtual that remains empty. The gonads do not enter into it. They fill all the remaining available space in the general cavity between the digestive tube, the two dorsal and ventral walls of the test and the vertical calcareous pillars that connect the two surfaces.

The absence of calcareous pillars in the marginal region of the test that produces a different arrangement of the digestive tube appears to me to be very important in justifying a generic separation. I believe the old Clypeaster reticulatus should be placed into another genus than Clypeaster Annandalei, humilis, destinatus, fervens and rarispinus, species whose internal structure I have been able to examine. I can add $\mathrm{Cl}$. amphificatus, because the radiographic examination shows me it has an arrangement of the digestive tube and internal calcareous pillars similar to that in the other species of Clypeaster I just cited. 
As we shall see later, a difference of the same order exists between the genus Fibularia, where the calcaraeous pillars are missing and the digestive tube occupies an absolutely marginal location and the genus Echinocyamus, where the digestive tube is separated from the border of the test by peripheral partitions. I propose thus to add to the diagnosis given by Lambert and Tbiéry for the genus Rhaphidoclypus some words: Because of the complete absence of internal calcareous pillars in the peripheral part of the test, the digestive tube has a marginal location instead of being separated from the border by a more or less great thickness of calcareous partitions.

The only living species reported by Lambert and Thiéry to the genus Rhaphidoclytus is $R$. reticulatus. The other species cited by these authors are all fossils. They are $R$. depressus Sowerby, elongatus Egozcue, goirensis, pelciformis, pulcinatus, Waageni Duncan and Sladen. As I noted above, it is without doubt appropriate to add to the genus Rhaphidoclytus the Cl. lytopetalus described recently by H. L. Clark (1914, p. 33, pl. 124, fig. 1 and 2; pl. 138, fig. 1-3)

\title{
Rhaphidoclypus reticulatus (Linné)
}

\author{
(PL VI, fig. 3 and 4; PI. XV. fig. 10.
}

Echinus reticulatus Linné. 1758. p. 666.

Clypeaster scutiformis Lamarck. 1816. p. 11.

Clypeaster scutiformis A. Agassiz. 1872-74. p. 512, pl. Xl11, fig. 1-4.

Clypeaster reticulatus Loriol, 1883, p. 37.

Clypeaster scutiformis Meijere, 1904. p. 131. pl. XVIII. Fig. 344-351.

Clypeaster scutiformis R. Brown. 1910 a, p. 11.

Clypeaster reticulatus H. L. Clark. 1914. p. 34. |pl. CXXIV, fig. 3-6.

Clypeaster reticulatus Lambert. 1914, p. 12 and 13.

Rhaphidoclytus reticulatus A. Agassiz. 1863, p. 25.

Rhaphidoclytus reticulatus Lambert and Thiéry, 1914, p. 301.

Andaman Islands. 270-45 fms. Two small specimens.

Laccadive Islands. 30-50 fms. Two small specimens.

North of Cheduba. $10 \mathrm{fms}$. Two small specimens.

Coast of Cheduba. 20-30 fms. Two specimens.

South of Terribles. $13 \mathrm{fms}$. Two specimens.

W.S.W. of Honawar. 30-50 fms. Four small specimens.

Southern coast of Ceylon. $6^{\circ} 01^{\prime}$ N., $81^{\circ} 16^{\prime}$ 'E. 31 fms. Three specimens.

The two names of Clypeaster scutiformis (Lamarck) and reticulatus (Linné) have both been used to designate this species. Among the modern authors A. Agassiz and Meijere have used the first name. Loriol, H. L. Clark and Lambert and Thiéry have used the second. It seems that the latter should prevail. Loriol has already noted in his work of 1883 (p. 38) that he could not find reference to Echinuis scutiformis in Gmelin that Agassiz cited without mentioning the page. For him, the author of the name was Lamarck who had taken the characteristic phrase from Seba. On the other hand, Lambert and Thiéry wrote "It is wrong that Loven wanted to remove from this species the name that it carried for more than a century to give it to the swollen species with concave ventral surfaces of Antilles. The synonymy proposed by Agassiz to impose on Clypeaster reticulatus the name Clypeaster scutiformis is unacceptable. It is based on a material error, because Echinius scutiformis Gmelin is not a Clypeaster, (Lambert 1914, p. 12, said it is an echinolampid)." 
Rhaphidoclypus reticulatus is a well-known species. It was described correctly by A. Agassiz, and Meijere has given precise information on the spines and pedicellariae. I shall content myself here to add some remarks on the subject of the pedicellariae and to give a detailed description of the digestive tube.

The pedicellariae are of three different forms. There are two kinds of tridactyl pedicellariae, trifoliate and ophiocephalous. The most characteristic tridactyl pedicellariae are of large size. Their head is 0.45 to 0.50 millimeters in length. The basal part of the valves, fairly wide and a little wider than long, have small lower arcs (Pl. XV, fig. 10b). The height of this part is more than a third and sometimes even two-fifths of the total length. The perforations are small and not very dense. The borders are a little irregular, or even with some extremely low teeth. The apophysis, which is not very developed, has on its free border, some fairly marked teeth. The blade is first fairly narrow, but it widens rapidly into a spoon of lancelate form. It has on its free border conical teeth that are close together. At first they are very small and extremely fine, but that become stronger as they approach the end of the valve. The perforations are fairly small, oval and close to each other. They are evidently the pedicellariae that Meijere has represented in 1904 (pl. XVIII, fig 346) and Clark in 1914 (pl. CXXIV, fig. 3). Clark has reported some variations in the form of the valves, notably the spoons, which I have not observed (see his fig. 4 and 5). The tridactyl pedicellariae of the second form are similar to the preceding, but the length of the valves ae barely 0.2 millimeters (fig. 10a). The blade is relatively wider at its origin and it widens more rapidly than in the preceding into a spoon that remains shorter overall. The lower arcs are very short. These small tridactyl pedicellariae are much more widely distributed than the large. They have been represented by Meijere (pl. XVIII, fig. 347) and by Clark (pl. CXXIV, fig. 6).

The trifoliate pedicellariae that have not been indicated by the preceding authors, are very small. They are only 0.08 millimeters in length (fig. 10c). The basal part is very short and the blade is widened nearly at its base into a spoon that is about three-quarters of it total length. This spoon, rounded and nearly as long as wide, has numerous teeth, elongated, dense and pointed, all along its length.

The head of the ophiocephalous pediellariae is only 0.1 millimeter. The basal region is separated from the blade by a very narrow portion (fig. 10d). The blade is short, little widened transversely and has all along the length of it borders, strong teeth that join a group of some teeth of the narrow part of the blade. I do not see the teeth that have the great development that Meijere seems to indicate in his fig. 349.

The beginning of the first intestinal loop (Pl. VI, fig. 4), that follows the esophagus located between radius III and interradius 3. It is wide and very strongly folded. But the folds are not slow to disappear at the same time that their width decreases and the digestive tube becomes simply round. In the specimen that I represent here, the maximum width is about 4 millimeters. It decreases rapidly to 2 millimeters, and then decreases again a little. At the end of the first loop, its width is barely greater than 1 millimeter. The passage of this intestinal loop to the second loop occurs beyond radius II in the area of interradius 3. We note, in posterior interradius 5, that the digestive tube has a slight forward inflexion due to the presence of the calcareous are that I reported and that passes under the rectum.

The intestinal gland is little developed. It is narrow and short and barely passes the Aristotle's lantern. I have nothing particular to report about the intestinal siphon and the internal and external marginal lacunae. The latter are fine and slightly brown in color. The transverse branch that goes under the beginning of the first loop with a path a little more oblique than in the preceding species because of the little development of the intestinal gland. It is moreover little apparent because it is 
in part hidden by the folds of the intestinal wall itself. The siphon is white, very thin, and ends before even reaching the posterior interradius. But no change in aspect or color of the intestinal wall corresponds to this distal opening.

The gonads are confluent except in radius III. They fill, in very great part, all the space left free between the digestive tube and the Aristotle's lantern. I have not seen extensions of the gonads into the extremely narrow circular space between the external border of the digestive tube and the internal wall of the test.

\title{
Arachnoididæ Gregory
}

The family contains on the single genus Arachnoides. It is remarkable for its very depressed body, the poriferous zones of the divergent petals, the supramarginal periproct and the separated auricles. The pedicellariae are very small and very rare. They appear to be only the bifoliate form. From the anatomical point of view, we will see later that the genus Arachnoides is near the genus Clypeaster by some structures, while by others it is distant. It is a perfectly characterized type, very distinct from Clypeaster and whose classification into a family is completely justified. It is presently known by two species, A. placenta (Linné) and zelanda Gray.

\section{Arachnoides placenta (Linné)}

\author{
(PL V, fig. 8-10; PL XV, fig. 14)
}

Echinus placenta Linné, 1758, Systema naturæ, édit. 10, p. 666.

Arachnoides placenta L. Agassiz, 1841, p. 94, pl. XXI, fig. 35-42.

Arachnoides placenta A. Agassiz, 1872-74, p. 90 and 530, pl. XIII b, fig. 1-4.

Arachnoides placenta Loven, 1874, p. 34, pl. VIII, fig. 77-78; pl. LI and LII.

Arachnoides placenta Loven, 1892, p. 63, pl. VIII, fig. 73-78.

Arachnoides placenta Loriol, 1893, p. 376.

Arachnoides placenta Meijere, 1904, p. 137.

Arachnoides placenta H. L. Clark, 1914, p. 43, pl. CXXV, fig. 1-3.

Arachnoides placenta Mortensen, 1921, p. 181, pl. VI, fig. 26 and 27.

Non:

Arachnoides zelandice Gray, 1855, p. 14, pl. II, fig. 2.

Arachnoides placenta A. Agassiz, 1872-1874, p. 90 and 530, pl. XIII b, fig. 1-4.

Araclmoides zelandice Loven, 1875, p. 34, pl. VIII, fig. 77-78, pl. LI and LII.

Arachnoides placenta Farquhar, 1894, p. 197 and 1898, p. 321.

Arachnoides placenta, Benham, 1907, p. 28.

North Andaman Island. - Two specimens.

Station 503. - Mergui Archipelago. Elphistone, Port Maria. Eight specimen.

Station 593. - $11^{\circ} 25^{\prime} \mathrm{N}$; $98^{\circ} 31^{\prime}$ E.; Sumatra, Paway Island. — Two specimens.

The depths were not indicated. The specimens were very probably collect at the coast. Their diameter varies between 35 and 60 millimeters.

The genus Arachnoides contains presently two different species, A. placenta (Linné) and A. zelandice Gray. The geographical distribution is different. The second form, which is special to New Zealand, was distinguished by Gray in 1855 and Loven, in 1875, confirmed the necessity of 
separating the two species. However, in his "Revision", A. Agassiz did not preserve the distinction established by Gray. His example has been followed by most authors. Very recently even, H. L. Clark united A. zelandice and A. placenta.

Mortensen (1921, p. 180) has returned to the question. He has shown in the most formal way that the two species are very different from each other. In particular, two important characters separate them in the clearest way. The first, which had been invoked by Gray, is the relative difference in the areas of the ambulacrals and interambuacrals of the two forms. In A. placenta, the width of the interambulacral areas, measured on the border of the test, is scarcely one-fourth of that of the ambulacral areas, while in A. zelandice, this width is half the latter. This difference appears both on the dorsal side and the ventral side of the test. The second character indicated by Loven is offered by the form of the plates of the ventral surface in the area of the peristome. In $A$. placenta, the ambulacral plates of the second, the third and part of the fourth pairs of the radius are contiguous along the median interradial line and we see at the border of the test on the oral side, only one interambulacral plate in each interradius. In A, zelandice, to the contrary, we can see in each interradius two or three pairs of interambulacral plates toward the border of the test on the oral surface and only the ambulacral plates of the second pair are contiguous with those of the adjacent radius. We can even note that the unpaired posterior interradius has on the ventral side, on the ventral median line, a very marked furrow that is missing in A. zelandia, that the peristome is clearly larger in the latter than in A. placenta, etc. I refer to the memoir of Mortensen for details.

Meijere has indicated in a very brief way but sufficiently precise and exact, the character of the spines and rosettes of the tube feet. Most of the primary spines widen very gradually toward the end. Others widen more, and more rapidly. Their widened end is more or less curved. The secondary spines also have a widened asymmetrical end. Mortensen (1921, p. 183) has noted that the oral interambulacral spines ae shorter and the dorsal spines less think at their end in A. zelandia than in a specimen of $A$. placenta from Queensland to which he had compared them. As I do not have a specimen of $A$. zelandiae that has preserved it spines, I have not been able to make comparison concerning the form of the spines in the two species.

Pedicellariae were found on A. placenta from the Sunda Islands by Meijere. This author called the tridactyls. Theyo are moreover very rare and very small. H. L. Clark noted that the pedicellariae really had only two valves and should be called didactyls. He gave some figures in 1914 (pl. CXXV, fig. 1, 2 and 3). Mortensen described and represented the pedicellariae that he found in $A$. zelandice (1921, p. 182, pl. VII, fig. 25 and 28). They also had two valves. They are comparatively a little larger and narrower than the pedicellariae represented by Clark. Their length oscillates about 0.2 millimeters. I have not found this form of pedicellariae in the specimens of the Indian Museum. The only form that I have seen have extremely small pedicellariae. The length of their head is not greater than 0.02 to 0.025 millimeters. There are always only two valves. The name should be bifoliate. The valves resemble the bifoliate pediceariae of other clypeasteroids. They are not much longer than wide. The borders of the latter have short, low teeth. I represent two of the valves here (Pl. XV, fig. 14).

I thought I could sacrifice three specimens of the collection of the Indian Museum to study their internal organs. In addition, my excellent friend, Bedot, Director of the Museum of Natural History of Geneva has kindly sent me two A. placenta he collected at Ambon Island. I very much appreciate his extreme kindness. The internal organization of A. placenta is very interesting to study because it has a very peculiar form whose affinities are discussed. We see that some of the anatomical structures of the genus Arachnoides are close to the genus Clypeaster s. lat. The only information that we have on the internal organization of the genus Arachnoides outside of the 
Aristotle's lantern consists of a photograph that Agassiz published in 1874 (pl. XIII b, fig. 4) of an individual seen by the dorsal surface. A part of the surface had been removed in a way to show the internal calcareous pillars that are developed over a great extent. But the specimen was dry.

A very good description of the Aristotle's lantern was published in 1892 by Loven, who made know the structure of this apparatus with his usual talent in describing the results given by his predecessors.

He has notably emphasized the arrangement of the auricles of the ambulacra and of other similarities with the genus Clypeaster. These common characters have been invoked by some recent authors to bring the genus Arachnoides closer to the genus Clypeaster or even to put it into the same family as the latter, as done by Gregory ${ }^{8}$, while establishing two subfamilies, Clypeastrinse and Arachnoidinse. Previous authors, to the contrary, placed the genus Arachnoïdes among the Scutellidæ, beside the genus Echinarachnius, as done by L. Agassiz in his Monographie des Scutelles (1841) and A. Agassiz in his "Revision".

In his excellent very recent study of clypeasteroids (1914, p. 602), H. L. Clark noted that the genus Arachnoides have a very primitive form, as indicated by the presence of ambulacaal auricls and he supramarginal anus. While classifying it, because of the arrangement of the auricles, in his synoptic table under the same recognition as the genera Clypeaster and Anomalanthus, he recognized however that we cannot unite them. He proposed the establishment of a family Arachnoididæ distinct from that of the Clypeastridse.

The anatomical study will show us that the genus Arachnoides is even closer in its internal organization to the genus Clypeaster than we thought and nearer to the Laganidæ and Scutellidæ. Nevertheless, the differences are very great so that it is not possible to unite the two genera in the same family. The establishment of a special family, as Clark proposed, is perfectly justified.

Here are the observations that I have been able to make on the internal structure of specimens that I have dissected/

The animal being opened from the dorsal side ( $\mathrm{Pl}$. V, fig. 9) shows me, first, in the central region of the body, the mass of gonads covers all of the digestive tube and part of the lantern. Exteriorly, the gonads go between the peripheral calcareous pillars that are particularly developed in the genus Arachnö̈des, as we know, and extends at least half the length of the radius of the test. We note that the gonads form an absolutely continuous mass from which leave canals that go toward the center following respectively the latero-anterior and posterior interradii. There is no gonoduct in interradius 5 where the rectum is found although it also is completely covered by the gonads. The gonopores are four in principle. It is the number that I have observed and that is indicated by Clark ${ }^{9}$.

By removing and setting aside the mass of gonads, we find the entire digestive tube as seen in figure $10 \mathrm{of} \mathrm{pl}$. V. The different organs do not have limits as distinct as in some clypeasters because they all are deep grayish or brownish. But we can distinguish them however in our photograph (fig. 8 and 10). The esophagus, directed forward, is very short. It does not pass the supra-alveolar processes of the lantern because, leaving the latter, the digestive tube enlarges rapidly. It continues its path toward the anterior end of the body while moving obliquely toward interradius 2 . The strongly convex curve it has on its external border is nearly tangential to this interradius. After having made a complete circumvolution and formed its first loop, the digestive tube returns again to interradius 2, then it turns back and forms a recurrent loop, or second circumvolution, much

\footnotetext{
${ }^{8}$ Ray Lancaster. Treatise of Zoology 1900, part III. The Echinoderms, p. 318.

${ }^{9}$ L. Agassiz indicated five gonopores and A. Agassiz said that the posterior opening was often missing.
} 
narrower than the first. After having made very accentuated sinuosities corresponding to the contours of the lantern, it recurves into a short radial loop in reaching interradius 5 along which it goes to open outside by the anus.

We note that the width of the digestive tube reaches its maximum, 7 millimeters, at the beginning of the first loop as in Clypeaster. This width decreases then gradually to about 3 millimeters in the terminal part. This first ventral circumvolution is flat and nearly empty for a large part of its length. The second loop, to the contrary, from its origin is much thinner than the preceding, cylindrical and full of diverse debris. I have said above that this loop has sinuosities that correspond to the protruding or reentering corners of the lantern. This sinuous path of the second dorsal intestinal loop is not seen in the Clypeastridæ. We shall find a similar arrangement in Echinarachnius parma.

The test of the specimen represented in Pl. V, fig 10 is 45 millimeters in the length by 44 millimeters in width. The digestive tube fills a circular spacye in which the lantern that measures about 23.5 by 25 millimeters in diameter is in the center. In the individual opened by the ventral surface and represented in fig. 8, the test is 50 x 51 millimeters and the circle occupied by the digestive tube has a diameter varying from 25.5 to 28 millimeters. In another specimen, the region occupied by the digestive tube is still more reduced. The diameter of the test being 46 millimeters, the diameter of the circle with the digestive tube is hardly 20 millimeters.

The other portions of the digestive system are better distinguished in the animal opened by the ventral surface. But, before going on to study the latter, I shall call attention to the inetional siphon whose origin appears clearly in the specimen represented in fig. 10, and we can see that with its beginning, this tube has a path completely different from that we have seen in the genus Clypeaster. In fact, the siphon begins at the esophagus itself, very near the dorsal surface of the lantern and a little toward the middle of the very short esophagus, as I have said above. But instead of accompanying immediately the digestive tube, the siphon abandons to the contrary the esophagus from its beginning and goes perpendicularly to the direction of the esophagus, to interradius 3 to approach, after an oblique path of several millimeter in length, the first intestinal loop that it encounters after a nearly right angle. During this transverse path, the siphon is located nearly immediately above the gonoduct that follows the same intermedius 3. Meeting the digestive tube, the siphon curves abruptly toward the rear following an angle that also is near $90^{\circ}$, but is round. It then remains applied against the internal border of the ventral intestinal loop that it accompanies up to the area of posterior interradius 5 where we shall find it later.

To finish the study of the digestive tube, it is convenient to examine a specimen opened by the ventral surface and in which the tube will appear nearly entire without preparation (Pl. V, fig. 8). The gonads fill well the ventral side of the urchin, but they cover only very little of the intestine itself. They are seen in all the interstices that remain free between the internal border of the first intestinal loop and the lantern. Outside, they extend between the marginal partitions to pass over the dorsal surface of the body. In the photograph that I reproduce here (fig. 8), I have removed only a very small portion of the gonads that hid the transverse branch of the siphon that I reported above. The first intestinal loop is shown here from its origin. It describes, as we know, a circle beginning at interradius 2 and returns exactly to it origin so that the two circumvolutions are perfectly in contact with each other. This first half of this first loop has some transverse folds. It remains flat and empty for three-fourths of its length. The recurrent loop, or second loop, is extremely narrow and partly hidden by the preceding.

If we study the siphon by the ventral side, we shall see easily that the canal, immediately after being applied against the digestive tube and curved back, produces from the dorsal side a tube with 
a smaller diameter but, however, very distinct with a magnifying glass. It is nothing other than the internal marginal lacuna. It is insinuated between this lacuna and the internal border of the digestive tube to which it remains closely attached. It covers the internal marginal lacuna that was first very apparent on the first part of its path. But, from the point where the siphon is applied to the digestive tube, i.e., from ambulacral IV, it is no longer visible because the siphon completely hides it. The latter, which is accompanied by a thin mesenterial strand, after having crossed radii IV and $\mathrm{V}$, opens into the intestine a little beyond radius $\mathrm{V}$. The wall of the digestive tube is brownish gray its entire length and the place where the siphon ceases is not marked by any change in color.

As for the internal marginal lacuna, it can be recognized only for a very short distance beyond the distal opening of the siphon and ends by completely disappearing. If we follow the lacuna in the opposite direction, i.e., toward the beginning of the first intestinal loop, after which it crosses the siphon, we find arrangements recalling those we have observed in various Clypeaster, but a little different nevertheless. At the very top of the anterior end of the lantern, i.e., at ambulalcral III, this lacuna goes on the ventral surface from the intestine immediately before the first loop. It is applied it and then crosses obliquely this portion of the intestine and going from the internal border to the external border, as in the genus Clypeaster. But in A. placenta, this transverse branch cannot be followed without dissection up to the internal border of the intestine because it is covered by a large glandular mass that covers at the same time the ventral surface of the portion of the digestive tube between the esophagus and the beginning of the first intestinal loop. This gland can be recognized by its very faint grayish color, very distinct from the deep color of the gonads to which it is contiguous. It has the usual arrangement of acinal glands. Its walls are very transparent. It corresponds to the gland that we have found in the genus Clypeaster, applied along the external borer of the same portion of the digestive tube and that I have called "intestinal gland." But here this gland takes a much greater development and, instead of being localized on the border of the intestine, it extends onto the ventral surface. To make the marginal lacuna that covered it visible, I had to turn back a small portion and place some of it outside before taking the photograph reproduced in Pl. V, fig 8 . In an animal thus prepared, we see the marginal lacuna first produces three small branches that clearly enters into connection with the tissue of the gland. Then the lacuna bifurcates before and behind to produce the two branches that we already know. The first that continues along the external border of the first loop and the other that goes toward the esophagus. The relations of the internal marginal lacuna with a gland related to the first portion of the digestive tube are thus fundamentally the same in the genus Arachnoides as in the genus Clypeaster. This resemblance merits underlining, because the gland exists only in these genera alone. At least they are completely missing in all the other forms I have studied that belong to the families Laganadæ, Scutellidæ and Fibulariidæ. As for the different path of the siphon, it evidently has only a much lesser importance. We see moreover differences of the same order in other genera of clypeasteroids.

I shall confine myself to these few characters, keeping for later a study of sections of $A$. placenta.

The discovery of $A$. placenta at the Adaman Islands extends singularly the area of geographical distribution of the species. I recall that the form from New Zealand belongs to a different species.

Laganidæ (A. Agassiz) 
I shall distinguish in the family Laganidæ two genera, Laganum and Peronella. The first has five gonopores and the second, only four, the posterior interradius lacking one. This classification is moreover presently accepted by most zoologists.

Lambert and Thiéry have adopted a different classification. The divide, in fact, the family into two groups according to whether the ventral ambulacral grooves are absent or limited to the immediate vicinity of the peristome, or, to the contrary, they are well developed and very apparent. The latter arrangement exists in the Rumphinés, while the first characterizes the Echinodiscinés. This subdivision corresponds nearly to the classic division into the genus Laganum and into the genus Peronella. It would correspond exactly if the fossil genus Merriainaster Lambert, having peristomial grooves and only four genital pores, did not make an embarrassing form that Lambert and Thiéry place in the Rumphinés. If we set aside this fossil genus, we note that the tribe of Echinodiscinés, having four gonopores, is divided by Lambert et Thiéry into two genera, the genus Echinodiscus, whose gonopores are contiguous with the apical plate and the genus Peronella, whose gonopores are separated from this plate. On the other hand, the Rumphinés are divided by these authors into two genera, the genus Jacksonaster with a round periproct and the genus Laganum with an elongated periproct. The first group corresponds to the genus Peronella of authors, and the second to the genus Laganum.

I do not think that it is necessary to introduce divisions into each of these two groups. In the present state of our knowledge, the distinction into two genera alone suffices. If it were appropriate to subdivide, perhaps it would be preferable to invoke another character that I shall indicate later. It is moreover very difficult to decide what character should have precedence in establishing genera. Is it the number of gonopoes or is it the development of ventral ambulacral grooves? This is a matter of personal opinion. For me, I take the number of gonopores. H. L. Clark (1914, p. 44) is of the opinion that the number of gonopores has more importance than their location. It is because I adopted this point of view that I do not believe it necessary to distinguish generically either Peronella Peronii or Laganum Putnani from other Laganidæ having gonopores contiguous with the apical plate and placed by Lambert and Thiéry in their genus Echinodiscus (they do not speak of Laganum Putnani). To support my opinion, I shall cite the case of a small species described by L. Agassiz, Laganum stellatum. According to the figure published by the author (1838, pl. XII, fig. 7), the gonopores are separated by the apical plate, but they are less elongated than in Peronella Peronii. The two openings remain contiguous to the external poriferous zones of the petals. The species, which comes from New South Wales, has never been reviewed since L. Agassiz and one could wonder if it is valid or if it is not a matter of a young P. Peronni. If the species is good, it should be placed in the genus Peronella, restricted in the sense of Lambert and Thiéry. It forms a transition between this genus s. str. and the genus Echinodiscus of these authors. It shows that the location of the gonopores is variable and that their number is more important than their location. If it is, to the contrary, a young specimen, we can say with strong reason the location of the openings is essentially variable because it is modified with age in the same species and we consequently cannot base generic distinction on the location of the gonopores. I shall add that I shall describe later, under the name of Peronella macroproctes, a species in which the gonopores, at least the posterior, are a little spaced from the apical plate and represent again an expression of transition, the first one can say, toward the forms whose gonopores are frankly separated from the apical plate. In any case, if we must separate generically the forms that have elongated openings on the apical plate, it is not the only genus that it would be appropriate to distinguish, but two. One 
would be forms with four gonopores (Peronella Peronii and sellata) and the other Laganum putnani that has five.

From another point of view, the classification of Lambert and Thiéry created an unfortunate confusion by the use of the name Echinodiscus instead of Peronella to designate the species of Laganidæ with four gonopores contiguous with the apical plate. The authors clearly invoked the priority established by Breynius. But it is not at all certain that the Echinodiscus orbicularis of Breynius is the same Echinodiscus orbicularis created by Leske in 1778 at the same time that he established Echinus auritus, bisperforatus, etc. Now, since Leske, the term Echinodiscus has always been used to distinguish a genus of Scutellidæ represented principally by E. auritus, tenuispinus and bisperforatus. The introduction of this term into the family Laganidæ to designate species formerly placed in the genus Laganum or Peronella would create an upheaval such that we would have to reject such a radical measure. The advantages being far from compensated by the disadvantages.

Meijere has insisted correctly on very uniform characters of the microscopic structure of spines in Laganidæ, and perhaps even has exaggerated the importance of this structure from the systematic point of view. Regarding the pedicellariae, I confirm that they have a very great uniformity in the entire family Laganida, a remark moreover made before me by Meijere and $\mathrm{H}$. L. Clark. The pedicellariae belong to three different forms that it is very rare not to find together: tridactyl, trifoliate and ophiocephalous. The tridactyl pedicellariae are generally of two kinds, one have an elongated head the other having to the contrary a shortened head. The pedicellariae with an elongated head have narrow and delicate valves, with a short and very enlarged basal part ( $\mathrm{Pl}$. XIV, fig. 4a, 6a, 7a; Pl. XV, fig 7b). The blade has the form of a gutter or sometimes a closed tube that remains very thin for most of its length. It has smooth borders. This blade is widened only in its terminal part into a little developed spoon, strongly toothed on it borders. In the pedicellariae with a short head (Pl. XIV, fig. 4b, 6e; Pl. XV, fig. 9b and 13c), the valves widen rapidly into an oval spoon, with strong teeth on more than half its length. Thee teeth become stronger and stronger as they approach the end of the valve. The trifoliate pedicellariae (Pl. XIV, fig. 6b, Pl. XV, fig. 5c, $6 c, 7 c$, etc.) are distinguished from the preceding by their short and much smaller oval or round valves, with teeth relatively stronger. Transition forms can exist between the trifoliate and tridactyls with short heads, as we can find likewise between the latter and the tridactyls with elongated heads. It should be noted that very often the short tridactyls and the trifoliates have only two valves. Pedicellariae with four valves have been found by Mortensen in an Australian species, Peronella tuberculata. Finally, ophiocephalous pedicellariae (Pl. XIV, fig. 4c, 7d; Pl. XV, fig. 6b, $7 \mathrm{c} 11 \mathrm{~b}$, etc.) are noted by the development of teeth on their free border and by the very different forms of the lower arcs according to the valve to which they below. Thus it happens in other clypeasteroids in which one of the arcs form a long, narrow and curved extension that the article with the enlarged arc of the second valve, while that of the third has only a little developed arc.

From the point of view of internal organization, I will pay particular attention to the very variable development that can be provided, in the Laganidæ, by the internal calcareous pillars of the test. In some species, like Laganum Bonanni (Pl. IX, fig. 4), these pillars form only a small number of partitions widened parallel to the periphery of the test and making two or three concentric circles, exactly localized on the margin. In other species, the pillars take a considerable development in width and can extend for half the radius of the test. These differences in the arrangement of the calcareous pillars are already seen in the various photographs published by L. Agassiz, A. Agassiz, H. L. Clark, etc. They appear to be of very great importance. We can see the arrangement of the internal pillars either by removing the dorsal surface or the ventral surface of 
the test or more simply by radiography of the specimens. If we consider, for example, the radiography of Peronella Leseuri, whose length is 114 millimeters that I reproduce in Pl. VIII, fig. 6 , we note that the very thin vertical pillars from two distinct groups on each side of the radial and inerradial lines. The radial groups are much more developed than the interradial groups. In the latter, the partitions closest to the periphery of the test remain exactly and regularly parallel to the border. As one moves away from the border, the partitions become shorter, and especially irregular and have some branches. There is in each group of partitions with a radial direction that have lateral branches. The whole forms on both sides of the interradial line a triangular mass with a round proximal top. In the radius, the two groups of pillars are much narrower, and, except for some peripheral partitions that join the adjacent interradial partitions, the pillars are irregularly branched. There are some branches extending in a radial direction and others in all directions. In some smaller specimens, the arrangement of the partitions is simpler and they are less numerous (Pl. XI, fig. 4). We recognize in each group some peripheral partitions, parallel at first, and two principal partitions in a radial direction. On their external edge are some secondary perpendicular or oblique partitions. They may be branched and have various forms. This group of partitions covers about half the width of the test. The digestive tube is in the fairly reduced central region.

There is thus in the Laganidæ, two different arrangements of the internal calcareous pillars. These two arrangements are seen in both the genus Peroonella and the genus Laganum. If we want to establish a subdivision in each of the genera Laganum and Peronella, perhaps we could find in the internal calcareous partition a more important character than those that have been proposed by some authors. But it is necessary to study from this point of view the different known species. This I have been able to do only for some of them. I recommend to authors who have Laganidæ available to make radiographs of their tests. They would thus obtain very interesting information on the relations that unite the species of these different genera. The radiographs that I have obtained, either in the Laganidæ or in other clypeasteroids, allow seeing the ease with which this type of investigation can be done.

The digestive tube of the Laganidæ has some arrangements that differ from what we have seen in the Clypeasteridæ. In principle, the digestive tube is shorter in the Laganidæ. We never see in it three different portions of the intestine, the beginning of the first loop, its terminal part and the beginning of the second loop are in the anterior radius III. In general, the first loop begins in the area of radius IV or interradius 3, makes a nearly complete tour and returns to near its origin but without passing it to turn back and form the second loop. The location of the digestive tube or, if you prefer, its development, depends greatly on the space occupied by the internal calcareous pillars of the test that, as we just saw, form a very thin peripheral border or, on the contrary, covers a considerable area and greatly narrowing the general cavity. In the first case, there remains a very large place and in the second, a much more restricted place for the digestive tube.

Two important anatomical characters characterize the digestive system of the Laganidæ: first the intestinal gland that extends along the initial part of the first intestinal loop in both the Clypeasteridæ and in Arachnoides placenta in radius III is completely missing in them. I have not been able to find the least trace of them in any of the species I have studied. I have searched to see if there are glands in the walls itself at the beginning of the first intestinal curve but it has been impossible to recognize them. This negative result is not of great value because the state of preservation of my specimens did not lend itself to histological investigations. In the second place, the intestinal siphon, instead of being applied its entire length against the internal border of the first intestinal loop, remains free in the first half of its path and is applied against the intestine only in the second half. The siphon originates on the esophagus itself and, consequently, even before 
the beginning of the first intestinal loop, instead of having its proximal origin on the loop itself as is the case in the Clypeasteridæ that we have studied up to now. Then, leaving the digestive tube, it is directed obliquely outside, crosses the general cavity supported only by the mesentery, following a line that corresponds near to radius IV and rejoins the intestine that it accompanies toward the posterior region of the test, i.e., up to interradius 5 or a little beyond. I often see at this level a change in color of the wall of the intestine. It is lighter before the distal opening of the siphon, becoming darker afterwards. The path of the siphon resembles that we know in Arachnoides placenta.

\section{Laganum Bonani (Klein)}

(PI. IX, fig. 4; PI. XIV, fig. 6)

Laganum Bonani L. Agassiz, 1841, p. 108, pl. XXIII, fig. 8-12 and pl. XXII, fig. 25-29.

Laganum Bonani A. Agassiz, 1872-74, p. 517, pl. XIII, fig. 6 and 7 and pl. XXX, fig. 3-4.

Laganum Bonani Kœhler, 1895, p. 418.

Andaman Islands (tide) — One small specimen.

This individual is in very bad condition. The test is in part decalclified. I have studied the species according to some specimens that I have in my collection coming from the Tonga Islands. I can give some information on the pedicellariae and on the internal organization of $L$ Bonani. The characters of the species are well known. They remain very constant. We find good descriptions and figures in the memoirs of L. Agassiz (1841) and A. Agassiz (1872-1874). Meijere has added some remarks on the exterior form and the spines. Finally, H. L. Clark has published a figure of a valve of a tridactyl pedicellaria. This figure is of the small form of the tridactyl pedicellariae that are fairly common in L. Bonani, but that, according to what I see in my specimens, usually have only two valves. I see in my specimens the three usual forms of pedicellariae, i.e., tridactyl of two kinds, trifoliate and ophiocephalous. The tridactyls sometimes have a very elongated head that can be up to 0.45 millimeters in length. Usually the very narrow valves have the form of a gutter that form in the terminal part a short and a little wide spoon with long, pointed teeth on the edges ( $\mathrm{Pl}$. XIV, fig. 6a). Sometimes the valves are widened from their first half as happens in the tridactyls of the small form. In the latter, the valves are hardly more than 0.2 millimeters in length and their blade widens much more rapidly than in the elongated form (fig. 6, c and d). As I just said, they are usually didactyl. The trifoliate pedicellariae (fig 6 b) have the usual form. The main part of the valves is oval with strong teeth. Their total length is about 0.1 millimeter. The ophiocephalous, whose head is 0.2 millimeters, have nothing peculiar.

From the anatomical point of view, L. Agassiz has already published in 1841 (Pl. XXII, fig. 27 and 28), two figures showing the arrangement of the peripheral calcareous pillars and part of the first intestinal loop of L. Bonani. As we can see from these figures, as well as in the photograph that I reproduce here (Pl. IX, fig 4), the pillars, strongly widened and fairly thick, are not numerous. They are very exactly located in the marginal region of the test in the form of wide partitions hat are arranged in two more or less regular concentric layers with some rare branches. The middle of the radius has a single, thick pillar with bare indicated rudiments of lateral branches. There is a wide free space in the interior of the test in which the digestive tube is developed. The first 
intestinal loop is extremely wide and in the first portion is 7 millimeters wide in an individual with a length of 30 millimeters. This width falls to 3 millimeters at the end of the first loop. The beginning of this loop is located nearly equal distance between radius II and interradius 3 . The bad state of the internal organs of the specimen that I have opened does not permit a more detailed examination.

The three specimens I have in my hands have a fairly dark color. One is uniformly brown. The two others are paler. They have on the dorsal surface numerous brown patches very close together. In one of them they are found on the ventral surface but less numerous and smaller.

L. Bonani is especially known in the Pacific. It has been reported, in fact, at the Sunda Islands, at New Caledonia, on the coasts of Australia and Tasmania, at the Caroline Islands and Tonga, at Vanikoro, etc. The INVESTIGATOR showed it also exists at the Andaman Islands.

\section{Laganum decagonale (De Blainviile)}

(PI. VIII, fig. 5; PI. XI, flg. 3; PI. XV, fig. 13)

Laganum decagonale de Blainviile, 1827, p. 229.

Laganum decagonum L. Agassiz, 1841, p. 112, pl. XXIII, fig. 16-20.

Laganum decagonale Bell, 1885, p. 130.

Peronella decagonalis Dôderlein, 1885, p. 33.

Laganum decagonale Kœhler, 1885, p. 417.

Laganum decagonale Meijere, 1904, p. 117, pl. VI, fig. 58-62 and pl. XVIII, fig. 319-324.

Laganum decagonale R. Brown, 1910, p. 26, and 1910 a, p. 42.

Laganum decagonale H. L. Clark, 1914, p. 46.

Jacksonaster decagonalis Lambert and Thiéry, 1914, p. 313.

Station 328. - Gulf of Martaban, $14^{\circ} 46^{\prime}$ N., 95 52' E. - 61 fms. - Several specimens.

Coast of Orissa. - $25 \mathrm{fms}$. - Several specimens.

Coast of Ganjam. - $30 \mathrm{fms}$. - One specimen.

Coast of Vizigapatam. - $23 \mathrm{fms}$. - Two specimens.

Coast of Arrakan, Cheduba. - 20-30 fms. - Several specimens.

North of Cheduba. - $10 \mathrm{fms}$. - Several specimens.

$15^{\circ} 20^{\prime}$ N.; $94^{\circ} 55^{\prime}$ E. - 20 fms. - Several specimens.

Gulf of Martaban. - $67 \mathrm{fms}$. — One specimen

The specimens are in general of small size. The length of the test hardly passes 20 millimeters.and is often less than this. Some specimens only are large and in the largest the length is 35 millimeters. Nearly all lack their spines.

Laganum decagonalis is well known now but it has been confused by various authors with Peronella Lesueuri. This confusion came from an error of A. Agassiz who did not distinguish the two species in his "Revision" (p. 148). He united in fact as synonyms, and under the name of Peronella decagonalis, the Laganum that he called decagonum and P. Lesueuri. Later in the descriptive part (p. 520), he describes under the name $P$. decagonalis a species having only four gonopores and that is incontestably $P$. Leseuri. It likewise this species whose photographs he reproduced (pl. XIIIe, fig. 8-11). 
The characters of L. decagonalis were however very clearly indicated by L. Agassiz in 1841 under the name L. decagonum and the species correctly figured by him, pl. XXIII, fig. 10-20. These are the figures and the description that accompanies them that should be the point of departure for the study of the exterior characters of L. decagonale. More recently, Meijere has specified the characters of $L$. decagonale and described the primary and miliary spine as well as the pedicellariae. Meijere has represented three kinds of pedicellariae that correspond to the two known forms of tridactyl pedicellariae and to the trifoliates. The tridactyls of the first form have extremely elongated and narrow valves. They are 0.5 millimeters in length. The basal part is very wide and very short. The extremely narrow blade has the form of a gutter nearly from its origin. This is kept for a long time and widens only at its end into a small, short spoon with some fairly fine teeth on its distal border. It is this form that Meijere has represented in Pl. XIII, fig. 321. The tridactyl pedicellariae of the second form have larger and shorter blades, and the spoon, elongated and oval, has in its second half conical teeth that become stronger and longer as they approach the end (Pl. XV, fig. 13c). Between the shorter pedicellariae, whose valves are only 0.2 to 0.25 millimeters, and the elongated tridactyls of the first form, I have seen numerous intermediate forms. The trifoliate pedicellariae have short valves. Their length is only 0.08 (fig. 13d). Their blade widens very rapidly and takes an oval or nearly circular form with well-developed teeth. All the pedicellariae that I have observed have generally three valves but sometimes that are only two. I have not encountered in my specimens ophiocephalous pedicellariae. Meijere moreover has not indicated them.

L. decagonal is notable for its considerable flattening of the body, by its very short petals and by the very marked ventral grooves. It is a species that is very easy to recognize. As it is very often confused with Peronella Lesueuri, it perhaps is not useless to note that independently of the character offered by the number of gonopores, L. decagonale has a less elongated body. It is often as long as wide. Ordinarily its contour is polygonal, while in Peronella Lesueuri, the body is always longer than wide and often is polygonal. The petals are longer than in L. decagonale.

From the point of view of the internal anatomy, L. decagonal is nottble by the considerable development of the calcareous pillars that extends inside the test, on about half the length of a radius, leaving only a fairly reduced central space for the digestive tube (Pl. XI, fig. 3). The calcareous partitions in each interradius as well as in each radius form a group of two paired masses, each containing some widened and concentric partitions, some directed parallel to the border of the test and others arranged perpendicularly or obliquely and producing lateral partitions that are simple or branched. This arrangement is identical to that we observe in Peronella Lesueuri where the internal skeleton can be studied more easily because of the larger size of the specimens. The considerable development of the internal calcareous walls clearly separates L. decagonale from the other Laganum that I have studied, notably L. Bonani, depresum, retinens and versatile.

The digestive tube has the following arrangements. From its origin, the esophagus is directed obliquely from the right (the animal being opened by the dorsal surface), i.e., in the direction of interradius 2. It opens into the first loop at the very edge of the lantern (Pl. XI, fig. 3). The external border of this loop at its origin runs the length of interradius 2. The intestine develops in a way to describe a complete circle to return toward its point of departure, i.e., interradius 2 . The digestive tube turns back then to continue with the recurrent loop that is located inside the preceding. The first loop is very wide at its origin. In an individual whose test is 33 millimeters long, as is represented in Pl. XI, fig.3, the maximum width of the ventral loop is 5 millimeters. It then falls to 3 millimeters in the posterior interradius and then to 2 millimeters at the point where it is reflected. I always see a difference in color between the first half of the loop and the rest of the digestive 
tube. The first part is always a lighter color, yellow or yellowish-brown than the rest of the intestine that is darker and greenish. The change in color is very abrupt and occurs a little beyond the posterior interradius 5 .

The siphon is very apparent. As is the case in all the Laganidæ, it leaves the esophagus near its origin, a little above the lantern. It is directed obliquely toward the left in radius IV, but curves a little behind. It opens into the digestive tube between radius IV and interradius 4. Its distal opening is found a little beyond the rectum and corresponds to the point of change in color that I indicated above. It is a nearly toward this same point that the internal marginal lacuna ends. But is hardly possible to recognize the path of the marginal lacunae in the specimens of L. decagonsle that I have opened.

The gonads are confluent. They are a shapeless mass that fills the interstices between the digestive tube and the body wall, on the dorsal surface as on the ventral surface. They extend widely into all the intervals of the peripheral pillars.

The color of specimens in alcohol is white or clear yellow.

Because L. decagonale has been confused Peronella Lesueuri by various authors, it is difficult to indicate exactly its geographical distribution. The species should be very widespread in the Indo-Pacific region. It is very common in the Sunda Islands. It exists in the Bay of Bengal, at Singapore, in the Philippines, in the Arafura Sea and the coasts of Australia. H. L. Clark has likewise indicated it is at Durban (Natal).

\section{Laganum depressum (Lesson)}

(PI. IX, fig. 1, 2, 7 and 8; PI. XIII, fig. 3; PI. XIV, fig. 2)

Laganum depressum L. Agassiz, 1841, p. 110, pl. XXIII, fig. 1-7.

Laganum ellipticum L. Agassiz, 1841, p. 111. pl. XXIII, fig. 13-15.

Laganum depressum A. Agassiz. 1872-74, p. 518. p1. XIII L fig. 5-8; pl. XXXIII, fig. 3-4.

Laganum depressum Loriol, 1883, p. 37. pl. V, fig. 1.

Laganum dcpressum Duncan and Sladen. p. 318.

Laganum depressum Bedford, 1900, p. 283.

Laganum depressum Meijere, 1904, p. 114.

Laganum depressum R. Brown, 1910, p. 26 and 1910 a, p. 42.

Laganum depressum H. L. Clark, 1914, p. 45, pl. CXXIV, fig. 7-12.

Laganum depressum H. L. Clark, 1915, p. 91.

Jacksonaster conchatus Lambert and Thiéry, 1914, p. 313.

Mergui Islands. - Five specimens.

Ford Bay, Grand Cocos Island, Andaman. — Several specimens.

Port-Blair, low tide. - Three specimens.

I must note here that the species figured by Loriol has only four gonopores. Is this an error of the artist or a matter of another species that was without doubt Peronella Lesueuri? I do not believe this, however, because the figure recalls well L depressum. Moreover, in the text, p. 37, Loriol mentions formally the presence of five gonopores.

In the largest specimens from the Mergui Islands, the length of the test is 38 millimeters and the width is 34 millimeters. Those of Ford Bay are much smaller. The largest does not exceed 28x25 millimeters. I reproduce here in Pl. IX, fig. 7 and 8, two photographs of a specimen from the Mergui Islands that I believe will indicate the principal dimensions that I measured in this 
individual that will serve to compare with $L$. tonganense about which I shall speak later, as well as a new species I shall describe under the name L. Joubini.

$\begin{array}{ll}\mathrm{m} / \mathrm{m} & 38\end{array}$

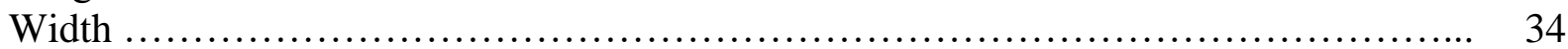

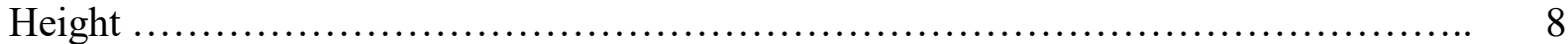

Distance between the center of the apical plate and the anterior border of the disk ....... $\quad 19.5$

Distance between the center of the apical plate and the posterior border of the test....... 19.5

Length of the unpaired anterior petal ....................................... 15.5

Length of the antero-lateral petals .......................................... 13.5

Length of the postero-lateral petals ............................................ 16

(These three lengths were measured from the center of the apical plate.)

Distance between the end of the unpaired anterior petal and the border of the test. ....... 4

Distance between the distal end of the antero-lateral petals and the border of the test..... 4

Distance between the end of the postero-lateral petals and the border of the test......... 5.5

Distance between the anterior border of the peritome and the anterior border of the test... 18

Distance between the posterior border of the peristome and the posterior border of the

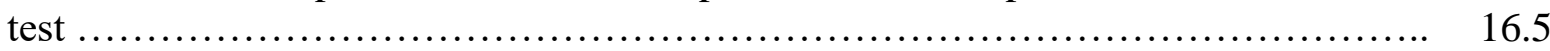

Distance between the posterior border of the peristome and the anterior border of the periproct............................................................... 12

Distance between the posterior border of the periproct and the posterior border of the

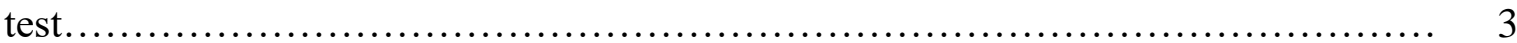

Length of the ventral anterior ambulacral groove................................ 13

Length of the ventral antero-lateral ambulacral groove............................ 11.5

Length of the ventral postero-lateral ambulacral groove............................ 15

Ratio between the length and width of the test....................................... 1.12 90

The form of the test varies a little. In the specimens I have in hand, the contour is ordinarily polygonal and more particularly pentagonal with a very marked posterior border, straight and often a little concave and round corners or slightly truncated. The longest primary spines on the ventral surface are 1.5 to 1.8 millimeters in length. They are fine, pointed and smooth. Those of the dorsal surface are much shorter. Their length ranges between 0.35 to 0.45 millimeters. They are fairly thick and slightly widened in the second half, to end more round than pointed. It is evidently one of the spines that Meijere has represented in fig. 317, but those that I observe have nearly smooth borders. The few teeth that exist in the widened part are barely visible and always very low, less developed in any case than in the figure of Meijere. These teeth are, to the contrary, very developed and usually very dense on the miliary spines. These were described and figured by Meijere.

The pedicellariae belong to the three ordinary forms, tridactyl, trifoliate and ophiocephalous. The tridactyl pedicellariae are, as usual, of two kinds. In the larger, the head is longer and on average 0.25 millimeters. The valves are very thin. Their basal part is extremely short but widened. The blade remains narrow for the largest part of its length. It first has the form of a tube. Then it is transformed into a very narrow gutter that is widened only in the last fourth to form a palette filled with fairly strong, conical teeth. They become larger as they approach the end (Pl. XIV, fig. $2 \mathrm{a}$ and $\mathrm{b}$ ). The valves are especially made up of a hyaline tissue. The perforations are extremely 
reduced. The form only two longitudinal rows. They do not exist in the tubular part of the blade and disappear in the widened part before the end. The tridactyls of the second kind, which are often didactyl, have very short valves. The blade, which is very narrow at the beginning, rapidly and abruptly widens into a convex spoon, nearly two times longer than wide, oval, with a round end. It has all along its length strong and spaced teeth whose size increases from the base to the end of the spoon (fig. $2 \mathrm{~d}$ ). The trifoliate usually have only two valves. They are 0.08 millimeters in length. They absolutey resemble those of $L$ decagonale. The ophiocephalous pedicellariae (fig. 2c) have fairly variable dimensions. Their head is on average 0.18 millimeters in length and 0.08 millimeters in width. The blade has very strong teeth on its terminal border.

The internal organization of $L$. depressum has some interesting anatomical peculiarities to report (Pl. IX, fig. 1 and 2). The peripheral calcareous pillars are very little developed. They are transversely widened and in general do not form more than two or three concentric circles, very strictly limited to the periphery of the test. They are interrupted on the radial and interradial lines. Their branches that are few amd little developed are seen only on both sides of the interradial line. The width of the band formed by the pillars does not exceed 3.5 millimeters in the specimens I have opened. This width is not increased in the posterior region of the body. There thus remains in the interior of the test, between the lantern and the peripheral pillars, a very large space filled with the digestive tube.

The first intestinal loop is extremely wide as shown in the specimen represented in Pl. IX, fig. 1 and 2. This loop has a width of one centimeter in radius II. Then the width decreases gradually to 8 millimeters in radius IV and 5 millimeters in interradius 5. It continues to decrease and falls to nearly 3 millimeters in the terminal part of this loop as well as nearly the entire length of the second loop. The esophagus is extremely short. Its length nearly equals the radius of the lantern. Beyond this, it widens very abruptly to be continuous with the first intestinal loop. The free edge of this follows an oblique path that corresponds nearly exactly to interradius 3 . This loop describes a nearly complete circle to end a little before its origin, so that there is an interval between its two ends of about 2 millimeters that is filled with gonadal tissue. The recurrent loop is located entirely within the first loop. It is visible both in looking at the animal by the ventral or the dorsal surface. Its fairly short path is between interradii 3 and 5. It curves at the latter to be continuous with the rectum that is short and very slightly sinuous. The color of the entire digestive tube is greenish or greenish yellow. I have never seen very marked differences in color between the different parts. I note however that the first part of the ventral loop, between its origin and the point where the intestinal siphon ends, the color is more yellowish or more brownish that the rest of the digestive tube.

The intestinal siphon is very short (Pl. IX, fig. 2). It originates toward the middle of the esophagus. Then it goes obliquely outside between interradius 3 and radius IV. It goes to connect to the first intestinal loop that it accompanies on its very short path to open before reaching radius V. This opening is very apparent. I cannot distinguish the path of the internal marginal lacuna. The external marginal lacuna is, on the contrary, very distinct thanks to its white color. It disappears toward radius I.

The gonads are confluent. When we open the animal by the ventral surface (Pl. IX, fig. 1), we see that the tissue of the gonads partly covers the digestive tube. We have to put this tissue to the side in order to see the different parts of the intestine.

A. Agassiz has already represented in his "Revision" (pl. XIIIf, fig 8) an opened L. depressum in which we recognize little developed calcareous peripheral partitions that leave a large space for the digestive tube in which we see the two loops. 
L. depressum is very widely distributed in the Indian and Pacific Oceans. It is known from a large number of localities: Madagascar, Mauritius, Zanzibar, Fiji Islands, Philippines. Bay of Bengal, Singapore, Sunda Islands, Australia, etc.

We noted above that I have not cited above, among the synonyms of $L$. depressum, $L$. tonganense that L. Agassiz described in 1841 as a distinct species according to specimens brought back for the Tonga Islands by Quoy and Gaimard and of which he gave good figures. This species has not been maintained by authors. A. Agassiz was the first to consider it a synonym of $L$. depressum. In my opinion, this point of view is incorrect. I keep $L$. tonganense as a very distinct species and very different from $L$. depressum. Judging first of all by the description and figures of L. Agassiz, L. tonganense is essentially characterized by its very elongated periproct of the posterior border of the test, located nearly equidistance between this border and the posterior border of the peristome. Now, among the species of the genus Laganum, a similar situation of the periproct exists only in L. Bonani. On the other hand, authors agree that the location of the periproct has great importance for the separation and distinction of species in the genus Laganum. It does not seem possible to me to unite in one and the same species, two Laganum in which the location of the periproct is so different: very far from the posterior border of the test in L. tonganene of $\mathrm{L}$. Agassiz and near this border as in L. depressum. Although there can be some variation in the location of the periproct, these variations never determine such a conspicuous difference as that we see between these two species.

There are still some other differences between $L$. tonganense and $L$. depressum that, truthfully, do not come out from the description of Agassiz. But I note in the two specimens brought back to the Jardin des Plantes by Seurat from his voyage to the Gambier and Touamotu Islands that I consider as $L$. tonganense. These two individuals conform very well to the description and figures of L. Agassiz. One is $55 \mathrm{~mm}$ long and the other 49 millimeters. The periproct is located exactly like that of the individual represented by L. Agassiz in Pl. XXVI, fig. 7. The contour is not completely oval as in the last specimen. It approaches rather, with a width a little less, the individual that this author has represented in fig. 8. But it does not absolutely conform to it because the anterior region of the body is a little thinner. The posterior end is widely rounded. I reproduce here in Pl. XII, fig. 5, the photograph of the dorsal surface of the smaller specimen. The form of the two individuals is in any case very different from that of $L$. depressum whose contour is clearly pentagonal with a straight or even often concave border. I shall add that the border of the test is sensibly thinner in L. tonganense than in L. depressum.

Here are the principal dimensions that I have taken of the two specimens in the Jardin des Plantes.

Length......................................................... 53

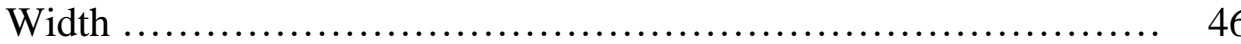

Height

Distance between the center of the apical plate and the anterior border of the test.

\begin{tabular}{ll} 
Specimen & Specimen \\
A & B $\mathrm{m} / \mathrm{m}$ \\
$\mathrm{m} / \mathrm{m}$ & \multicolumn{1}{c}{$\mathrm{m}$} \\
53 & 50 \\
46 & 44.5 \\
8 & 8
\end{tabular}

Distance between the center of the apical plate and the posterior border of the test 
Length of the unpaired anterior petal $\ldots \ldots \ldots \ldots \ldots \ldots \ldots \ldots \ldots \ldots \ldots, 17 \quad 14$

Length of the antero-lateral petals .............................. $14 \quad 13$

Length of the postero-lateral petals ............................ $16 \quad 13$

(These three lengths were made from the center of the apical plate.)

Distance between the end of the anterior petal and the border of the

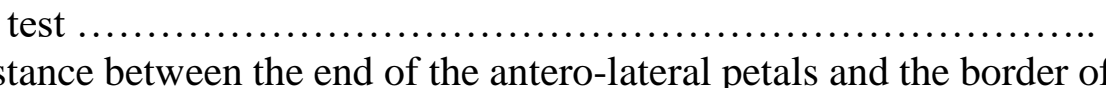

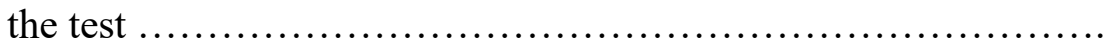

Distance between the end of the postero-lateral petals and the border of the test ............................................... 14

$11-8$

$10 \quad 10$

$14 \quad 12$

Distance between the anterior border of the peristome and the anterior border of the body 25

Distance between the posterior border of the peristome and the posterior border of the body

Distance between the posterior border of the peristome and the anterior border of the periproct $\ldots \ldots \ldots \ldots \ldots \ldots \ldots \ldots \ldots \ldots \ldots \ldots \ldots \ldots, 12$

Distance between the posterior border of the periproct and the posterior border of the body ............................... 12

Length of the ventral anterior ambulacral groove ................. $15 \quad 12$

Length of the antero-lateral ambulacral groove .................... 13 11

Length of the postero-lateral ambulacral groove ................... 16 13

Ratio between the length and the width .......................... $1.15 \quad 1.12$

The only difference I see between the two specimens of the Museum and the figures of L. Agassiz is that of the petals that are a little shorter than in the type. The measurements that I made from the figure of Agassiz in pl. XXVI, fig. 6, of a specimen 68 millimeters long and 63.5 millimeters wide, are, for the anterior petal of 23 millimeters, for the antero-lateral petals of 20 millimeters and for the postero-lateral petals of 22 millimeters. If we take from the figure of $\mathrm{L}$. Agassiz with a length of 53 millimeters, which is that of the largest specimen of the Museum, we shall find, instead of the above numbers, respectively 17.8, 15.5 and 17.1 millimeters. The petals are very narrow in L. tonganense as in L. depressum. As we see in fig 7 of L. Agassiz, the ventral ambulacral grooves are a little shorter in the first species than in the second.

The two specimens of the Museum being preserved in alcohol, it has been possible for me to examine the spines and the pedicellariae. The spines are, as usual, very short on the dorsal surface, longer on the ventral surface. The largest spines near the peristome are nearly 2 millimeters in length. The others vary between 1 and 1.5 millimeters. They are straight and recall those of $L$. depressum. The length of the primary spines of the dorsal surface do not exceed 0.6 to 0.7 millimeters. They are fairly thick. The miliary spines are 0.4 to 0.45 millimeters in length.

The pediellariae are, as is the rule, the tridactyl, trifoliate and ophiocephalous. The tridactyles resemble those of $L$. depressum but their valves are much larger and stronger. They are 0.4 to 0.45 in length. The valves (Pl. XIV, fig. 4a), tubular for the first quarter, then form a gutter that widens at its end into palette filled with about ten strong teeth on each side. The gutter is slightly wider in L. depressum and ordinarily has three rows of perforations, of which the median one is irregular. The small tridactyls are three times shorter than the large ones. They end in extremely fine teeth (fig. 4b). The head of the trifoliate pedicellariae are about 0.12 millimeters in length. The valves, at first very thin, widen very rapidly into an oval spoon with strong teeth. There sometimes two, 
sometimes three valves. We could also consider these pedicellariae as small tridactyls. The ophiocephalous have the usual structure (fig. 4c), but they are distinguished from those of $L$. depressum by their larger size. Their length varies between 0.2 and 0.25 millimeters and their width between 0.10 and 0.12 , while in $L$. depressum the length is little more at 0.18 and the width at 0.08 .

If there remains some doubts about the validity of $L$. tonganense and about the necessity of distinguishing it from $L$. depressum, radiographic examination will dissipate them in an absolute way. Compare the radiographs that I reproduce here of the smallest individual of L. tonganense (Pl. XIII, fig. 9) to that of L. depressus (fig. 3). We see that, in the first species, the peripheral partitions form concentric circles, more irregularly arranged than in L depressum, but four to five at least and with more numerous and more developed branches. Moreover, these branches are not strictly localized to the interradial lines but can be seen elsewhere also. All the partitions are spread over a fairly large area that reduces the general cavity. It is notably relatively narrower in $L$. depressum. The radiographs of the peripheral partitions of $L$. depressum that I reproduce here whose length is 38 millimeters, does not exceed an average width of 3.5 millimeters and the width of the general cavity varies between 23 millimeters (in the posterior region) and 27 millimeters (in the anterior region). In a L. tonganense, whose width is 46 millimeters, the width of the partition varies between 7 and 10 millimeters and the width of the general cavity is between 26 and 32 millimeters. If the L. tonganense had a length identical to that of the L. depressum considered, the partitions forming a peripheral band of 5.8 to 8 millimeters in width and the width of the general cavity would vary between 21.5 and 26.4 millimeter.

My radiograph of $L$. tonganense permits recognition of the contour of the digestive tube. This recalls that of $L$. depressum, but the intestinal loops, in particular the first part of the ventral intestinal loop, are less wide.

L. tonganense is not the only species of Laganum in which the periproct is far from the posterior border of the body. I have referred to L. Bonani above. But I have found in the collections of the Jardin des Plantes two unidentified Laganum labeled as "Mozambique, M. Heurtel, 1886" that struck me immediately by the very elongated form of the test and the location of the periproct that was, as in L. tonganense, nearly equidistance between the posterior border of the peristome and the posterior border of the body. These two specimens are separated by various characters from $L$. tonganense and I consider them as belonging to a new species that I propose to call $L$. Joubini. It appears useful to give a description here.

\section{Laganum Joubini nov. sp.}

(PI. VIII, fig. 9; PI. IX, fig. 6, 9 and 12; PI. XIII, fig. 2 and 8; PI. XIV, fig. 7)

Coasts of Mozambique. - Two specimens.

In the largest, the length is 47.5 millimeters and in the smaller, 36 millimeters.

The body is rather oval, notably longer than wide, narrowed anteriorly with the anterior and anterior borders round in the smaller specimen. In the larger, the posterior border is very slightly truncated. In the latter, the contour has a tendency to take a polygonal form (Pl. VII, fig. 9 and Pl. IX, fig. 9), while in the smaller, it is clearly oval (Pl. IX, fig. 6 and 12). The test is slightly narrowed anteriorly. The borders are round but not very thick. The test is fairly low but, seen in profile, it follows a fairly regular line from the apical plate to the borders. There is no indication of a 
depression between them and the top of the test. The ventral surface is very slightly concave. The apical plate is found forward, especially in the smaller individual. The lateral borders of the body are regularly round in the latter, and a little flatter in the large specimen. In the latter, the width is nearly the same at the level of the end of the anterior and posterior petals, while in the smaller, the width at the posterior petals is very slightly greater than that I measure at the level of the anterior petals.

Here are the principal measurements that I have taken of the two individuals:

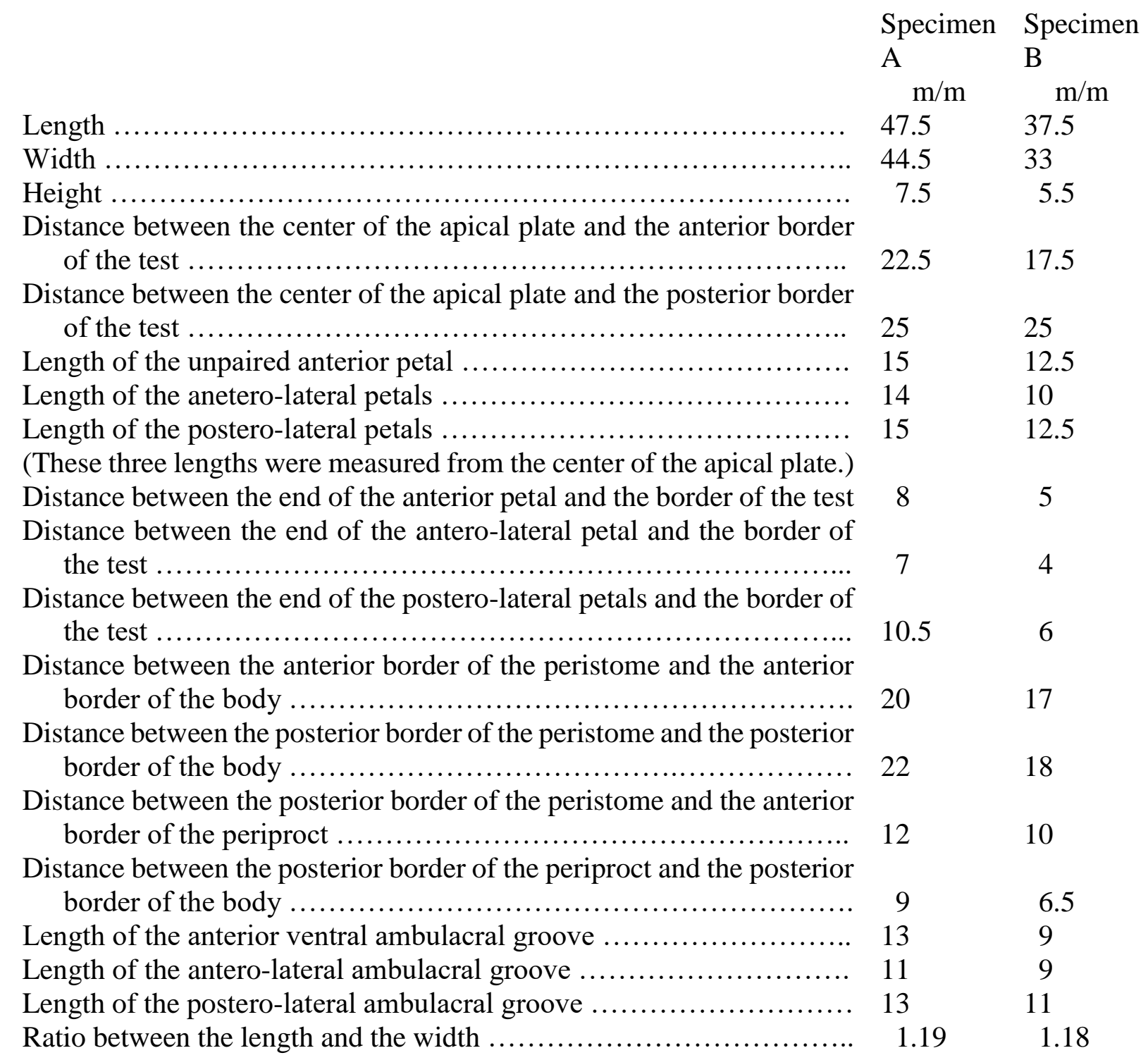

The petals are narrow, lanceolate and relatively very short. They ae slightly open at their distal end. The poriferous zones are slightly widened at their distal end and the interporiferous areas are narrowed more or less toward the end. The gonopores are small. The ventral ambulacral grooves are less marked than in L depressum and sensibly shorter. The periproct is a little nearer the 
posterior end of the body than in L tonganense, but is notable narrower than in L. depressus. It is small and transversely oval.

The peristome is, like the apical plate, moved a little forward and, while in the large specimen the apical plate is a little less moved forward than in the small, the peristome there is, to the contrary, a little nearer the anterior border of the body than in the latter.

The primary spines are fairly developed on the ventral surface, a little longer and stronger than in L. depressum and tonganense. The length is greater than 2.0 millimeters in the area of the peristome and can likewise exceed 1.6 millimeter on the rest of the ventral surface. On the dorsal surface they are scarcely more than 0.18 millimeters in length. The miliary spines are 0.4 millimeters in length and have nothing peculiar.

I have recognized two kinds of tridactyl pedicellariae and ophiocephalous pedicellariae. The lage tridactyl pedicelariae (Pl. XIV fig. 7b) have the same characters as in L. tonganense and depressus but their valves are smaller and their length generally does not exceed 0.25 millimeters (a). These valves are a little thinner and more delicate than in the two preceding species. The tubular part of the blade is a little more elongated and the spoon is widened like a palette in the terminal part in a more progressive way. This palette is thus a little narrower and less clearly separated from the region that precedes it. These pedicellariae sometimes have two valves. I consider as small tridactyls other pedicellariae much smaller than the preceding whose valves are only 0.06 millimeters in length (fig. 7c). The blade begins by a narrow region that is nearly half the length. Then it widens little by little into an oval, very wide spoon whose width nearly equals the length and that has on its border conical, slightly pointed teeth whose height increases in reaching the end of the spoon. I have not encountered trifoliate pedicellariae strictly speaking. The ophiocephalous pedicellariae greatly resemble those of $L$. depressum. Their length is 0.15 millimeters on average and their width is 0.07 millimeters (d). They are sensibly shorter, narrower and more slender than those of L. tonganense.

Radiographic examination shows that the internal skeleton of $L$. Joubini is nearer to $L$. tonganense that to $L$. depressum. The peripheral partitions are more developed and a little more irregular than in L. depressum. They form a wider group than in the latter, but less wide than in $L$. tonganense. It is especially in the posterior region of the body that the extent increases while in $L$. depressum the extent remains uniform for the entire periphery. Examination of the radiograph that I reproduce here in Pl. XIII, fig. 2, of the small specimen of L. Joubini makes a description of the internal partition unnecessary, but it is particularly interesting to compare the radiograph of this specimen, whose test has a length of 37.5 millimeters, to that of the L. depressum represented in fig. 3, whose length is 38 millimeters, i.e., nearly equal. We see immediately that the peripheral partitions form a band sensibly greater in the first species than in the second. It is 5 millimeters for nearly all its extent and 7 millimeters in the posterior region of the body in L.Joubini. The general cavity is also notably narrower and the intestinal loops less wide than in L. depressum. Because the two specimens that I compare have nearly exactly the same length, we cannot think that the variations in the extent of the peripheral partitions results from a difference in size of the specimens.

SIMILARITIES AND DIFFERENCES. - L. Joubini is near L. tonganense that it recalls by the location of the periproct far from the posterior border of the test and located nearly equidistant between this border and the posterior border of the peristome, by the shortness of the petals and the ventral ambulacral grooves and finally by the fairly regularly rounded contour of the test. It differs from it by its much more elongated form, by the peristome and apical plate moving a little 
forward and by the form of the pedicelleriae. The head of the tridactyls are shorter and their valves are more slender than in L. tonganene, but especially the ophiocephalous pedicellariae are shorter, weaker and narrower than in the latter. The difference is quite striking.

L. Joubini is also separated from L. depressum by its more elongated form, its more regularly oval form, having however a tendency to take a sub-pentagonal form in one of the specimens of the Museum, by the body less narrow anteriorly and wider, on the contrary, in the posterior region (the maximum width is found in L. depressum at the level of anterior petals). In L. Joubini, it is found both at the level of the anterior and posterior petals or the latter only), by the peristome and apical plate moved a little anteriorly, by the much shorter petals and ventral ambulacral grooves and finally by the location of the periproct. The pedicellariae do not provide very marked differences in the two species. The ophiocephalous pedicellariae are identical. Hoever the valves of the tridactyl pedicellariae are much shorter and thinner in L. Joubini. I have indicated above the differences that examination of the radiographs show between the two species.

I wondered if the two specimens of the Museum could be referred to the L. ellipticum described and figured by L. Agassiz. The latter is a species of smaller size. Its length, accoding to the figure of Agassiz (1841, pl. III, fig. 13-15) is only 29 millimeters. The periproct is fairly far from the poerior border of the test, a little less, however, than in the two specimens from Mozambique. The various characters of L. ellipticum do not apply to the latter. In fact, accoding to L. Agassiz, the posterior border of the test is very swollen and there is a very marked depression between the border and the apical pole, the petals nearly completely round at their top and, in addition, the poriferous areas of L. ellipticum wide from the base of the petal up to their distal end where they are relatively wide, according to the figure of Agassiz. All these characters are appropriate for the Laganum of Mozambique. As for L. ellipticum itself, I cannot decided if it is distinct specis or if I should unite it with $L$. depressum. I must note, however, that the form of the petals is not the same in the two species.

I dedicate this species to my excellent friend, L. Joubin, member of the Insitute, Professor at the Museum.

Laganum retinens $\mathrm{sp}$. nov.

(PI. X, fig. 5, 6, 8, 9 and 13; PI. XV, fig. 7)

Station $238 .-13^{\circ} 16^{\prime}$ N.; $93^{\circ} 08^{\prime}$ E. $-60-75$ fms. - Seven specimens.

A single individual is fairly large. Its length is 30 millimeters. This will serve me as the type for the following description. I shall designated it by the letter A (Pl. X, fig. 5 and 13). The two others, that I shall call B (fig. 9) and C (fig. 8), are small. Their dimensions are, respectively, $18.5 \times 16.8$ and $21 \times 19$ millimeters. Finally, the last four are very young. Their length is between 7 and 13 millimeters. The specimens are in general in good condition. Only individual $\mathrm{C}$ is nearly completely lacking its spines and the apical region of the test is missing. Here are the principal dimenions that I have taken on the two individuals $\mathrm{A}$ and $\mathrm{B}$ :

Length

Width

$\begin{array}{ll}\begin{array}{l}\text { Specimen A } \\ \mathrm{m} / \mathrm{m}\end{array} & \begin{array}{c}\text { Specimen B } \\ \mathrm{m} / \mathrm{m}\end{array} \\ 30 & 18.5 \\ 28.5 & 16.8\end{array}$


Height

Distance between the middle of the apical system and the anterior border of the test

Distance between the middle of the apical system and the posterior border

Distance between the posterior border of the periproct and the posterior border of the test

4

$10.3 \times 4.4$

$11 \times 4.3$

$12 \times 4$
2.6

$7.3 \times 2$

$6.3 \times 2$

$6.3 \times 2$

In individual A, the body is slightly pentagonal. The length does not exceed much the width. The greatest width is at the level of the ends of the anterior peals. This pentagonal form is hardly indicated in specimens B (fig. 9) and C (fig. 8) that are nearly regularly elliptical. Their maximum width is always before the apical system, but the length is a little larger in relation to the width. The small individuals are more regularly elliptical. The ratio of the length to the width varies a little in each of them. In the larage specimen A (fig. 5 and 13). The slight truncation of the corners makes the contour a little decagonal with a very small anterior side. The test is very little elevated but the bord are ery thick. A very slight depression of the doral surface 3 or 4 millimeter from the periphery, makes an inconspicuous border.

The apical system is of medium size. We see a single sinuous transverse aquifer furrow. There are five gonopores of very small size on individual A. They are still very apparent on the two individiuals B and C but absolutely invisible in the others. The apical system is forward.

The petals are fairly large and elongated. The width is moderate. The latero-anteriors and posteriors are 4 millimeters from the border of the test. The anterior petal, a littler shorter than the others, is about 4.5 millimeters. All five petals remain widely open. They even widen at their end. This widening involves the last four pore pairs of the lateral petals and the last three pore pairs of the anterior petal. As, on the other hand, the petals are widened in the middle, they thus have the form of a very elongated lyre. The poriferous zones are fairly wide. The fairly large pores nearly have the same dimensions in the internal row as in the external row. Successive pairs are separated by a row of extremely fine granules. The wide interporiferous zones have primary granules identical to those on the rest of the dorsal surface. In the interambulacral zones, the primary granules remain fairly small and very dispersed. The miliary granules are extremely dense.

The ventral surface is flat, very slightly depressed in the area of the peristome. The ambulacal grooves are not conspicuous. The miliary granules are fairly dense towrd the periphery and a little large than on the dorsal surface. They become less numerous 5 millimeters inside the border.

The periproct is moderate in size, transversely widened and elliptical. In specimen A, it is relatively larger than in the others, scarcely longer than wide, with the form of a lozenge with rounded corners. It is aout $3 \times 2$ millimeters. It is not very far from the edge of the test. The distance that separates it from the edge is nearly a fourth of the distance that separates it from the peritome.

The primary spines of the ventral surface are fine and elongated. They are 1.8 to 2 millimeters in length. Their end is a small hyaline point. Sometimes we see toward this end some small teeth are are most often on the same side. Other spines are a little thicker and shorter, with an end sometimes slightly curved, with fairly strong teeth that are close together. The miliary spines are 0.5 to 0.6 millimeters in length. Their end is a little widened. The primary spines of the dorsal 
surface are much shorter than thoe of the ventral surface. Their length is less than 1 millimeter. They are thin and end in a small hyaline point. The miliary spines are on average 0.6 in length.

There are three kinds of pedicellariae: tridactyl, trifoliate and ophiocephalous. The most common tridactyl pedicellariae are small (Pl. XV, fig. 7a). The valves have nearly the same structure as in Peronella Lesueuri. Their length is not more than 0.15 or 0.16 millimeters. The spoon is perhaps a little wider in this last species and the perforations are not arranged as regularly in two parallel rows. They most often form three or four irregular rows. The other tridactyl pedicellariae are larger. Their head is 0.4 millimeters (fig. 7b). The valves ae elongated and very thin. The blade remains narrow for three-fourths its length. Then it windens in the terminal part. Its borders have conical and pointed teeth. The trifoliate pedicellariae (c) are distinguished from the small tridactyls only by their smaller size, by the length of heir values that are only 0.08 millimeter and by their longer and sronger teeth. The ophiocephalous pedicellariae are very widespread on the ventral surface. Their valves reach 0.2 millimeters in length. These valves hav the same structure as in L. depressum.

I have not believed it necessary to sacrifice the individual that has served as the type to study the arrangement of the internal organs because I could easily recognize the path of the digestive tube by transparency. The first intestinal loop is very side. It is very near the periphery of the test as in both L. depressum and Bonani. In individual A, the width of this loop is at least 5 millimeters. Its external border is scarecely 3 or 4 millimeters inside the periphery of the test. As in $L$. depressum, the passage of the first loop to the second is near the level of radius II. To confirm that the information on the path of the digestive tube and extent of the marginal pillars obtained by transparency, I have removed a part of the ventral surface of specimen B. I reproduce here the photograph ( $\mathrm{Pl}$. X, fig. 9). We see that the structure is similar to that we know in L. depressum with a little more development in width of the first intestinal loop.

SIMILARITIES AND DIFFERENCES. - There is a certain resemblance in the exterior form between Laganum retinens and $L$. depressum, but the elongated petals open at their distal end, lyre-like form with the interporiferous area widened in its distal half has a completely different form from that we know in L. depressum. The ambulacral grooves are also less marked in this latter species. The form of the petals separates equally L. retinens from L. Bonani, which is separated moreover by the thinner test and by the hardly visible ambulacral grooves on the ventral surface. We cannot confuse L. retinens with the other species of the genus Laganum such as L. ellipticum, fudsyama, solidum and tonganense. In L. fragile Mazetti from the Red Sea, the petals are a little open at the end, but the petals are shorter, comparatively wider with very narrow poriferouos zones and interporiferous zones, to the contrary, very widened. Finally, there is no relationship to make with L. decagonale whose test is thinner, very short petals and internal organs with a completely different arrangement.

Laganum (?) Rullandi sp. nov.

(Pl. IX, fig. 3, 10 and 13; PI XIII, fig. 5; PI. XV, fig. 2)

Rulland. - 35 fms. - Two specimens. 
Because the gonopores have not yet formed, it is imposible to decide if the species should be in the genus Laganum or in the genus Peronella. All that we can say is that it is a form not know in either genus. I place it provisionally in the genus Laganum.

The smaller specimen is in a very good state of preservation, but it has been abraded and a good part of the spines are lost. As for the other, which is a little larger and very bad state, all the spines are lost and most of the posterior end is missing. The rest is even broken into two fragments. It should measure 22 millimeters. I shall make my description especially according to the smaller specimen.

Here are the principal dimensons:

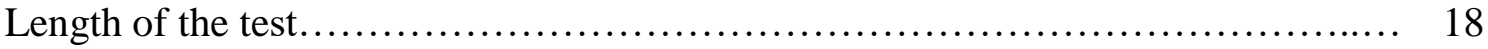

Width at the level of the end of the anterior petals ............................ 16.3

Maxium width ......................................................... 16.5

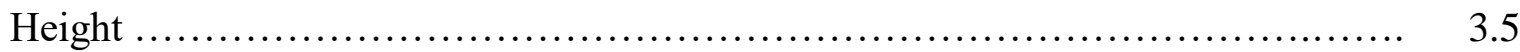

Distance between the center of the apical plate and the anterior border of the test ... $\quad 8.6$

Distance between the center of the apical plate and the posterior border of the test. $\quad 9.4$

Length and width of the unpaired anterior petal ............................. $3.8 \times 1.7$

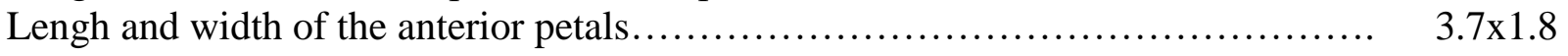

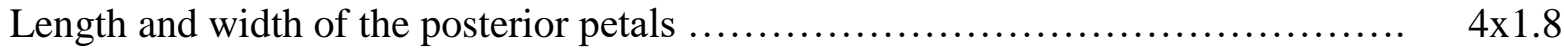

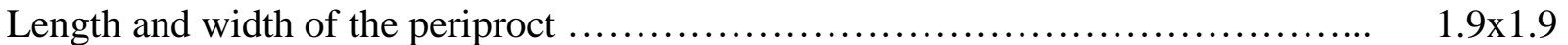

Distance beween the anterior border of the periproct and the posterior border of the peristome

Distance between the posterior corner of the periproct and the posterior border of

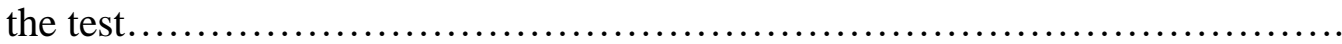

The contour is fairly regularly oval. The maimum width is bfehind the apical system. The anterior half of the test is a little narrower than the posterior half. The test is a little elevated with thin edges. The dorsal surface is a little swollen. The ventral surface is completely flat.

The apical system is a little forward. The exterior form recalls a little that of Laganum decagonale although the test is a little narrower and more clearly oval. The petals are very short as in the latter. The species of Rulland is notable by the absence of ambulacral grooves that are very apparent in $L$. decagonale as well as by the location and dimensions of the periproct

The apical plate is very large and its contours are very distinct ( $\mathrm{Pl}$. IX, fig 3). It is pentagonal with concave sides and fairly sharp corners although round at the end. We did not see grooves on the surface of this plate, but only fairly numerous openings, small and circular, that are nearlly all localized in the right half of the plate (the animal being placed on its ventral surface).

The petals are extremely wide at their origin because of the large size of the sides of the apical plate. Their width scarcely increases for half of their length. Then the width decreasse gradually to the end that is pointed. However, the petals are not absolutely closed at the end, but the poriferous zones are very near each other. These zones, extremely narrow at their origin, widen progressively by the separation of the internal and external pores up to the end of the petals where the pores of each row are still very far from each other. The pores have nearly the same form and size in each row. They are round. Those of the external row are however very slightly larger and a little oval obliquely. The primary tubercles of the interporiferous zone are small, extremely flat and indistinct. Their scrobicular circle, slightly sunken, is indistinct. Those of the rest of the dorsal 
surface are more protruding, but of small size and fairly separated from each other. There is no great difference in size between them and the intercalated miliary tubercles. Each interporiferous zone has numerous ambulacral pore forming, inside the internal poriferous zone, two elongated groups, each with three and sometimes even four irregular rows of pores (Pl. IX, fig. 3). The same pores are found outside the petals, especially on the ambulacal paes. They form on each of these a small transverse row curved in an arc toward the middle of the plate. There are fifteen to twenty per plate. On the interambulacral plates, the pores are much less numerous and form small irregular groups.

The peristome, of medium size, is round. The periproct is very large. It has a strongly convex anterior border and a posterior corner a little round, limited by two slightly concave sides. It is nearly as long as wide. The group is nearer the peristome than the posterior border of the test. This form and location of the periproct recalls that in Peronella macroproctes that I shall describe later. But in the latter, the periroct is near the posterior border of the test.

The primary tubercles of the ventral surface are much larger than on the dorsal surface. The scrobicular circle is large amd very distinct. Thee tubercles are not very numerous nor very dense. They are rather located in the central part of the plates where we find numerous ambulacral pores both on the radial plates and interradial plates.

The primary spines are 0.35 millimeters on average. They widen slightly before the end that then thins and ends in a point (Pl. XV, fig. 2a). The miliary spines ae 0.2 to 0.25 millimeters. They are thin, but fairly wide at their end. They have no or few teeth at their free end (fig. 2b).

I have found no pedicellariae.

Examination of the radiographs of the specimens (Pl. XIII, fig. 5) shows an arrangement of internal calcareous pillas similar to that we have seen in Laganum retinens, but here the pillars protrude more into the general cavity without taking hoever a develop similar to that we know in Laganum decagonale or Peronella Lesueuri. The interradial regions have three very thin concentric partitions on each side of the median interadial line and joined or not by an interradial partition. The most internal partition may have very short branches. The radial regions are free on the median line. Each side of the median line has a partition with lateral branches. All the branches remain extremely thin.

The path of the digestive tube has nothing peculiar. The first intestinal loop begins and ends toward radius IV. In the radiographs, the first portion that extends to the posterior radius 5 is very pale. It is without doubt empty and little colored while the rest of the digestive tube is very dark.

SIMILARITIES AND DIFFERENCES. - Although it is impossible to decide, because of the absence of gonopores, if the species should be placed in the genus Laganum or in the genus Peronella, I have believed I should describe it here because it certainly is new and has some particular characters that permit us to recognize it easily. These characters are especially offered by the very large apical plate and having five peripheral lobes, by the likewise very large periproct located nearly equidistant between the peritome and the posterior border of the test. By the form of the petals, the species from Rulland is near Laganum decagonale and by its very large periproct and closeness to the peristome, it recalls Peronella merguiensis and especially macroproctes. But it cannot be confused with either of these species or with other Laganum. As we shall see later in studying Peronella macroproctes, the four gonopores of this species are well-formed and even larger in individuals smaller than our two L. Rullandi where we cannot find the least trace of them. From this point of view, the two species are totally different. 


\section{Laganum versatile nov. sp.}

(Pl. XII, fig. 1 to 4; PI. XV, fig. 3)

Station $220 .-13^{\circ} 16^{\prime} 30^{\prime \prime}$ N.; $93^{\circ} 08^{\prime}$ E. -79 fms. - Three specimens.

The test is nearly completely lacking spines in the three specimens. Only individual A (Pl. XII, fig. 1, 2 and 4) still has some spines around the peristome. The ventral surface of this individual is partly crushed but it remains intact. On the other hand, a fairly great part of the ventral surface is missing in specimen B (fig. 3) as well as all the apical region of the test. I took advantage of the fact that a part of the test was already missing in specimen B to remove what remained of the ventral surface in order to uncover the calcareous pillars. I represent the individual thus prepared in Pl. XII, fig. 3. Here are the principal dimensions I took of the three specimens:

\begin{tabular}{|c|c|c|c|}
\hline & \multicolumn{3}{|c|}{ Specimens } \\
\hline & & B & $\mathrm{C}$ \\
\hline & $\mathrm{m} / \mathrm{m}$ & $\mathrm{m} / \mathrm{m}$ & $\mathrm{m} / \mathrm{m}$ \\
\hline Length & 27.5 & 27 & 24 \\
\hline Width . & 24.8 & 24.3 & 22.4 \\
\hline 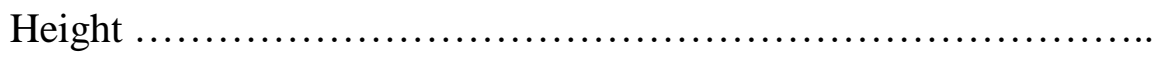 & 8 & $?$ & 5.5 \\
\hline $\begin{array}{l}\text { Distance between the middle of the apical system and the anterior } \\
\text { border of the test } \ldots \ldots \ldots \ldots \ldots \ldots \ldots \ldots \ldots \ldots \ldots \ldots \ldots \ldots \ldots \ldots \ldots \ldots \ldots \ldots \ldots\end{array}$ & 12 & 12.5 & 11 \\
\hline Distance between the middle of the apical system and the posterior & & & \\
\hline 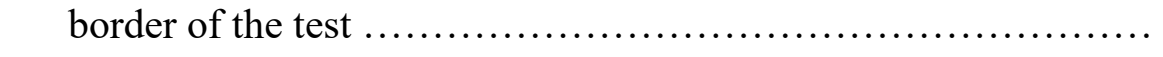 & 15 & 14.5 & 14 \\
\hline $\begin{array}{l}\text { Distance between the posterior border of the periproct and the } \\
\text { posterior border of the test } \ldots \ldots \ldots \ldots \ldots \ldots \ldots \ldots \ldots \ldots \ldots \ldots \ldots \ldots \ldots\end{array}$ & 3 & 3 & 3 \\
\hline Ratio between the length and height of the test $\ldots \ldots \ldots \ldots \ldots \ldots \ldots \ldots$ & 3.43 & $?$ & 4.36 \\
\hline
\end{tabular}

I shall describe the species principally according individual A that is largest and whose test is nearly intact. The body is elongated, oval and its cornes a little angula, especially in specimen B where it is frankly decagonal with fairly marked corners. The corners are more round in individual A. They are barely indicated in individual C. The apical system is a little anterior. It is at its level that the test has its maximum width. It narrows gradually approaching the posterior end. Overall, the test is thus wider in the anterior half than in the posterior half. Its edge is thick. It is separated from the rest of the doral surface by a slight circular depression. The ventral surface is flat, a little depressed only in the area of the peristome. The five ambulacral groovs are distinct although they are marked nevertheless. The height of the test varies greatly. Specimen A notably is higher than specimen C. It is nearly conical. As for the height of specimen B, it could not be measured. Seen in profile, the test of specimen A has a rapid decrease in height from the apical pole that is round. The test flattens about the three-fourths of the length of the radius. But then the height remains nearly constant to the edge. This thus results in the formation of a wide, thick border with rounded edges. The decrease in the height of the test, that is moreover more flattened, is more gradual in specimen $\mathrm{C}$ and the marginal border is less apparent.

The petals are elongated, narrow and open at their end. They stop 2.5 to 3 millimeters from the edge. Their length is greater than two-thirds of the radius. The poriferous zones remain nearly exactly parallel to each other for the greatest part of their length. The internal rows of pores are 
nearly parallel to each other. The poriferous zone keeps nearly the same width its entire extent. It is even a little wider toward its proximal end than its distal end. Only the external row of pores is slightly convex so othat the petals are a little wider in their middle. But the interporiferous zones keep a nearly uniform width for the geatest part of their length. In individual A, I count twenty-six pore pairs on each side of the antero-lateral petals, twenty-nine on the posterior petals and thirty on the unpaired anterior petal. The pores are hardly different in each row. The externals are, however, a little larger and a little wider in the middle region of the petals. The internal pores are very small and rounded. They are continued inside by a small superficial furrow that passes the middle of the poriferous zone. The last four or five pore pairs of each row are arranged a little irregularly and are more separated from each other than the preceding one. They do not correspond exactly in each row. The two rows of each petal usually become a little divergent. The successive pore pairs, which are very dense on the rest of the petal, are separated by a small slighty projecting ridge that has a row of very fine tubercles. The interporiferous zone, always wider than the poriferous zone, has some primary tubercles interspersed with miliary tubercles.

The dorsal surface of the test also has scattered primary tubercles that are not very dense. They are separated by numerous miliary tubercles. The primary tubercles become more numerous toward the periphery on the horizontal part that preceds the rounded and slighty thick edge. These tuoercles are larger on the ventral surface, but remain widely separated.

The ambulacral grooves are fairly distinct as I said above. But they remain short and do not reach the middle of the width of the test. The peristome is round. The periproct is instead a little large and near the posterior border of the test. It is covered with small, irregular plates. The periproct is slightly oval transversely in individual A, but nearly circular and hardly wider than long in specimen $\mathrm{C}$.

The five gonopores are round, small, but however very distinct.

We can be assured in specimen B that the internal pillars of the test are localized at the periphery in a fairly narrow band and that they scarcely exist in the interadial areas. In each of these, we note, on each side of the median interradial line, a partition parallel to this median line and that has outside two or three partitions parallel to the periphery of the test that can produce some small, secondary, very short branches. These partitions extend up to the median radial line of each adius. But the middle of the ambulacal zone itself lacks partitions.

As I said above, the three individuals are nearly completely lacking their spines. However I have been able to find some pedicellariae among the small number of primary and miliary spines preserved in the area of the peristome.

The primary spines have nothing in particular. The miliary spines are not very wide at the end. They have only two or three unequal and irregular teeth on their slightly thickened free edge. As for the pedicellariae, I have found a single ophiocephalous that is in very bad state and some tridactyl pedicellariae with fairly short valves. The blade of these valves, very narrow at the base, widens rapidly up to the middle into a fairly wide spoon. It then narrows very rapidly and has on this second part some fairly short 109 conical teeth, and that elongate as one approaches the end of the valve (Pl. V, fig. 3). I see, on each side of the median line, two elongated perforations and, outside them, some round, smaller holes. These pedicellariae are about 0.18 to 0.20 millimeters. I also found a very short trifoliate valve only 0.04 millimeter in length.

SIMILARITIES AND DIFFERENCES. - L. versatile is distinguished from all known Laganum by the form of the test that is narrow in the second half, conical and fairly high, as well by the elongation of the petals that remain open outside but that are fairly narrow as a whole and having 
nearly parallel poriferous zones. In Laganum Bonani, the test is narrowed anteriorly, the petals are shorter and the periproct is nearer the mouth. L. decagonalei has shorter and pointed petals at their distal ends. L. depressum, whose periproct has nearly the same location as L. versatile, with the test narrowed in the anterior half, it is more or less strongy flattened and the petals are pointed and closed. L. fudsyama has a conical test like L. versatile, but the height is comparatively larger in the latter, the border is thinner, the petals are very narrow and short. I have been able to make comparison of specimens from the INVESTIGATOR with a type specimen from Japan that I have in my collection. I have confirmed these two species are very different. L. versatile has more affinities with L. conicum Meijere. I admit I have had great difficulty in deciding whether they should not be united or if there was reason to keep them distinct. I believed I should take the latter point of view. In fact, L. conicum was described by Meijere from specimens of large size that measured 92x86 millimeters, which makes comparison a little difficult, the specimens of the INVESTIGATOR not exceeding 27 millimeters in length. However, we can see from the photographs given by Meijere (pl. VI, fig. 68), that the contour of the test is different and that his L. conicum did not have this very marked decrease in width in the posterior half of the test that exists in L. versatile, a decrease that begins at the anterior petals. Meijere say that the petals are long with nearly straight poriferous zones that are open at their distl end. But in fig. 325 of pl. XVIII, which represents a specimen of $L$. conicum seen in profile, thee petals are shown as being closed and pointed. According to the figure and the information given by the author, L. conicum has a high test, conical and pointed, with thin borders. The decrease in height is gradual from the apical system to the edge without a distinct marginal border. This is is not the case in L. versatile. The periproct is also comparatively smaller in L. conicum. On the other hand, the arrangement of the calcareous pillars in the latter is very comparable to that I see in L. versatile. H. L. Clark is of the opinion that $L$. conicum Meijere is identical to to L. fudsyama Döderlein. But the form of the petals is completely different in the two species. In any case, $L$. versatile appears to me to be very distinct from $L$. fudsyama. For these various reaons, I have believed it necessary to describe the three specimens from the INVESTIGATOR and give them a new name.

\section{Peronella Lesueuri (L. Agassiz)}

(PI. VIIT, fig. 1 to 4,6 to 8 and 10; PI. XI, fig. 4; PI. XV, fig. 5)

Laganum Lesueuri L. Agassiz, 1841, p. 116. pl. XXIV. fig. 36.

Laganum elongatum L. Agassiz, 1841, p. 117, pl. XXIV, fig. 1 and 2.

Laganum rostratum L. Agassiz, 1841, p. 118, pl. XXV.

Peronella Lesueuri A. Agassiz, 1872, p. 148 (p. p.).

Peronella decagonalis A. Agassiz. 1872-74. p. 520. pl. XIIIe. fig. 8-11 amd pl. XXXVII, fig. 3.

Laganum elegans Pfeffer, 1881, p. 63, pl. I, fig. 4.

Peronella decagonalis var. pallida. Pfeffer, 1181, p. 60.

Laganum Lesueuri Meijere, 1904. p. 122 pl. VI, fig. 63, 67 and 70, and pl. XVIII, fig. 329-333.

Peronella Lesueuri H. L. Clark. 1914. p. 53, pl. CXXIV, fig. 23-24.

Rumphiaa Lesueuri Lambert and Thiéry, 1914, p. 313.

Peronella aphanostina H. L. Clark, 1914, p. 168, p1. XXIV.

Peronella Lesueuri H. L. Clark, 1916, p. 120.

Peroiella Lesueuri Mortensen, 1918, p. 14, pl. V, fig. 25.

Station 146. - $11^{\circ} 05^{\prime} .45^{\prime \prime}$ N.; $75^{\circ} 04^{\prime} 08^{\prime \prime}$ E. $-38 \mathrm{fms}$. - One specimen.

Ceylan. - $261 / 2 \mathrm{fms}$. — One specimen. 
Maldive Islands; atoll (without other indication). — Two specimens.

The specimens of the INVESTIGATOR are all of very small size. Their length is between 20 and 25 millimeters. We know that Peronella Lesueuri can reach a very much greater size. The specimen whose photograph I reproduce in Pl. VIII, fig. 2, as well as the radiograph in Pl. VIII, fig. 6, that came from Singaapore, measured 114 millimeters in length. The other specimens that I also reproduce here (photographs VIII, fig. 1, 3, 4, 7, 8 and 10; Pl. XI, fig. 4), and that have principally served me for the study of Peronellal Lesueuri also came from this last location.

P. Lesueuri was described correctly by L. Agassiz in 1841 (under the name Laganum Lesueuri) and the figures this author gave are very correct. I shall only note that the form of the petals differs according to specimen. They are comparatively wider, especially in the first half in the young. Also they can be more or less closed at their end. The external form also varies. We can find in the same lot of P. lesueuri forms that compare to L. Lesueuri of L. Agassiz and others to his L. elongatum. In my opinion, there is no reason to maintain a distinction between these two species. I consider L. elongatum as sysnonymous with $P$. Lesueuri. It is obvious that A. Agassiz has represented P. Lesueuri in his Revision (Pl. XIIIe, fig. 8 to 11) and not Laganum decagonale.

The large specimens, such as those whose photographs are reproduced in Pl. VIII, fig. 2, have elongated petals, very narrow and relatively widened in the middle region. To the contrary, in the young individuals, the petals are clearly lanceolated, widened at their base or very near the base. They narrow gradually and regularly to their end that is pointed. We can also see some differences in the dimensions of the periproct in the young and the adults. The periproct is relatively larger in the first, but they never reach the considerable dimensions that we see in P. macroproctes and Rullandi.

The test is a little elevated and the edges fairly swollen. The dorsal surface always has, near the periphery, a very wide and well marked border, as in the small individuals. Seen in profile, the test decreases gradually in height to some distance from the edgs. From this point to the edges themselves, the height no longer decreases.

The characters of the primary and miliary spines have already been indicated by Meijere. The pedicellariae belong, as usual, to three kinds: tridactyl, trifoliate and ophiocephalous. The head of the tridactyl pedicellariae is sometimes elongated and sometimes shortened. The valves of the tridactyls with an elongated head are 0.15 to 0.2 millimeters in length (Pl. XV, fig. 5b). The narrow blade remains tubular for three-quarters of its length. It widens in the terminal part into a small spoon with strong and elongated teeth on its borders. These pedicellariae have been figured by $\mathrm{H}$. L. Clark. Mortensen has represented some whose valves are thin. The valve of the small tridactyls (fig. 5 a) measure 0.10 to 10.12 millimeters. The blade widens gradually and rapidly into a fairly large oval spoon with strong teeth that beomce larger toward the end. The perforations are not numerous. They form especially a regular row on each side of the median line of the blade. The trifoliate and ophiocephalous pedicellariae has no pecular characters.

I have indicated above the arrangement of the calcareous partitons that reach here a very great development and fill a good part of the general cavity. Nearly all of the free central region of this cavity is filled with the first intestinal loop. The esophagus, at its origin, is directed toward interradius 2 where the first intestinal loop begins. It makes a nearly complete loop and return very near its orgin to be continuous with the second loop. At its origin, the first intestinal loop is extremely wide. Its width reaches or even exceeds 7 millimeters in a specimen 35 millimeters in length, while the end of this loop is no more than 3 millimeters. My specimens of $P$. Lesueuri, not being in good state of preservation, the internal organs are very brittle and I cannot give more information about them. 
We see from the preceding that the internal organization of $P$. Lesueuri is very comparable to that of Laganum decagonale. On the other hand, the external form is fairly close in the two species that have sometimes been mistaken for each other. The distinction, however, is very easy to make. Without speaking of the essential difference in the number of gonopores that determines the classification of the two species into two different genera, the form of the petals permits their immediate separation. The petals are always longer in P. Lesueuri than in L. decagonale and there can be no confusion.

Among the species of the genus Peronella that one could confuse with P. Lesueuri, it is appropriate to first separate the forms that have gonopores more or less separated from the apical system, such as P. Peronii and stellata L. Agassiz, as well as those whose periproct is more separated from the posterior border of the test as in P. Lessueri, (P. analis Meijere, minuta Meijere, pellucida Dôderlein, rubra Dôderlein). Among those whose periproct is in neary the same location is in P. Lesueuri, P. orbicularis (Leske) has a very thick test and P. strigata Agassiz and Clark has very short peals. We cannot confuse them with $P$. Lesueuri. $P$. conica is likewise distinguished by its conical test and the weak development of the internal calcareous partitions. $P$. pallida Pfeffer and elegans Pfeffer are considered by H. L. Clark as synonyms of P. Lesueuri. The same author says that $P$. ludwigi is synonymous with $P$. orbiciularis. But I am not of this opinion because the test of P. Ludwigi has less swollen borders. In any case, this species, that is the only one of the genus Laganum that we know on the west coast of Africa, differs from P. Lesueuri by the petals that are wider at the base and more pointed at the end. It appears to me rather to be intermediate between $P$. Lesueuri and orbicularis. But to be able to define its exact affinities, it would be necessary to have specimens with spines and to study the internal organization, something that I have not been able to do in my memoir of 1914a (p. 251, pl. XI, fig. 8, 9 and 10).

It is also very probable that $P$. rostrata (L. Agassiz) is synonymous with $P$. Lesueuri. Meijere says he observed a prominent posterior end in some of his specimens as in the form distinguished by L. Agassiz. I consider finally the Peronella of Australia, recently described by H. L. Clark as $P$. aphanostina, is nothing other than a special form of $P$. Lesueuri. Lambert and Thiéry believe the form described by Meijere as Laganum Lesueuri does not correspond exactly with this species. They propose to give it a new name and call it $P$. (Echinodiscus) Meijeri. I shall note on this subject that Meijere did not report formally the absence of the ventral grooves. He only says that the ventral surface is flat. Actually, his photographs do not show these grooves, but they are not clear enough that we can see their state. I wonder moreover if the author from Holland has not combined under the name Laganum Lesueuri two different species. In any case, fig. 63 from his Plate VI represents the ventral surface of a specimen whose periproc is locaed nearly equidistance from the peristome and the posterior edge of the test. This surely is not a $P$. Lesueuri. P. Lesueuri should be widespread in all the Indo-Pacific. We know it in fact in the seas of China and Japan, the Bay of Bengal, at Singapore, at the Philippines, in the Sunda Archipelago, on the coasts of Australia and New Zealand, at Zanzibar, etc.

\section{Peronella macroproctes nov. sp.}

(PI. IX, fig. 5, 11 and 14; PI. X, fig. 10 to 12; PL XIII, fig 4; PI. XV, fig. 11)

$6^{\circ} 01^{\prime}$ N.; $81^{\circ} 16^{\prime}$ E. — 34 fms. — 25 Aprill 1888. — Four specimens of small size. 
Here are the principal dimensions that I took on these individiuals that I shall designated by the letters A, B, C, D

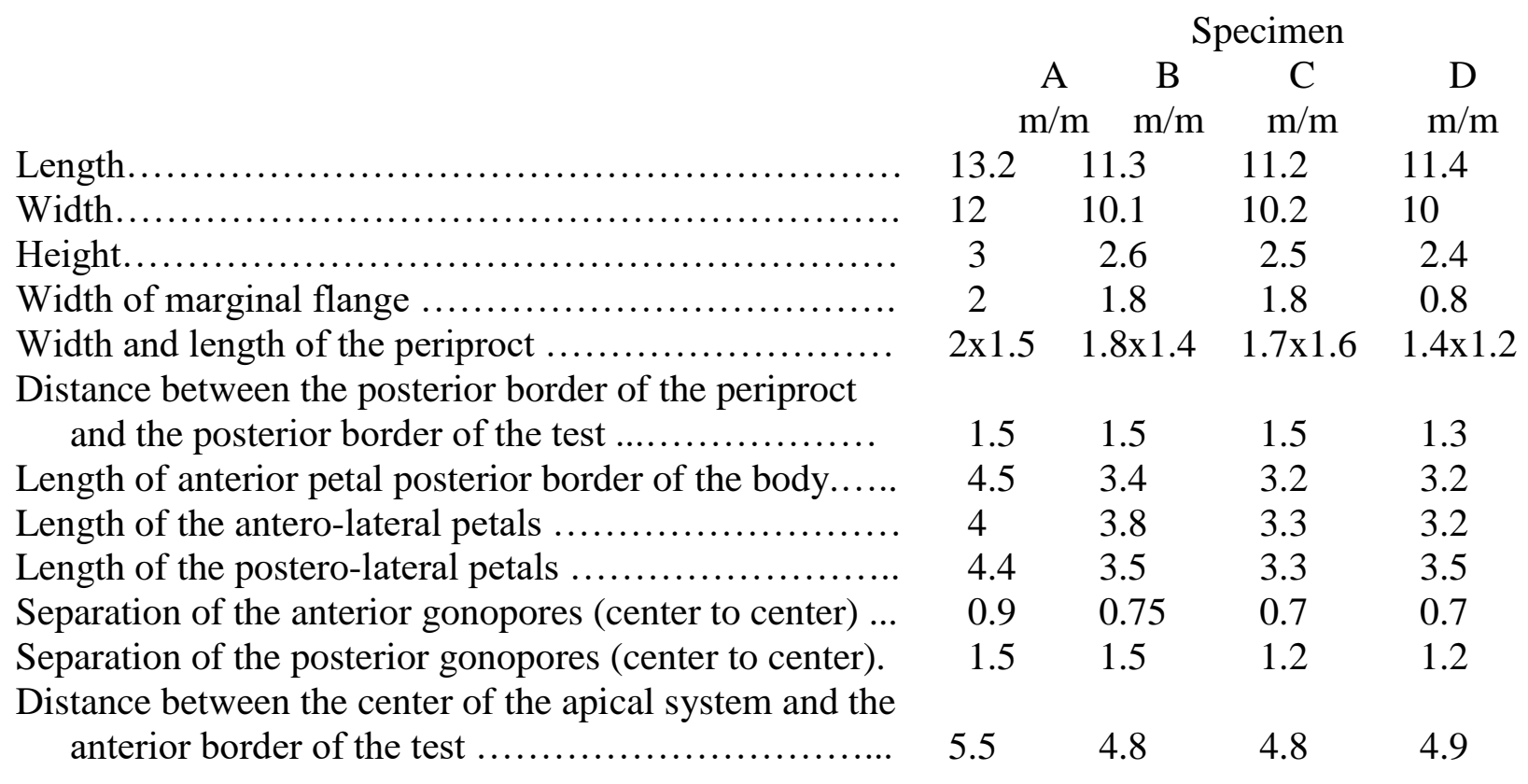

The test is oval, a little elevated, but the profile of the dorsal surface is very rounded. The edge is a little thick. The apical system is large and forward. It is limited by four gonopoes that not only are very very apparent but also are in general relatively very large, especially in specimens A and D. They are notbly small in specimens B and C. The petals are very wide at their base. They begin only at a fairly great distance from the center of the apical plate. They are rather short. These petals are lancelate. The dimish rapidly in size up to their end that remains far from the edge of the test. The end is open in the five petals. The poriferous zones are rather narrow and the interporiferous zones are very wide. The pores are very marked. The outer pores a little larger than the interior. But all are round. The poriferous zones are slightly narrow at their origin. They keep the same width for all their length. The successive pore pairs are moderately close to each other. The last two or three pairs are more separate from each other.

The gonopores of specimens A (Pl. IX, fig. 5 and Pl. X, fig. 11) and D (Pl. IX, fig. 14) are oval and directed obliquely, much larger in the first individual. They form four corners of a trapezoic whose anterior border is shorter than the posterior border. The contours of the apical.plate are very difficult to perceive. The anterior pores appear to be contiguous. In the two other individuals, where the openings are much smaller, the openings are circular (Pl. IX, fig. 11).

There is a slight indication of ambulacral grooves in the area of the peristome. The most characteristic structure of $P$. macroproctes is the periproct that is remarkably large (Pl. X, fig. 10 and 12). The periproct is triangular with round corners. The top of the triangle is anterior. The wide base is more or less strongly convex. It generally has a more or less protruding lobe. When this lobe is prominent, the periproct tends to take the shape of a lozenge, with the posterior rounded, like that in specimen B (fig. 12). The width is always a little greater than the length. The periproct is nearer the posterior of the body than to the peristome. Its anterior end is nearly the same distance from the posterior border of the peristome as from the posterior border of the test. The slightly 
oval peristome is a little longer than wide. It is also fairly large, but nevertheless, much smaller than the periproct.

The size of the periproct appeas to me to be an essential character of the species. It is certainly relted to the young age of the specimens because the presence ofo very distinc gonopores, mmost often or lage size, indicaes rather the animals are alrady adult. If the periproct issometimes comparative a little large in young than in the dult laganids, we do not knowo species that have at a young age and at a similar size as our four specimens of $P$. macroproctes, a periproct as large.

The primary tubercles of the dorsal surface are fairly spread out. They are very small, but fairly protruding, surrounded by a narrow scrobicular circle. Their diameter is 0.10 to 0.12 millimeters, including the scrobicular circle. They are a little larger on the ventral surface, but less protruding, with a little larger scrobicular circle. Their total diameter is 0.14 millimeters. The miliary tubercles are not very dense. The spines no longer exist on individuals A and B. They are preserved in part in the other two. The primary spines are sometimes straight, sometimes strongly curved. They are 0.6 to 0.9 in length. They have perfect smooth edges and are round at the end. The large spines around the peristome are a little larger. They are usually a little swollen in the region before the end. The miliary spines are fine and short. Their length is 0.25 to 0.3 millimeters. These spines are widened at the end. They have only a few teeth, two to four, fairly unequal and regular.

The pedicellariae are not abundant. I have seen two forms of the tridactyles, trivoliate and ophiocephalous. The large tridactyles have very peculiar characters. The head is 0.25 millimeters in length on average. The valves (Pl. XV, fig. 11a) are elongated but very wide, applied against each other nearly their entire length. They lack teeth. The have numerous large perforations, rounded and ovulate. The basal part is fairly narrow. It is separated from the limb by two large adjacent perforations. There are two fairly developed lower arcs. I do not know similar forms of tridactyl pedicellaria in the Laganidæ. The small tridactyles, whose heads are 0.12 to 0.15 millimeters on average, have the usual characters. The basal part is short and very wide. The limb, first very narrow, widens rapidly into an oval, elongated spoon with teeth in the second half that become very long and sharp in the terminal part. The valves of the trifoliates are sometimes round, sometimes elongate. This makes their length vary between 0.05 and 0.08 millimeters. Their teeth are, as usual, very elongated and strong. The length of the head of the ophiocephalous varies between 0.15 and 0.17 millimeters.

Examination of the animal by transparency indicates that the digestive tube is near the border of the test. As a consequence, the peripheral pillars must not have a very great development. Radiographic examination (Pl. XIII, fig. 4) shows that the digestive tube is near the periphery of the test and that the peripheral pillares are little developed. They remain however transversely widened and form at most two or three concentric circles. They do not have lateral branches. The path of the digestive tube is fairly peculiar. Instad of going toward the anterior border of the test, the esophagus goes rapidly toward the right (the animal being placed on is ventral surface) and the beginning of the free border of the first intestinal loop follows radius IV. This circumvolution, instead of reaching, as usual, the anterior part of the body, does not pass interradius 4, i.e., it stops toward the top of the peristome and at a point much nearer than usual to the posterior end. It curves to form the second intestinal loop whose path in consequence is extremely reduced.

SimilaritiES AND DifFERENCES. - Among the already known Peronella with which our species has affinities, I shall cite first $P$. analis (Meijere), placed by Meijere in the genus Laganum, but that, not have four gonopores, should be placed in the genus Peronella. This species has a conical and pointed test. Its periproct is of large size, but it is oval and longitudinally elongated, a 
form that has no relation to that I have indicated for $P$. Macroproctes. In $P$. analis, the miliary spines end in numerous small teeth. Meijere has represented a valve of a tridacatyl pedicellaria that has a special form, if the figure is correct: the border of the valve has very large wide teeth that merit rather the name of lobes and that give the valve a very irregular contour. There is nothing similar in $P$. marcroproctes.

Independently of the size of the periproct, the new species is also separated from $P$. Lesueuri by its open petals as well as the size and form of the spines. It is nevertheless interesting to compare the specimens of the INVESTIGATOR to the very small $P$. Lesueuri. The smallest specimens of the latter species that I have in my hand are 14 to 15 millimeters in length. They are consequently a little larger than the largest individual of $P$. macroproctes. I represent here (Pl. VIII, fig. 7, 8 and 10), three of these small $P$. Lesueuri. We can see immediately that they differ from $P$. macroproctes. First, the form of the test is not the same in the two species. The borders are thicker and the test is less high in $P$. Lesueuri where the peripheral border is better marked. In $P$. macroproctes, the test gradually decreases in height from the apical system to the border of the test, while in P. Lesueuri, the height diminishes from the apical system to some distance from the periphery, leaving a maringal border that keeps the same thickness on all its width. Moreover, the test is a little more flattenrd as a whole in P. Lesueuri than in P. macroprocte. I describe below, under the name $P$. merguiensis, a new species of Peronella in which the periproct is located nearly equidistant between the peristome and the posterior border of the test. But P. macroproctes is distinguished immediately by its small size, by the much larger periproct that is nearer the posterior border of the test, by the wider petals and by the ventral grooves that are little or not apparent.

$P$. stellata (L. Agassiz) of New South Wales has a periproct much smaller than that in $P$. macroproctes. The four gonopores, greatly separated from each other, are not contiguous on the apical plate. I have described above, under the name Laganum Rullandi, a new species that I have provisionally placed in the genus Laganum because the gonopores are still not formed although the specimens are larger than than the four $P$. macroproctes of the collection. This character immediately separates it from this last species that it recalls by the large size of its periproct. But in L. Rullandi, the periproct is farther from the posterior border of the test than in P. macroproctes (compare Pl. IX, fig. 10 and Pl. X, fig. 10 and 12), and in addition the petals cover a more restricted area of the dorsal surface of the test (compare Pl. IX, fig. 13 and Pl. X, fig. 11).

\section{Peronella merguiensis nov. sp.}

(PI. X, fig. 1 to 4; PI. XIII, fig. 7; PI. XV, fig. 8)

Gregory Island, Mergui Archipelago. — Five specimens.

In the two largest specimens, whose length are respectively 42 and 34.6 millimeters, the test is elongated with a slightly decagonal contour. The maximium width is at the level of the end of the lateral petals. The anterior region narrows very rapidly to end in a small, narrow transverse border. The posterior region is less narrow but ends nevertheless in a very marked transverse border. In the third specimen, whose length is 27 millimeters, the decagonal form is still fairly apparent. The contour remains a little angular, especially in the posterior half. But in the two other specimens, smaller, and in which the length is respectively 25.2 and 2.2 millimeters, the contour is simply oval.

Here are the dimensions I have taken of the two larger specimens. 


\begin{tabular}{|c|c|c|}
\hline & \multicolumn{2}{|c|}{ Specimens } \\
\hline & A & B \\
\hline & $\mathrm{m} / \mathrm{m}$ & $\mathrm{m} / \mathrm{m}$ \\
\hline Length of test & 42 & 27.5 \\
\hline Width............ & 37.5 & 24.5 \\
\hline Height & 4.9 & 4 \\
\hline Length and maximum width of anterior petal .......... & $11.3 \times 3.5$ & $7.9 \times 3$ \\
\hline Length and maximum width of latero-anterior petals $\ldots \ldots \ldots \ldots \ldots \ldots \ldots \ldots \ldots \ldots$ & $10.5 \times 3.3$ & $7.5 \times 3$ \\
\hline Length and maximum width of latero-posterior petals .............. & $10.5 \times 3.5$ & $7.5 \times 3$ \\
\hline $\begin{array}{l}\text { Distance between the center of the peristome and the center of the } \\
\text { periproct }\end{array}$ & 11 & 7 \\
\hline istance beween the center of the periproct and the posterior border & & \\
\hline & 10 & 6.2 \\
\hline
\end{tabular}

I shall describe the species according to the larger individual (A).

The form recalls that of the large specimens of Laganum depressum, with the posterior end a little narrower, or even that which L. Agassiz has represented in his L. elongatum (pl. XXIV, fig. 1 and 2). The test ends in front in a small, straight transverse border. Then it widens rapidly to reach its maximum width at the level that nearly corresponds to that of the anterior gonopores. It then narrows very slowly and ends in a straight posterior border, longer than the anterior border. The test is extremely depressed and its maximum height does not exceed 4.5 millimeters. The anterior border is fairly thickened and reaches about $3.5 \mathrm{~mm}$ in height. Then the thickness decreases gradually and the posterior border is no more than 2.5 millimeters. The ventral surface is nearly exactly flat.

The gonopores are very apparent. They are easily seen in the individuals, even in the smallest. The two anterior openings are separated by an interval of 2.6 millimeters and the posteriors by 3.7. The anterior openings are 18.5 millimeters from the anterior border and 23 millimeters from the posterior border of the test. The apical plate, a little convex, is nearer the anterior border than the posterior border.

The petals are small, lanceolate and nearly pointed. Their maximum width is attained toward their first third. Beyond that, the petals narrow very rapidly to their end that is very thin without, however, the two poriferous zones joining. These zones are extremely narrow. The successive pore pairs are very close to each other. They are separated by a very narrow ridge that has a very regular row of extremely fine and very dense granules. Among them we fairly frequently find a tubercle larger than the others. The interporiferous areas, relatively wide, have a covering of very regular miliary granules mixed with primary tubercles identical to those we see on the rest of the dorsal surface. This has on nearly its entire area a very regular covering of fine miliary granules, very dense and nearly contiguous. In the midst of these are seen some very small primary tubercles surrounded by a very narrow scrobicular circle. These primary tubercles are absolutely uniform in size. They are arranged with a very great regularity. They are moreover fairly near each other. Toward the periphery of the test, about 2.5 millimeters from the border, these tubercles become gradually a little larger. They even tend to be arranged in seven or eight rows parallel to the border. But their size always remains fairly small. It is only on the ventral surface that they are a little more developed. 
The ventral surface is nearly flat. It is very slightly depressed in the peristomial region. Five ambulacral grooves leave the peristome. They are slightly sunken and very short, especially the three anterior ones whose length does not reach half the radius. The two posterior grooves are a little longer. The primary tubercles are very dense towards the periphery of the test. In the immediate area of the border, they form some fairly regular and fairly apparent parallel rows. They then separate from each other little by little as they go toward the peristome. Between these primary tubercles are the same very fine and very dense miliary granules as on the dorsal surface. Below them the contours of the plates disappear completely.

The peristome is a little nearer the anterior end than the posterior end of the test. It is round. Its diameter is about 3 millimeters. It is hardly sunken. It is hidden as usualy by large horizontal spines.

In the large specimen that I describe, the periproct is located nearly equidistance from the posterior border of the peristome and the posterior border of the test. It is, however, a little nearer the latter. It is large and transversely oval, a little longer than wide with a slightly irregular contour. It is about 3x2.5 millimeters. In the smaller specimens, we see the periproct approaches a little the posterior border of the test. It always remains relatively fairly large. But its form is fairly variable while always remaining wider than long, except in the smallest specimen where it is nearly circular. The periproct is covered with very small plates. But these have numerous spines that hide them completely.

The miliary tubercles of the dorsal surface have extremely short spines. They are very close together and are erect in a way to form on this surface a very fine and very regular covering. At fairly regular intervals emerge primary spines that are also short and not very thick. They appear as small whitish granules on a violet gray background formed by the covering of the miliary spioness. These spines are erect vertically. Their length is hardly twice that of the miliary spines on a good part of the dorsal surface. All of this forms an extremely fine covering resembling velvet. But at several millimeters from the periphery, the primary spines elongate, become thicker and lie down obliquely. On the ventral surface, these spines develop still more. They do not have at all the regular arrangement they have on the dorsal surface.

The color of the two largest specimens in alcohol is gray violet. The other smaller ones are pale and a general yellowish gray. Examined with a microscope, the primary spines of the dorsal surface (Pl. XV, fig. 8a), that are about 0.5 millimeters in the largest individual, are wide and thick, cylindrical or slightly swollen a little beyond half their middle with a rounded end. The miliary spines all are 0.25 millimeters. They are formed (fig. $8 \mathrm{~b}$ and c) of a dozen columns that do not widen in a marked way at the end. The latter is jagged and forms four or five unequal and very fine lobes, but no teeth strictly speaking. The primary spines of the ventral surface are much more developed on the dorsal surface. They can attain 1.5 millimeters in length. They are cylindrical, sometimes round at the end, sometimes with a small truncated point at the end. Some of them are thicker and shorter than the others. The peristomial spines are very thick at their end. They are usually a little curved. All these spines are smooth. The length of the miliary spices of the ventral surface varies between 0.25 and 0.3 millimeters. Their structure is the same as on the dorsal surface.

I observe the three usual types of pedicellariae, tridactyls, trifoliate and ophiocephalous. The tridactyles have, as usual, a form with an elongated head and a form with a short head. The valves of the elongated tridactyles are 0.2 millimeters in length. The teeth that end the spoons, short and a little widened, are short and little pointed. The trifoliate pedicellariae (Pl. XV, fig. 8e) have a 
round blade. The total length of the valves is 0.05 . The ophiocephalous (fig. 8d) are 0.15 millimeters in length. None have special characters.

The second specimen B has had part of the dorsal surface removed to examine the internal organs when it was sent to me. But these were not preserved in their integrity ( $\mathrm{Pl}$. X, fig. 3). I have been able to confirm, that which it is moreover easy to observe by transparency, or easier with the aide of radiography (Pl. XIII, fig. 7) in other individuals whose test is fairly thin, that the digestive tube fills only a fairly restricted part of the general cavity and that the calcareous pillars are developed over a wide peripheral band. In specimen B, the digestive tube occupies an oval space measuring 19x16.5 millimeters. The arrangement of the calcareous pillars is very similar to that we have seen in Laganum decagonale. As for the path of the digestive tube itself, it has nothing special. I have been able to verify that the intestinal siphon leaves, as usual, from the beginning of the esophagus to join directly the ventral intestinal loop.

SimilaritiES AND DifFERENCES. - Among the forms of the genus Peronella whose ambulacral grooves of the ventral surface are very marked, the species from the Mergui Islands approach especially $P$. Lesueuri, but it is clearly separated from it by the wider posterior region and especially by the location of the periproct that is far from the posterior border.

The laganids in which the periproct is located fairly far from the posterior border of the test belongs especially to the genus Laganum. Among the species in this group, Peronella merguiensis has much resemblance in exterior form with L. tonganense. But this is only a matter of appearance. L. tonganense, which has five gonopores, is a true laganid and, consequenty, we cannot confuse it with $P$. merguiensis.

\section{Scutellidæ Agassiz}

This family represents a group of clypeasteroids very different and relatively high in organization. Among the genera it contains, some are noted by by very special forms and characters. The collection of the INVESTIGATOR contains only representative of the single genus Echinodiscus. I have studied the pedicdellariae as well as the path of the digestive tube in $E$. auritus. I already have had the opportunity, in 1914, to make known the arrangement of this latter organ as well as the characters of the pedicellariae in the genus Rotula, where the intestine has an arrangement completely different from that we can observe in the genus Echinodiscus. In order to be able to extnd the comparison to another form, I have dissected some specimens of Echinarachnius parma and I have confirmed a still different aarrrangement of the digestive tube from those of the two preceding genera. I shall describe later these arrangement. It would certainly be very interesting to study the genera Encope, Mellita and Dendraster from the same point of view, something that I still have not been able to do. The pedicellariae, themselves, that have fairly constant characters in the other families of the clypeasteroids and do not have very remarkable differencs in the genera of the same family, in scutellids show forms more varied and more characteristic in each genus. It is thus in the genus Rotula I had the opportunity to encounter globiferous pedicellariae. I refer for their description to my memoir of 1914 where I have described these pedicellariae. I gave there the photograph of a valve (1914a, p. 262, pl. XV, fig. 23). I have 
observed in Echinodiscus auritus tridactyl pedicellariae whose valves, strong and elongated, narrow and curved in their second half, greatly recall those of rostrate pedicellariae in spatangoids. These are two completely unexpected pedicellariae in clypeasteroids. The few pedicellariae reported by H. L. Clark in Encope emarginata, Echinarachnius mirabilus and in the genus Mellita also appear to have fairly characteristic forms. Briefly, it seems to me that the different known genera in the family Sctuellidæ do not have in their structure this homogeneity that we know in the other families of the clypeasteroids. The zoologist who would have in hand enough material to undertake a comparative study of the anatomical characters of the different genera of scutellids would certain make very interesting observations.

\section{Echinodlscus auritus (Leske)}

(PI. IV. fig. 9; PI. X, fig. 14: PI. XI, fig. 5 and 6; PI. XV, fig. 12)

Echinodiscus auritus Leske, 1778, p. 202.

Lobophora aurita and L. bifissa L. Agassiz, 1841, p. 67 and 70, pl. XIII and XIV.

Echinodiscus auritus A. Agassiz, 1872-74, p. 531, pl. Xla. fig. 9-13 et pl. XIIIc, fig. 1-3.

Echinodiscus auritus Loriol, 1881. p. 36.

Echinodiscus auritus Loriol, 1893, p. 375.

Echinodiscus auritus Dôderlein, 1902, p. 80 (722).

Echinodiscus auritus Bell, 1904, p. 247

Echinodiscus auritus Meijere, 1904, p. 138, pi. XIX, fig. 366-368.

Echinodiscus auritus Hcrdman, 1904, p. 120.

Echinodiscus auritus R. Brown, 1910a, p. 42.

Echinodiscus auritus Southwell, 1911, p. 208.

Echinodiscus auritus H. L. Clark. 1914, p. 71. pl. CXV, fig. 9-10.

Echinodiscus auritus H. L. Clark, 1915, p. 91.

Tetrodiscus Rumphii Klein, Lambert and Thiéry, 1921, p. 323.

Coast of Orissa. - 6-10 fms. - Numerous specimens in general of small size.

Coast of. -10 miles to the N.-E. of the river Devi. $-8 \mathrm{fms}$. - Five specimens.

Coast of of Ganjam. - 24-30 fms. - One specimen.

Sept Pagodes. - 5-10 fms. - One specimen.

Palk Strait. - Three small specimens.

South of Cape Comorin. - 12-15 fms. - Two small specimens.

Andaman Islands. - $20 \mathrm{fms}$. - One small specimen.

Santapalii, Presidency of Madras. "Golden Crown". - Two specimens.

Mouth of the river Hugli, "Golden Crown". - One specimen.

Most of the individuals are of fairly small size. Their length does not exceed 30 to 35 millimeters. Some are much smaller like those from Palk Strait whose length varies between 5 and 12 millimeters. The length of two species from Orissa were 60 and 88 millimeters. Finally, the two specimens of Santapalii are still larger. One of them is 108 millimeters. But they are incomplete and their tests are in part broken. The largest specimen comes from the coast of Ganjam. Its width, which nearly equals the length, is greater than 11.5 millimeters. In all these individuals, the two posterior notches remain open at their distal end and, in this regard, they compare well to the typical form of $E$. auritus. But I note some variation in the location of the periproct. In fact, in the largest specimens notably, this is fairly near the posterior border of the test. If is located nearly beyond the transverse line that connects the middle of the posterior notches. In the small specimens, on the contrary, this system is moved more or less anterior to this line. 
The large primary spines of the ventral surface are 1.5 to 2 millimeters in the large specimens (Pl. XV, fig. 12c). They are nearly cylindrical, but slightly wider in their distal third or fourth part. Then they taper gradually to the end that is a small obtuse point.The spines are fairly often very slightly incurved in this terminal part. They have small triangular, more or less marked teeth over their entire length. But they are always less developed or disappear in the third terminal part. Meijere has indicated the characters of the miliary spines. Their integumentary sheath is developed at the end to form a round expansion (fig. 12a). The very thin calcareous stalk is elongated, measuring 0.3 to 0.5 in length. The small teeth that they have on their entire length are abruptly developed toward the end to form a small head according to the spine (fig. 12d).

The miliary spines of the dorsal surface have the same characters as those of the ventral surface. The primary spines, that always have a fairly uniform size, are not much larger than the miliary spines, but they are much thicker. The keep the same width for two-thirds of their length. They then widen a little up to the end in a way to form a club. At the same time they slightly curve. The small teeth become also much stronger on this widened part.

Meijere has indicated, without describing them, three kinds of pedicellariae in E. auritus: tridactyls, trifoliate and ophiocephalous. On the other hand, H. L. Clark has seen only didactyle pedicellariae and bifoliates. To the contrary, all the pedicellariae that Mortensen encountered in $E$. auritus have three valves. This scholar thinks from this that two different species have been combined uner the name E. auritus. He wondered if the two species would not correspond to the two forms that previous authors had distinguished under the names of Lobophora aurita and $l$. bifissa and that have been united for a long time ${ }^{10}$.

For my part, I observe in the specimens collected by the INVESTIGATOR three kinds of pedicellariae: there is first the large tridactyls with three valves, with which are associated other much smaller and much more delicate pedicellariae that are also tridactyl, then the biofoliates and the ophiocephalous. The large tridactyl pedicellariae (Pl. XIV, fig. $12 \mathrm{~b}$ and c) recall a little by their characters the rostrate pedicellariae so ofen found in spatangoids. We can nearly apply this last name to them. Their head measures 0.4 to 0.5 millimeters. The values are thin and elongated. The basal part is narrow and triangular, wider than long with smooth borders. The apophysis is slightly projecting. Its free border is a little irregular. The perforations are very small and very dense. The blade is narrow and elongated in the form of a gutter. Its borders have conical teeth, very low, widened and separate. The blade gradually opens in the second half. It is widened a little at its end by flattening. This widened part, also very short, has a series of conical and fairly strong teeth. The perforations of the blade are small, sparse and form some longitudinal series. These pedicellariae are obviously very close to those that Mortensen represented in 1918, pl. V, fig 1 and 5 , but their valves are much thinner and more elongated, and the terminal teeth are less developed. The other tridactyl pedicellariae are much smaller than the preceding. The length of their head does not exceed 0.16 to 1.8 millimeters, but their form is similar. The basal part is however more developed. It is nearly half the total length of the valve. It is wider than long. The blade is short, in the form of a gutter.It ends in a small palette with teeth. The perforations are relatively more numerous than in the preceding form. I suppose that it is these pedicellariae that Meijere has indicated and represented that he said the valves measured 0.16 millimeters. I likewise wonder if these are the same pedicellariae that Clark represented in 1914, Pl. CXXV, fig. 10, under the name

\footnotetext{
${ }^{10}$ These two species have been distinguished according to the location of the periproct, the contour of the anterior border of the body, the form of the posterior notches, etc. Their respective geographical distribution has not been indicated. The specimens that L. Aggasiz described both came from the Red Sea.
} 
"bidentate" and that I cannot relate to the forms that I observe. They differ equally from those that Mortensen has figured in pl. V, fig. 9.

The trifoliate pedicellariae merit rather the name bifoliate because they have nearly always only two valves. Their length does not exceed 0.06 millimeters (fig. 12f). The basal part is very short. The blade remains narrow for nearly half its length, then it rapidly widens into a spoon nearly as wide as long, with small teeth that are extremely fine and dense on most of its length. The perforations are very large. These pedicellariae are identical to those that have been represented by Mortensen in pl. V, fig. 10, but they differ from those that Clark figured in pl. CXXV, fig. 9. Finally, I have observed ophiocephalous pedicellariae, fairly rare but very large, in which the length of the head exceeded 0.4 millimeters (fig. $12 \mathrm{~g}$ ). It is to note that Clark did not encounter them and that Meijere affirmed that the ophiocephalous are very small in E. auritus. Mortensen has not observed them.

We thus see that the pedicellaiae of $E$. auritus are susceptible to having very different forms accoding to the specimens studied. I am not far from thinking, like Mortnsen, that at least two species were united under the same specific name. The specimens that I have examined are not absolutely identical to those that Mortensen has studied and that came from Australia. They are also different from those Clark and Meijere have had. It will be interesting to compare Ech. auritus from different locations and investigate if the characters of the pedicellariae remain constant in individuals found in the same localities, at the same time they are compared to individuals coming from distant locations.

A. Agassiz has already described the internal calcareous network of the test at its periphery. He has reproduced a photograph (1872-1874), p. 531, pl. XIIIe, fig. 1). The network is extremely fine and dense, very regular and very elegant. It forms in the part nearest the border of the polygonal areas that correspond to the plates of the test. It becomes more irregular as it goes away from the periphery. The calcareous supports that form it are, in fact, stronger and the spaces they limit become larger. The gonads are found in these spaces. This peripheral network leaves free a central cavity occupied by the digestive tube. In a specimen like that whose photograph I reproduce in Pl. XI, fig. 6, and that measured about 10x10 centimeters, this central region had a width of only 42-43 millimeters. In the individual whose radiograph is reproduced in Pl. X, fig. 14, and that measured 122x110 millimeters, this central region measured 43-47 millimeters. The peripheral calcareous network continues toward the central region as branched trusses that are applied against the ventral surface of the test that we see in my radiograph.

The digestive tube of $E$. auritus has a peculiarity that, to my knowledge at least, does not exist in any other form of clypeasteroid and that L. Agassiz has already observed in 1841. The two photographs that I reproduce here (Pl. XI, fig. 5 and 6) of two E. auritus opened, one, the larger, by the ventral surface and the other, the smaller, by the dorsal surface to permit recognition of the principal arrangements of the intestine. The esopohagus is short. It widens even before reaching the anterior edge of the lantern. It continues with the first intestinal loop. The first part of this loop is very wide and exceeds more or less strongly radius III, according to the size of the specimen. It scarcely enters it in the small specimens while, in the large ones, it touches interradius 2 . The width of the first intestinal loop gradually decreases after its beginning. It describes a nearly complete circumvolution to return to radius II that it passes. But instead of curving at this point in order to continue as the second loop, it follows its path in follow an inverse curve. i.e., it strongly inflects towards the left (the animal being opened by the ventral surface as in fig. 6) and follows nearly the direction of interradius 2. It then is turned back to form the recurrent loop. This results from the fact that the intestine has in interradius 2 a very conspicuous and fairly elongated loop (in an 
individual like that I represent here in fig. 6 and whose width is 20 centimeters, the loop is more more than 15 millimetrs in length). The recurrent loop remains applied against the internal border of the loop up to interradius 5. Then it continues with the rectum whose path is completely straight.

L. Agassiz has indicated this peculiar loop of the intestine of E. auritus. He has represented it in his memoir of 1841, pl. XIII, fig. 6.

The path of the digestive tube is easy to see by transparency in young specimens that are little colored. Naturally, we recognize it in a very clear manner by radiography. The sinus of interradius 2 is already visible in individiualls measuring 12 to $13 \mathrm{~mm}$ in length. But it still is not formed in smaller specimens.

The widest part of the the first intestinal loop has, in its width, two regions distinctive by their appearance and color.These differences correspond doubtlessly to a difference in structure and function of this part of the digestive system.We can see this especially in the small individual whose photograph seen by the dorsal side I reproduce here. We recognize, in fact, that the digestive tube for most of its width has more or less transverse folds and a grayish color while the external part is flat, lacking folds and has a yellow color, clearly distinct from the preceding. The width of this marginal region is nearly a fourth of the total width of the first intestinal loop. It reaches its maxium at the level of radius III. Then it narrows gradually as it approaches radius IV. It ceases to be distinct before reaching radius $\mathrm{V}$. In the largest specimen, these two regions are equally recognizable, but the difference is less clear because the folds are less pronounced. The color remains darker.

The marginal intestinal lacuna remains recognizable, thanks to its deep violet color the entire length of the first intestinal loop. We distinguish the external marginal lacuna also in some regions.

The intestinal siphon no longer has the specific path we have recognized in all species of Langanidæ described before. Its first portion, instead of following a direct path above the lantern, remains as usual applied to the first intestinal circumvolution. The siphon no longer originates on the very path of the esophagus, but at the end of it, exactly at the point where the esophagus joins the first intestinal circumvolution. It remains attached to it and accompanies it to the posterior interradius 5 where its distal opening is located.

The Aristotle's lantrn has been described and figured by L. Agassiz.

E. auritus s. lat. is principally known on the east coast of Africa (Madagascar, Mauritius, Mozambique, Zanzibar, etc.), in the Red Sea, in numerous locations of the Indian Ocean (coasts of Hindoustan, Ceylon, Macassar Strait) and the Sunda Islands.

\section{Echinodiscus bisperforatus (Leske)}

$$
\text { (PI. XV, fig. 9) }
$$

Echinodiscus bisperforatus Leske, 1778. p. 196, pl. XXI, fig. A, B. Lobophora truncata L. Agassiz, 1841, p. 66, pl. XI, fig. 11-16. Echinodiscus bisperforatus Dôderlein. 1902, p. 723, p1. LXV, fig. 6. Echinodiscus bisperforatus H. L. Clark, 1914, p. 71.

Coast of Madras. — $7 \mathrm{fms}$. — Five specimens.

In the largest individual, the length of the test is 45 millimeters and the width 52 millimeters. The smallest measures respectively 27 x 30 millimeters 
The largest primarry spines of the ventral surface are cylindrical and in general very thin with a round end. They have very fine small teeth that are very close together on a fairly good part of their length. They are 1.5 millimeters. The other more numerous spines are shorter. Their length does not exceed 0.6 to 0.8 millimeters. They flatten rapidly and widen in their distal half. They develop at the same time some teeth that become stronger on the widened part. They are usually a little curved. The teeth are more developed on the convex side than on the concave side. Compared to those of E. auritus, these spines are weaker and shorter, but their terminal width is more marked. The primary spines of the dorsal surface have the same charcters as in E. auritus. The length hardly exceeds 0.5 to 0.6 millimeters. The miliary spines have nearly the same dimensons. They have the same characters as in E. auritus.

I have observed two kinds of pedicellariae: tridactyle and bifoliates. The tridactyl pedicllariae are of two kinds. Some have very developed heads similar to the large tridactyls I have indicaed in E. auritus. The valves are about 0.3 millimeters in length. They are truncated at the end and have along all their length conical and low teeth that are fairly spaced. The pedicellariae of the second kind appear fairly widespread. They are much smaller than the preceding (Pl. XV, fig. 9b and d). The valves are 0.12 to 0.15 millimeters in length. The basal part is wide and very high. The blade, at first very wide, then narrows to widen again in the form of a spoon that occupies half its length. This spoon, that is not very wide, has the form of a very elongated oval whose borders have, in the terminal part, some teeth at first very small, conical and low, but that are very elongated toward the end. The perforations, fairly large, are round or elongated. It is these pedicellariae that were indicated by H. L. Clark, who compares them to E. tenuissimus. But I have seen that in the latter, the blade forms an elongated spoon whose borders remain simply parallel and that is not widened as in E. bisperforatus.

The bifoliate pedicellariae are extremely small. The values ae not more than 0.005 millimeters (fig. 9a and c). The basal part is very short. The blade forms first a narrow part, shorter than in $E$. auritus. It widens into a spoon a little wider than long, with some very wide, elongated and conical spines on its borders. The perforations are fairly large, sparse, elongated in the median part of the blade and round on the sides. This spoon is comparatively wider than in E. auritus.

The family Scutellidæ is represented in the collections of the INVESTIGATOR by the single genus Echinodiscus. I have been able to examine the arrangement of the internal organs in $E$. auritus. It has seemed interesting to me to compare those of other representatives of the family of which I could sacrifice some specimens. I had already had the opportunity in my memoir on the echinoderms of the west coast of Africa, published in 1914, to indicate the arrangement of the digestive tube in Rotula Augusti. I have reproduced in this work a phograph that shows, in a very clear manner, the principal characters (1914a, p. 263). The digestive tube of $R$. Augusti has some fairly different arrangements from those that we have recognized in E. auritus. The most important are the very conspicuous sinuosities of the first intestinal circumvolution in the five success radii III, IV, V, I and II. These sinuosities thus increase considerably the path of the first intestinal circumvolution. This follows the esophagus without immediately reaching its maximum width, which is seen only after anterior radius III. Then its width decreases very gradually up to the end of the circumvolution, i.e., in radius II, the origin of the recurrent circumvolution. The path of the latter is very short. It does not have sinuosities. It is moreover attached to the first circumvolution only in its first half. It abandons it when it forms its loop in radius I. Its path is therefore direct. It is continuous with the rectum after a slight inflection. This second circumvolution is moreover slender and and not wide. The intestinal siphon does not originate on the esophagus but at the 
junction of the esophagus with first intestinal circumvolution. The proximal mouth of this canal is located, as usual, in interradius 5.

My excellent friend, Dr. J. Richard, Director of the Oceanographic Museum of Monaco, has kindly placed at my disposition two speciments of Echinarachnius parma collected by the HIRONDELLE. The individuals are in a good state of preservation. I have been able to study their internal organization. I reproduce here three photographs, of which two represent an individual opened by the dorsal surface, and the other, an individual opened by the ventral surface (Pl. XI, fig. 1, 2 and 3). Fig. 1 shows the specimen when the dorsal surface of the test has been removed. We see that the gonads, that are extremely developed and whose branches fill all the free space in the general cavity on the dorsal surface of the digestive tube, more or less completely hide the latter when we open the animal by the dorsal surface. We distinguish in my photograph the four gonoducts that correspond to the four external gonopores. I will note in passing that the internal partitions of the test in E. parma form a fairly narrow peripheral border that leaves a fairly large space for the development of the digestive tube. In the specimens that I represent here that measured 62 to 65 millimeters in length, the peripheral walls do not exceed a width of about one centimeter in the radius where they have a half-dozen concentric partitions that are very close to each other, having inside only some isolated pillars. In the interradius, there are on each side of the median line, a thick partition directed toward the center, 15 to 16 millimeters in length and leaving free the middle of the interradius. The radial partitions come to rest outside against the external surface of each of these partitions. The peripheral partitions being moreover a little more developed in one specimen than in the other, the free space occupied by the digestive tube has a diameter of about 35 millimeters in one of the individuals and 32 millimeters in the other.

The esophagus is continuous with the first intestinal circumvolution that is immediately at its greatest width. Its free border, that passes interradius 2 , forms a very strongly convex line. The width of the intestine reaches, at the beginning of the first circumvolution 14 millimeters, of the circumvolution where it is no more than 2 millimeters in one of my specimens and 3.5 millimeters in the other. This first circomvolution ends at the level of radius II. The recurrent loop has very marked inflections and the rectum also has a very sinuous path. All parts of the intestine have a pale grayish brown color. I do not see any difference in color of the different regions.

The intestinal siphon originates at the point where the esophagus becomes the first circumvolution. It is fairly large and remains connected to the digestive tube all along its length. Its path is easy to follow thanks to its color that is deeper than the intestine to which it is attached. The distal opening is located a little before interradius 5 . The marginal lacunae are not very apparent.

\section{Fibulariidæ Gray}

This small family contains only the two genera Fibularia and Echinocyamus that are easily distinguished. The first has a more elevated test and no internal partitions (except usually in the posterior interradius 1 . The second has a lower test and internal partitions. These two genera are accepted by all auhors, with the characters I just gave. Only Lambert and Thiéry made in 1914 a regrettable modification with the long-establish nomenclature. They in fact placed species with a flatter body and internal partitions in the Fibularia. As Echinocyamus, they placed those that have globular bodies and no internal partitions. In summary, they called Fibularia the genus called by 
everyone Echinocyamus and reciprocally. This reversal has no benefits or reason. The pedicellariae of Fibulariidæ are poorly developed and have no special forms. We shall see later that the absence or presence of internal partitions determines changes in the development of the digestive tube. But in the two genera, the path of the siphon remains the same. The general organization keeps as a whole a simplicity and inferiority that different authors have already emphasized.

Echinocyamus sollers nov. pp.

(PI. XII, fig. 6 to 14.18 and 19; PI. XV. fig. 6)

Station 151. - S. 64, E. 13 1/2 miles from the Colombo lighthouse. - 142- $400 \mathrm{fms}$. - Several dead specimens Station 250. - 6 $54^{\prime} 30^{\prime \prime}$ N.; 79"34'30" E. — $480 \mathrm{fms}$. — About forty specimens.

Coast of Malabar. - $8^{\circ} 10^{\prime}$ N.; $76^{\circ} 26^{\prime}$ E. — 445-386 fms. - One specimen.

The form of the body is a little variable. In some individuals, that are in general the largest, the test is a little longer than wide (Pl. XII, fig. 6, 8, 10,11). But in most of them, the length is not much greater than the width (fig. 7, 9, 12 and 13). The contour is hardly oval. Some specimens even have a nearly exactly circular contour. The anterior and posterior borders are very round. Sometimes, however, the posterior border is a little truncated. The anterior end is hardly narrower than the posterior end. The photographs I reproduce here of some specimens collected by the INVESTIGATOR give an idea of the variations, not very great, that can occur in the contour of the test. In a general way, the length varies between 6 and 7 millimeters and the width between 5.2 and 6 millimeters. The body is fairly high.The height varies between 2.5 and 3 millimeters. The ventral surface is flat. The dorsal surface is not regularly convex. The profile sometimes has the form of a very low cone with very rounded borders (fig. 18 and 19). The apical plate forms a small, slightly protruding button. It has medium dimensions. It is a slightly elongated oval. A little outside this plate are the gonopoes and ocellar openings. They are located at the four corners of a trapezoid. The two posteriors are a little more separated than the two anteriors. These openings are circular and slightly widened transversely. Their size varies a little with the specimen. The ocellar openings, smaller and rounded, are found located regularly on eiher side of the gonopoes. The single madreporite is located forward, at nearly the height of the anterior two pairs of ocellar pores. The rest of the apical plate has some equal primary tubercles, a little smaller than those of the dorsal surface, and some miliary tubercles.

The petals are very conspicuous. Their pores are well developed. They exend to a fairly short distance from the border of they test. They are unequal (fig. 9 to 12). Each petal has eight to nine pore pairs. The two poriferous zones of each of them are exactly parallel. The two rows of pairs of each zone also remain parallel for a good part of the length of the petals. They approach each other in the proximal region of the petal where the pores also become smaller. The poriferous zones are a little narrower than the interporiferous zones. The pores are rounded. Those of the external row are slightly larger than those of the internal row. The two pores of each pair are not located at the same height. The successive pairs are separated by an interval shorter than the diameter of the exterior pore and larger than the diameter of the interior pore. This interval is not protruding. It has only rare miliary granules. The band that separates the two rows of pores of each pair has first only miliary granules. But these become larger toward the distal end of the petals. Some primary tubercles are added. The interporiferous zones are a little convex. They have some primary 
granules with miliary granules. We can oboserve on the interporiferous zones some small supplementary ambulacral pores. They are extremely fine and and variable in number, very apparent in some individuals and scarcely visible or completely lacking in others. When they exist, these pores form on each side a small row parallel to the internal rows of ordinary pores.

In general, the petals end abruptly at their distal end by the disappearance of the rows of pores, without having any tendency to be opened or closed. We can however find immediately after the last pair of pores one or sometimes two supplemenry unpaired pores, or located outside the alignment of the others. The plates that follow the petals in the ambulacral zones increase rapidly up to the ambitus. I usually count three plaes between the end of the petals and the ambitus on the dorsal surface of the test. The primary tubercles are arranged fairly regularly on these plaes. They form only one transverse row on the small specimens. But in the larger ones, we can recognize several distinct rows in which the tubercles are arranged irregularly. They are moreover not numerous. Passing to the ventral surface, the plates become longer and narrower toward the peristome. The primary tubercles, also not abundant, are a little larger than on the dorsal surface. Their scrobicular circle is wider and better marked. The small ambulacral pores of the dorsal surface and of the ambitus also remain arranged in a single row and forming regular small arcs. On the ventral surface, we see the same arrangement on the plates adjacent to the ambitus whose pores follow principally the external border. But on the plates near the peristome, the arrangement becomes very irregular.

The interradial regions, little developed, have tubercles identical to those of the radial regions.

The peristome is located in the middle of the ventral surface, equal distance from the anterior border and posterior border of the test. It is rather large, sometimes circular, sometimes slightly pentagonal. Its diameter varies between 1.3 and 1.5 millimeters. It is surrounded by a row of primary tubercles, more dense than on the rest of the ventral surface, and having larger and stronger spines directed obliquely inside so as to protect the peristomial membrane. The periproct, much smaller than the peristome, is nearer the posterior border of the test. Its form and dimensions are a little variable. It is sometimes circular, sometimes a little irregular. In general, it is oval and slightly widened transversely. It has four or five large triangular plates that lack spines.

The spines that surround the peristome are wide and flat for their distal two-thirds. They ae 0.8 to 0.9 millimeteres in length. Others are a little shorter. These spines widen gradually, but very slowly from their base. Then they thin rapidly to a short distance from their end that is round. Their borders have very strong small teeth. The other primiary spines of the ventral surface are thinner and cylindrical. Their length reaches or even exceeds 1 millimeter. They are pointed at their end. The largest have some small teeth on the distal half. The primary spines of the dorsal surface of the test have the same characters. The miliary spines are 0.035 millimeters on average and have about a dozen transverse shafts. Their wide head is a least two times wider than the rest. The longitudinal rods have, at the wide end, six to eight conical teeth, fairly small and a little irregular (Pl. XV, fig 6a).

The pedicellariae are small and fairly rare. I have encountered only two kinds that correspond to the trifoliate and ophiocephalous. In the latter, the head measures about 0.09 to 0.1 millilmeters. The elongated valves (fig. 6b) greatly recall those that Mortensen represented in E. pusillus in 1907 (pl. XII, fig. 4). The blade has the form of an elongated triangle that widens gradually with a very convex free border. The three sides of the valve have strong teeth. The trifoliates are extremely small. The length of the valves does not exceed 0.08 millimeters (fig. $6 \mathrm{c}$ ). The base is wide and very short. The blade has at first a narrow peduncle. Then it widens rapidly into a round 
spoon with numerous teeth, conical, pointed and close together, fairly fine and not becoming stronger toward the end.

The color of the animal is yellowish, yellowish gray, or grayish yellow.

The internal partitions of the test are thin and elongated. They are all the same shape and are vertically arranged. Their length equals nearly half the radius of the body. The two partitions of each pair are relatively separated from each other (Pl. XII, fig. 14). The partitions leave free in the center of the test only a rather restricted area for the digestive tube. The part of the latter can be recognized easily in the specimens from which the dorsal surface of the test is removed. The esophagus first follows radius III. Then it is reflected toward the right (the animal being opened by its dorsal surface) in making a very marked curve. At the border of the lantern, it widens abruptly and goes to the first intestingal cicumvolution. It passes interradius II, returns to radius III and continius its path in passing by IV, $\mathrm{V}$ and I up to interradius 2 where it turns back to form the recurrent loop. The first part of the ventral loop at first keeps the same length, then it narrow very slightly up to the posterior interradius 5. From this point, it becomes much more slender. The second intestinal loop is equally very thin. In E. pussilus, to judge from the figure published by Cuénot in 1891 (pl. XXIV, fig. 16), the different parts of the intestine keep a very uniform diameter and, in particular, the beginning of the first intestinal loop is much less wide than in E. sollers. The siphon also follows, in the latter, a path different from that we know in E. pusillus. Instead of going transversely in the direction of interradius 4, it forms a very open curve and its distal opening is located much further away than in E. pusillus, i.e., toward posterior interradius 5.

SIMILARITIES AND DIFFERENCES. - E. sollers ranks with the Echinocyamus petals that are elongated, very distinct and formed by several succsssive pore pairs. We shall distinguish it easily from the two species described recently by H. L. Clark, E. megalopetalus and elongatus that have much more elongated bodies and an oval contour. The first species, from Mauritius, has poriferous zones of each petal very divergent and non-parallel. The second has the periproct placed nearly equidistance between the posterior border of the peristome and the posterior border of the body.

E. crispus, which the INVESTIGATOR has also encountered, also has a more elongated body. If we compare the photographs that I reproduce here (Pl. XII, fig. 16 and 17), the two specimens of the INVESTIGATOR to those of E. sollers (fig. 9 to 12), we shall note that in E. crispus, the petals are comparatively shorter, but that they are formed of more numerous and denser pores. Moreover, the periproct is nearer the posterior body of the peristome than the posterior border of the test. Finally, the ventral surface of E. crispus is concave and the internal partitions of the test are more elongated (fig. 21).

In E. provectus that Meijere described from specimens collected in the Sunda Islands, the body is also longer than wide, a little wider anteriorly than posteriorly, the poriferous zones are generally not parallel, except sometimes in the anterior unpaired ambulacrum. But they are to the contrary clearly convergent. The periproct is found nearly equidistant between the peristome and the posterior border of the test. Finally, the internal partitions are arranged less regularly than in the other Echinocyamus. Only, the two partitions of posterior interradius 5, located on each side of the periproct, are nearly exactly perpendicular to the walls of the test while the others are directed more of less obliquely.

There is no possible confusion with E. pusillus.

In another species from the Sunda Islands described by Meijere, E. scaber, the test is not much longer than wide and the contour recalls that shown by E. sollers. It has a distinct posterior border, but the pore pairs of the petals are much less numerous and the petals are shorter. In addition, the 
two dorsal and ventral surfaces of the test are nearly parallel and the body is discoidal. Dôderlein has reported Echinocyamus scaber found by the VALDIVIA on the east coast of Africa at depths varying between 693 and 1,134 meters $\left(1^{\circ} 3^{\prime} \mathrm{S}\right.$ and $\left.40^{\circ} 45^{\prime} \mathrm{W}\right)$ and perhaps near the Maldive Islands (2,253 meters). It has a more elongated body, sensibly longer than wide, and petals having fairly numerous pore pairs (up to seven in the largest specimens. I wonder if it is the same species that has been described by Meijere. In any case, the species of the VALDIVIDA is not the same as that of the INVESTIGATOR in which the petals are much more distinct, more elongated and formed by a larger number of pore pairs and in which the periproct is nearer the posterior border of the body.

\section{Echinocyamus crispus Mazetti}

(Pl.XII, fig. 16, 17 and 21)

Echinocyamus crispus Mazetti, 1894, p. 215, pl. XIII, fig. a-d.

Echinocyamus crispus Meijere, 1904, p. 105, pl. VI, fig. 48-50 amd pl. XVIT, fig. 300.

Echinocyamus crispus H. L. Clark, 1914, p. 62.

Fibularia crispa Lambert and Thiéry, 1914, p. 292.

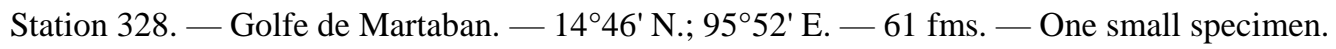

Pedro Shoal. - Two specimens.

$6^{\circ} 01^{\prime}$ N.; $81^{\circ} 16^{\prime}$ E. - $34 \mathrm{fms}$. - Three specimens.

Andaman Islands, west coast. - $15 \mathrm{fms}$. - One small specmen.

Mangalore. - 26-31 fms. - Three specimens.

The specimens recall more the figures of Mazetti than those of Meijere. The form is, in fact, always oval, with the anterior end slightly narrow. The contour of the body is slightly pentagonal. In the small specimens of Pedro Shoal, the test is even a little more elongated than in the others, while the test of the largest is comparatively shorter.

Meijere has already emphasized the variations in the form of the body of E. crispus. I believe I can refer the specimens of the INVESTIGATOR to this specis. The peristome is clearly pentagonal. The periproct is sometimes round as I note in a specimens from Mangalore, but usually it is widened transversely. It is medium in size. It is a little nearer the posterior border of the peristome than the posterior border of the test. Meijere says that the peristome is located equidistance between the mouth and border of the test. This is true if we consider the distances from center to center. But if, to the contrary, we consider the exterior contours of the two openings, we note that the distance separating the anterior border of the periproct from the posterior border of the peristome is notably smaller than that which separates the posterior border of the periproct from the posterior border of the test. Although Mazetti says in his text that the anus is located nearly equidistance between the mouth and the posterior border of the test, he shows, in his figure $\mathrm{c}$, the periproct is very near the border of the test, that this is evidently incorrect. The pores of the petal form ten to twelve pairs according to the size of the individual. The small ambulacral pores are arranged in single rows. The primary tubercles are not very large.

The internal partitions of the body extend from the peristome to the end of the petals (Pl. XII, fig. 21). They are quite high and longer than in E. pusillus and especially than in E. sollers.

The characters of the spines have been indicated by Meijere. I have not found pedicellariae in the specimens of the INVESTIGATOR. 


\section{Fibularia craniolaris (Leske)}

(PI. XV, fig. 4)

Echinocyamus craniolaris Leske, 1778, p. 150, pl. XLVII, fig. 3 a.

Fibularia ovulum Lamarck, 1816, p. 17.

Fibularia ovulum Blainville, 1834, p. 211.

Fibularia ovulum L. Agassiz, 1836, p. 20.

Fibularia ovulum Gray, 1855, p. 30.

Fibularia ovulum A. Agassiz, 1872-74, p. 507, pl. XIII e, fig. 1-3.

Fibularia ovulum Anderson, 1894, p. 188.

Fibularia ovulum Meijere, 1904, p. 111, pl. XVIII, fig. 311 and 312.

Fibularia craniolaris H. L. Clark, 1914, p. 57.

Echlnocyainus craniolaris Lambert and Thiéry, 1814, p. 287.

Ford Bay, Great Coco Island. Andaman. - 192-193 fms. - Several specimens.

Maldive Islands. - 30-75 fms. - Four small specimens in bad condition and partially decalcified.

The length of the test of the largest individual is 6 millimeters.

The primary spines I see are cylindrical, with an obtuse, round end. They are not small teeth as Meijere indicates. They simply have wavy edges. They are about 0.4 millimeters in length. As Meijere says, the miliary spines (Pl. XV, fig. $4 \mathrm{~b}$ and c) are two times smaller. In the remarks that this author published regarding $F$. craniolaris (that he called $F$. ovulum), Meijere returns, p. 111, to figure $311 \mathrm{of}$ pl. XVIII for the figure of the primary spine. This is an error, because it is a miliary spine that this figue represents.

I see ophiocephalous and trifoliate pedicellariae. The first (Pl. XV, fig. 4a) have been represented by Meijere. Their head is 0.09 to 0.1 millimeters. The valves of the trifoliate (fig. $4 \mathrm{~d}$ ) are 0.1 to 0.15 millimeters. They widen rapidly into an oval spoon with very strong teeth, not numerous, whose size increases gradually to their end.

F. craniolaris has been reported up untl now in the tropical regions of the Indian Ocean and the Sunda Islands.

\section{Fibularia critbellum Meijere}

(PI. XII, fig. 20)

Fibularia cribellum Meijere, 1904, p. 112, pl. VI, fig. 53-54 and pl. XVIII, fig. 313-314.

Fibularia cribellum H. L. Clark. 1914, p. 58.

Echinocyamus cribellum Lambert and Thiéry, 1914, p. 288.

Palk Strait. — One small specimen lacking spines.

I believe I can refer this individual to the species established by Meijere. It is smaller than that which served as the type for this author, whose length was 7 millimeters. But it perfectly conforms to it and I have nothing to add to the description of Meijere.

Fibularia volva L. Agassiz and Desor 
(PI. XII, fig. 15)

Fibularia volva L. Agassiz and Desor, 1847, p. 142.

Fibularia oblonga Gray, 1855, p. 30, pi. II, fig. 5.

Fibularia voira A. Agassiz, 1872-74, p. 509.

Fibularia volva Bell, 1884, p. 122.

Fibularia volva Anderson, 1894, p. 194.

Fibularia volva Sluiter, 1895, p. 72.

Fibularia volva Meijere, 1904, p. 111.

Fibularia volva H. L. Clark, 1914. p. 58.

Echinocyamus volva Lambert and Thiéry, 1914, p. 288.

Fibularia volva H. L. Clark, 1915, p. 91.

Fibularia volva Mortensen, 1918, p. 18, pl. V, fig. 12, 13, 16, 20, 27 and 28.

Coast of Madras. - $25 \mathrm{fms}$. - One specimen lacking spines. The length of this specimen is 0.2 millimeters.

The species has been figured by Gray in 1855. The specimen of the INVESTIGATOR is more pointed at the two ends than in the figures given by this author. This form conforms to most of the descriptions. I reproduce here in Pl. XII, fig. 15, a photograph of the dorsal surface of this individual.

The specimen lacking spines, I have not been able to see pedicellariae. I refer for their study to the work of Mortensen. The discovery this author made in this species of globiferous pedicellariae is extremely interesting.

\section{Cassiduloids}

\section{Echlnolampas ovatus (Leske)}

(PI. VI, fig. 5; PI. XIV, fig. 8)

Echinus ovatus Leske, 1778, p. 191, pl. XX, fig. c and d.

Echinus oviformis Gmelin, 1788, p. 3187.

Echinolampas oviformis Blainville, 1834, p. 209.

Echinolampas oviformis Agassiz and Desor, 1847, p. 105.

Echinolampas oviformis Gray, 1855, p. 35.

Echinolampas oviformis A. Agassiz, 1872-74, p. 553.

Echinolampas oviformis Loriol, 1876, p. 7, pl. I, fig. 4.

Echinolampas oviformis A. Agassiz, 1881, p. 123, pl. XXXVII, fig. 10 and 11, pl. XXXIX, XLI, XLIII and XLIV.

Echinolampas oviformis Sluiter, 1895, p. 73.

Echinolampas oviformis Fourteau, 1904, p. 428.

Echinolampas ovata Dôderlein, 1907, p. 240.

Echinolampas ovata Southwell, 1911, p. 208.

Echinolampas ovata H. L. Clark, 1915. p. 91.

Echinolampas ovata H. L. Clark, 1917, p. 114, pl. CLIII, fig. 1 and 2.

Echinolampas castanea Alcock, 1893, p. 5, pi. VIII, fig. 6. 
Echinolampas ovatus Lambert and Thiéry, 1921, p. 378.

Coast of Orissa. $-11 \mathrm{fms}$. - Three specimens.

All three specimens are in a good state of preservation and they are covered with their spines.

Alcock had believed he had to place these specimens in a new species that he described a little briefly in 1893 under the name E. castanea. He has not compared the new species that he established with other known living Echinolampas. He was content to say that E. castanea had a very great resemblance to E. spheroidalis, a Miocene species described by Archiac and Haime. For my part, I do not see in the specimens of the INVESTIGATOR any character that permits distinguishing them from $E$. ovatus and that E. castanea of Alcock should fall into synonomy with the latter species.

I shall add remarks to complete the information givn by Alcock.

Here the principal dimensions of he specimens of the INVESTIGATOR that I designated respecitively by the letters $\mathrm{A}, \mathrm{B}$ and $\mathrm{C}$.

Length

Maximum width

Height at the level of the apical system

Distance between the center of the apical plate and the anterior border of the test

Distance between the center of the apical plate and the posterior border of the test

Distance between the middle of the peristome and the anterior border of the test

Length of the anterior petal, poriferous zones a and $b^{11}$

Length of the anterior lateral petals, poriferous zones $a$ and $b . .$.

Length of the posterior lateral petals, poriferous zones $a$ and $b$..

Maximum width of the unpaied anterior petal ..................

Maximum width of the latero-anterior petals

Maximum width of the latero-posterior petals

Dimensions of the peristome

Dimensions of the periproct .... 142

The form varies with the individual. Large specimen A has a more angular contour than the two others. In specimen $\mathrm{C}$, the contour is nearly circular, while in $\mathrm{B}$, the test is a little wider. The maximum width is either a little forward or a little behind the lateral interradial line. The anterior border is a little flat. The posterior end is narrow and sometimes a little pointed. The maximum height of the test is at the apical plate that is forward. The plates of the anterior and posterior interradial pairs are very slightly swollen near their middle. In specimen A, this swelling is scarcely apparent on the two anterior interradii. It is more marked on the posteriors. This contributes to give

11 Due to the high convexity of the test, the petal measurements were not taken in projection, but using a flexible measure directly applied to the test. 
to this specimen a slightly angular contour when we look at it from above, with an anterior border nearly straight and a narrow posterior end. Seen in profile, the anterior border of the test is first nearly vertical with a convex line up to the middle of its height. Then it curves backward following a regular curve to the apical plate that is slight protruding. Behind, the profile of the test decreases regularly to a small distance from the ventral surface to which it is connected by a small surface directed obliquely forward and below with the periproct at the bottom. The ventral surface is united with the sides of the body by a very widely rounded edge. It is depressed very slightly at some distance form the edge to form, in the central part, a shallow depression in the middle of which is located the peristome. The periproct, in the oblique posterior side, is not visible from the dorsal surface while it appears, to the contrary, entire when we look at the animal from the ventral surface.

The apical plate has the ordinary structure. The four gonopoes are very apparent, equal and each with a small papilla.

The petals have a form that is little different from each other. Althogh they narrow at their distal end, that are widely open. Howver, the anterior petal has slightly curved and nearly parallel poriferous zones, while in the four lateral petals, these zones separate at first very rapidly from each other for a third of the length of the petal. Then they move together to separate a little further the end. The form of the posterior petals is similar although a little less accentuated. The poriferous zones scarecely exceed one millimeter in width and the interporiferous band can reach about 3 millimeters in the widest part. The two poriferous zones of each petal have different lengths as, moreover, in other species of Echionolampas. It is 2 to 3 millimeters. These are the zones IIIb, Ib, $\mathrm{IIa}, \mathrm{IVb}$ and $\mathrm{Va}$ that are longer. The successive pore pairs are extremely close to each other. I count forty-six in the posterior zone of the latero-anterior petals of specimen A. The pairs are separted by a fairly projecting line that has a fairly regular row of extremely fine granules, contiguous, much smaller than the other granules of the dorsal arc of the test. On the ventral surface, afer the peristome, the number of phyllode pores oscillates around seven in the anterior ambulacrum, nine in the latero-anterior ambulacra and eight in lateror-posterior ambulacra.

The primary tubercles, very small and extremely dense on the dorsal surface of the test, become a little larger on the ventral surface. Their dimensions increase slightly again on the depressed part of this surface in approaching the perisome. At the same time, the tubercles separate from each other and their scrobicular circle widens slightly. The middle of the ventral posterior interradius has, at some millemeters behind the peristome, only some extraordinary small tubercles that have only very fine spines. This is over the entire exend of the depressed region.

The peristome is pentagonal with concave sides, corresponding to the interradial thickenings, and with angles that are extended in becoming more superficial toward the floscelles. It is a little wider than long. The periproct, transversely widely enlarged, has a more convex anterior border than the posterior border. It is covered with some large, sparse plates with two small, tight tubercles. The anus is contiguous with its dorsal border.

The spines are very dense. They form a very uniform covering, both on the ventral surface, where they are stronger, as well as on the dorsal surface. On the latter, they are scarcely 0.7 millimeters in length. They are thick, slightly swollen distally and end in a blunt point. They have, on their distal half, conical teeth, low, widest at the base and fairly separated from each other. These spines become stronger on the ventral surface. Their length is greater than 2 millimeters. Those of the peristomial bourrelets are partaicularly thick. These spines remain cylindrical. Their small teeth are tighter on the dorsal surface, without being, hoever, stronger. Some of them, but not the largest, are often curved in their second half. The miliary spines are 0.4 to 0.5 millimeters in length. They are fine and slight swollen distlly. They also have in their distal half, and sometimes 
even for their entire length, teeth that are first very fine, but that become stronger and tighter in the distal part of the spine.

Pedicellariae are very rare. I have found only tridactyl pedicellariae of two kinds and trifoliates. The head of the largest tridactyls are 0.3 to 0.35 millimeters in length (pl. XIV, fig. 8c). The valves have a wide basal part, wider than long. The blade is very narrow at its base. It widens gradually into an elongated spoon that never becomes very wide. It has on its edges, in the distal half, small teeth that become stronger toward the end. This spoon occupies nearly a third of the total length of the valve. The tridactyls of the second kind are small. Their head is only 0.1 to 0.15 millimeters in length (fig. 81). The blade of the valves is thicker at the base than in the preceding form. It widens into spoon that fills nearly half of the length and that has numerous teeth, fine and tight. The valves of the trifoliate pedicellariae are wider than long. Their length is 0.1 to 0.2 millimeters. The teeth, lacking at the end of the valves are seen especially on the sides. They are conical, fine, pointed and tight.

The color of the specimens in alcohol is very faint yellow. Alcock indicates that the color is "yellowish green". Perhaps that is of living animals.

\section{Echiinolampas Alexandri Loriol}

(PI. IV, flg. 10)

Echinolampas Alcxandri Loriol, 1876, p. 4, pl. I, fig. 1-3.

Echinolampas Alexandri Meijere, 1904, p. 145.

Echinolampas Alexandri H. L. Clark, 1917, p. 114, pl. CXLIV, fig. 14 to 16, and pl. CLIII, fig. 3 and 4.

Dawei. - Two intact specimens plus one broken specimen.

Coast of Orissa. — "Golden Crown" August 1908. — One specimen.

All four specimens were dead and completely lacking in spines. Two specimens of Dawei are in good condition but the third is broken. The specimen from Orissa is less well preserved. Its test is covered by numerous commensals (bryozoans, sepulids, etc.) that more or less completely hide the characters. It meaures $57 \times 53 \times 38.5$ millimeters.

Here are the principal dimensions of the two intact individuals from Dawei that I shall expecially consider in the remarks that follow.

$\quad \mathrm{m} / \mathrm{m} \quad \mathrm{m} / \mathrm{m}$

Maximum width ........................................... $65.2 \quad 60.5$

Height at the level of the apical system ................... . $43.2 \quad 39$

Distance between the center of the apical plate and the anterior border of the test ........................................................... 29

Distance between the center of the apical plate and the posterior border of the test

Distance between the middle of the peristome and the anterior border of the test ........................................................................

Length the unpaired anterior petal, poriferous zones $a$ and $b^{12} \ldots \ldots \ldots .22 .5-24.5 \quad 20-23$

\footnotetext{
12 These measurements were taken with 49 and 65 a flexible measure applied on the test.
} 
Length of the latero-anterior petals, poriferous zones $a$ and $b$

$18.5-30$

$17-28$

Length of the latero-posterior petals, poriferous zones $a$ and $b$

$32-30$

$32-26$

Maximum width of the anterior petal

\section{5}

5

Maximum width of the latero-anterior petals

6.5

6

Maximum width of the latero-posterior petals .......................

Dimensions of the peristome.

$6 \quad 5.7$

$8.5 \times 5.5 \quad 9 \times 5.9$

Dimensions of the periproct

$10.1 \times 6$

$10.2 \times 5.5$

E. Alexandri was described by Loriel according to three specimens coming fromMauritius in which the length varied between 49 and 65 millimeters. The height indicated by Loriol was respectively 48 and 53 millimeters. The ratio between the length and the height was thus, according to the indications of Loriol, 65/53 or 1.22 in the longer individual. But if one considers the figure that he has given, we can confirm that the test is much flatter than we would suppose from the last number, and that is is in particular flatter than in L. ovatus. Since the publication of the memoir of Loriel, H. L. Clark has given some complementary informentation on this species known, he says, from Ceylon to Mauritius. He has published two photographs of an individual from Ceyon and has represented the pedicellariae. My specimens are closer to the photographs of Clark than to the figures of Loriol. Although they do not absolutely conform to the specimens described by the two authors, I do not believe I make a mistake in referring them to E. Alexandri.

In the specimens described by Loriol, the test is comparatively less elevated than in those of Dawei and if we judge from the figures of Loriol (Pl. I, fig. 1a and 1c). In fact, in fig. 1a, the length of the test (that should be represented in real size) is 65 millimeters, a number that is indicated by Loriol in the text (p. 4) and the height measured in the fig. 1c in the same plate is 31 millimeters. It is this last number that appears to me that must must be taken into consideration. I suggest the number given by Loriol on page 4 in the text for the height of the test in the three specimens are either 48, 51 and 53 milliimeters or are wrong. Otherwise the height of these three specimens would be considerable and completely out of proportion with the figures of the author. Thus, if we evaluate the height of the test according to the figure of pl. I of Loriol, we shall find that the ratio of the length and height is $65 / 31$ or 2.09 , while in the specimens of the INVESTIGATOR the ratio varies between 1.64 and 1.7. According to the photographs reproduced by Clark, pl. CLIII, fig. 3, the ratio is $49 / 37$, or 1.44 . The height of the test is thus greater in the specimens of Clark than in mine and especially those from Mauritius studied by Loriol.

One of the essential characters of E. Alexandri is the arrangement of the petals in which the poriferous zones are directed nearly parallel to each other in each petal. This character appears in the clearest manner in the individual photographed by Clark, pl. CLIII, fig. 4. In the specimens figured by Loriol in pl. I, fig. 1a and $2 \mathrm{a}$, these zones are very slightly inflected. We can see in the photograph that I reproduce here of the largest specimen from Dawei (Pl. IV, fig. 10), that the poriferous zones are nearly straight, and only the poriferous zone of the right latero-anterior petal is slightly curved. In the smallest specimen, the two zones a and b of this petal are also slightly curved. It is the same for zone $b$ of the left anterior-lateral petal. The petals always remain widely open at their distal end. This condition of the petals does not exist in any other species of Echinolampas, in particular this arrangement is completely different in E. ovatus.

I shall report likewise another character of E. Alexandri: the peristomial bourrelets are scarcely apparent in this species while they are very prominent in E. ovatus. There thus can be no confusion between the two species. 
I have been able to verify in the specimens of the INVESTIGATOR the correctness of the description of Loriol, except in what concerns the numbers he gave relative to the height of his specimens. But we should retain this fact resulting from more necessary comparisons between the specimens of the INVESTIGATOR and those that Clark and Loriol have represented, each on their side, that this height is susceptible to have variations.

The specimens of the INVESTIGATOR being represented only by two tests of dead individuals, I can add nothing to the description of Loriol relative to the spines and pedicellariae that are completely lacking in these individuals.

In his beautiful memoir of 1914, H. L. Clark has preserved E. Alexandri while noting that he did not have in his hands sufficient material to allow him to verify the validty of this species. For my part, I hold it to be perfectly valid. I consider it is sufficiently distinguished from other known species by the chaacters of the petals.

\section{Echinoneus cyclostomus (Leske)}

(See for the bibliography the work of Westergren "Echinoneus and Micropetalon. Memoirs of the Museum of Comparative Zoology, vol. XXXIX, no. 2" in which we find a very complete study of the genus Echinoneus).

The author reaches the conclusion that there exists, up until now at least, only a single species of Echinoneus, E. cyclostomus, and that the numerous forms under the names of É. ovalis Linné, minor Leske, semilunaris Gmelin. gibbosus Lamarck, echinonea Desmoulins, serialis Dcsor, conformis Desor, ventricosus Agassiz, cruciatus Agassiz, crassus Agassiz and abnormalis Loriol are synonyms. Concerning the last species, however, H. L. Clark is of the opinion contrary to that of Westergren. He holds that it is perfectly valid. Thus comprised, E. cyclostomus has a very vast geographic extension because it is found in the warm regions of the Atlantic Ocean as well as in those of the Indo-Pacific domain.

I shall recall that Agassiz reported in 1909 the preence in very young E. cyclostomus not yet 5 millimeters in length, a masticatory apparatus that no longer exists in the adult. We shall find figures of this apparatus in the memoir of Westergren. This discovery affects the affinities of the genus Echinoneus and could modify our ideas on its affinities, modifying at the same time the place that this genus has in classification. I shall recall on this subject that in 1891, Cuénot speaking of cassiduloids said "It is impossible that we do not find in the young, the rudiments of the apparatus in question (masticatory apparatus): This opinion of Cuénot thus has just been confirmed. I have to report here only three empty tests of E. cyclostomus found by the INVESTIGATOR on the coal reefs of Ancutta (Laccadive Islands). These specimens have already been indicated by Andeson is his note of 1894, p. 7. 


\section{LIST OF CITED WORKS}

Agassiz (A.). 1863. List of the Echinoderms sent to différent Institutions in exchange. Bull. Mus. Comp. Zoology. Vol. I. Cambridge.

Agassiz (A.). 1872-74. Revision of tlie Echini. Ill. Cat. of the Mus. of Comp. Zoology, $\mathrm{n}^{\circ}$ VII. Cambridge.

Agassiz (A.). 1881. Report on the Echinoidea. Rep. of the Sc. Results of the voyage of the “CHALLENGER”. Zoology, vol. III. London.

Agassiz (L.). 1836. Prodrome d'une monographie des Radiaires. Mèm. Soc. Sc. Neuchatel. Vol. I. Agassiz (L.). 1841. Monographies d'Échinodermes. II. Monographie des Scutelles. Neuchatel.

Agassiz (L.) and Desor. 1846-47. Catalogue raisonné des Echinides. Ann. Sc. Nat. Zoologie (3), volume 6, 7 and 8. Paris.

Alcock (A.). 1893. Natural History from steamer "Investigator". An account of the Deep Sea Collection made during the Season of 1892-93. Journ. Asiatic Soc. of Bengal. Vol. LXII, part. 2, $\mathrm{n}^{\circ}$ 4. Calcutta.

Anderson (A. R. S.). 1894. Natural History from Steamer "INVESTIGATOR". On the Echinoidea collected during the Season 1893-94. Journ. Asiatic Soc. of Bengal. Vol. LXIII, part. 2, n ${ }^{\circ}$ 3. Calcutta.

Bedford (F. B.). 1900. On Echinoderms from Singapore and Malacca. Proc. Zool. Soc. London, 1900.

Bell (J.). 1884. Report Zoological Collections made in the Indo-Pacific Océan during the voyage of "Alert" in 1881-82. Echinodermata. London.

Bell (J.). 1885. Observations of the generic and spécifie characters of the Laganidæ". Ann. Mag. Nat. History (5). PI. XI.

Bell (J.). 1902. The Actinogonidiate Echinoderms of the Maldive and Laccadive Islands, in: Fauna and Geography of Maldive and Laccadive Archipelagoes, by S. Gardinor. Vol. I, part. 3.

Blainville (H. de). 1834. Manuel d'ActinoIogie. Paris.

Brown (R. N. Rudmose). 1910. Echinoidea and Asteroidea from the Mergui Archipelago. Proc. Roy. Soc. Edinburgh. Vol. XVIII.

Brown (R. N. Rudmose). 1910a. Echinoidea from the Kerimba Archipelago (Mozambique). Ib. Vol. XVIIl.

Clark (Hubert Lyman). L911. The Gênera of Récent Clypeasteroids. Ann. Mag. Nat. Hist. (8), Vol. VII. I.ondon.

Clark (Hubert Lyman). 1914. The Clypeasteridæ, Arachnoididæ, Laganidae, Fibulariidæ and Scutellidæ. Mem. Mus.Comp. Zool.-Vol. XLVI. Cambridge, 1914.

Clark (Hubert Lyman). 1914. The Echinoderms of the Western Australian Muséum. Records W. A. Museum. Vol. I.

Clark (Hubert Lyman). 1915. The Echinoderms of Ceylan other than Holothurians. Spolia Zeylanica. Vol. X.

Clark (Hubert Lyman). 1916. Report on the Sea-Lilies, Starfishes, Brittle-Stars and Sea-Urchins obtained by the F. I. S. "ENDEAVOUR". Commonweallh of Australian Fisheries. Vol. IV, part. 1. Sydney, 1916.

Cuénot (L.). 1891. Etudes morphologiques sur les Échinodermes. Archives de Biologie. Vol. XI. Döderlein (L.). 1885. Seeigeln von Japan und den Liu-Kiu Inseln. Arch. f. Naturgeschicht. Bd. LI. 
Döderlein (L.). 1902. Bericht über die von Semon bei Amboina und Thursday Island gesammelten Echinoidea. Jenische Denschriften. 1902.

Döderlein (L.). 1907. Die Echinoiden der Deutschen-Tiefsce Expédition. Deutsche TiefseeExpedition. Vol. V. Berlin.

Duncan (P. M.) and Sladen (P.). 1888. Report of the Echinoidea of the Mergui Archipelago. Journal Linnean Soc. London. Zoology. Vol. XXI, London.

Fourteau (R.). 1904. Contribution à l'étude des Échinides vivants dans le golfe de Suez. Bull. Institut Egypte. Série 4, Vol. IV. 1904.

Gmelin. 1789. Caroli Linnei Systema Naturæ, v. VI.

Gray (J. E.) 1851. New genera and species of Scutellidæ and Echinolampidæ. Proc. Zool. Soc. London. 1851.

Gray (J. E.). 1855. Catalogue of the récent Echinida in the British Muséum. London, 1855.

Herdman (W. A.). 1904. Report on the Echinoderma collected by Prof. Herdman at Ceylan in 1902. Report Ceylan Pearl Oyster Fisheries. Part. II, report 10. London.

Kœhler (R.). 1895. Catalogue raisonné des Échinodermes recueillis par M. Korotneff aux îles de la Sonde. Mém. Soc. Zool. France. Vol. XX, 1895.

Kœhler (R.). 1914. Echinoderma of the Indian Muséum, parL. V1ll. 1. Spatangoidés. Calcutta, 1914.

Kœhler (R.) 1914a. Echinoderma I (Asteroidea, Ophiuroidea et Echinoidea in: Breiträge zur Kenntniss der Meeresfauna Westafrikas. Hambourg, 1914.

Kœhler (R.). 1921. Sur les services que la radiographie peut rendre dans l'étude des Clypeastridés. Comptes Rendus Ac. Sc. Paris, 28 novembre 1921.

Lamarck. 1916. Histoire naturelle des animaux sans vertébres. Paris, 1815-1822. Échinides. T. III. 1916.

Lambert (J.). 1912. Description des Échinides des terrains néogènes du bassin du Rhône. Abhand. Schweiz. Palaeont. Gesellsch. Vol. XXXVIII, 1912. Bàle.

Lambert (J.). 1914. Note sur la synonymie des espèces vivantes de Clypeastres. Ann. Soc. Linnéenne de Lyon. t. LXI. Lyon.

Lambert (J.) and Thiéry (P.). Essai de Nomenclature raisonnée des Échinides. 1909-1914. 5 fascicules. Chaumont.

Linné (C). Systema naturæ. Edition X. i758.

Leske (N. G.). Addimenta ad Kleiaii naturalem dispositionem Echinodermatum. 1778.

Loriol (P. de). 1876. Note sur quelques espèces nouvelles appartenant à la classe des Échinodermes. Mém. Soc. Phys. et Hist. Nat. de Genève, t. XXIV.

LorioL (P. de). 1883. Catalogue raisonné des Échinodermes recueillis par Robillard à l'île Maurice. Echinides. Ib. t. XXVIII, $n^{\circ}$ 8. Genève.

Loriol (P. de). 1891. Notes pour servir à l'étude des Échinodermes. I" série, fasc. III. Mém. Soc. Phys. et Hist. Naturelle. Genève. Volume supplémentaire, 1890.

Loriol (P. de). 1893. Échinodermes de la baie d'Amboine. Revue Suisse de Zoologie. Vol. 1.

Loven (Sven). 1875. Études sur les Échinoidées. Köngl. Svenska Vet. Ak. Handlingar. Bd. XI, $\mathrm{n}^{\circ}$ 7.

Loven (Sven). 1892. Echinologica. Köngl. Svenska. Vetenskaps Akad. Handlingar. Vol. XVIII.

Mazetti (Ab. G.). 1894. Gli Echinidi del mar Rosso. Mem. R. Acad. di Scienze, Lettere et Arti Modena. Modène, 1894.

Meijere (H. de). 1904. Die Echinoidea der "SIBOGA" Expédition. Siboga Expeditie. Leyden. 1904. 
Michelin (H.). 1861. Monographie des Clypéastres fossiles. Mém. Soc. Géol. France $2^{\circ}$ série, t. VIL Mém. $\mathrm{n}^{\circ} 2$.

Michelin (H.)-1861. Notice sur quelques espèces d'Échinides provenant de la Nouvelle-Calédonie. Recue et Magasin de Zoologie. Paris, 1861.

Mortensen (Th.). 1918. Results of Dr. Mjobergs swedish scientific Expéditions to Australia 19101913. XXI. Echinoidea. Kongl. Svenska Vet. Ak. Handlingar. Bd. LVIII, n ${ }^{\circ} 9$.

Mortensen (Th.). 1921. Echinoderms of New Zealand and the Auckland-Campbell Islands. Echinoidea (Papers from Dr. Th. Mortensen's Pacific Expédition 1914-1915. VIII). Vidensk. Medd. fra Dansk. Naturfr. Foren. Bd. 73.

Pfeffer (G.). 1881. Die Clypeastriden des Hamburger Muséums. Verh. Naturw. Vereins. Hamburg.

Sluiter (G. Ph.). 1895. Die Echiniden Sammlung des Muséums zu Amsterdam. Bijdr. Dicrkunde Amsterdam. Afl. 17. Amsterdam, 1895.

Southwell (T.). 1911. Notes on the gênera Margaritifera and Aviculidea, and on post-mortem colour changes in Echinoidea. Ceylon Marine Biological Reports, $\mathrm{n}^{\circ} 5$.

'l'ower (W. L.). An abnormal Clypeasteroid Echinoid. Zool. Anz. Bd. XXV, 1901, p. 188.

Westergren (A. M.). 1911. Echinoneus and Micropetalon. Mem. Mus. Comp. Zoology. Vol. XLIX, $\mathrm{n}^{\circ} 2$. 


\section{EXPLANATION OF THE PLATES}

\section{PLATE I}

All the photographs refer to Clypeaster Annandalei.

Fig. 1. Specimen A: Dorsal surface slightly enlarged.

Fig. 2. Specimen B: Ventral surface slightly enlarged.

Fig. 3. Apical plate and adjacent region. X 3.5.

Fig. 4. Vertical section of the test to show the internal pillars. Slightly enlarged.

Fig. 5. Vertical section of another individual. Slightly enlarged.

Fig. 6. Specimen C: dorsal suface. X 1.3.

Fig. 7. Specimen C: ventral surface. X 1.3.

\section{PLATE II}

All the photographs refer to Clypeaster Annandalei.

Fig. 1. Ventral surface of the test has been removed to show the internal organization. The Aristotle's lantern has also been removed. Slightly enlarged.

Fig. 2. Specimen G; dorsal surface; slightly enlarged.

Fig. 3. Arisotle's lantern seen from the ventral surface; slightly enlarged.

Fig. 4. Aristotle's lantern seen from the dorsal surface; slightly enlarged.

Fig. 5 to 10 . Lateral view of several specimens, slightly enlarged.

Fig. 5. Specimen E.

Fig. 6. Specimen D.

Fig. 7. Specimen G.

Fig. 8. Specimen F.

Fig. 9. Specimen C.

Fig. 10. Specimen $\mathrm{H}$.

Fig. 11. Enlarged portion of a petal. X. 4 .

\section{PLATE III}

Fig. 1. Clypeaster humilis from the Red Sea, opened by the ventral surface; the Aristotle's lantern has been left in place. X 1.3.

Fig. 2. Clypeaster humilis: dorsal surface of a specimen from the Red Sea. X 1.3.

Fig. 3. Clypeaster humilis: dorsal surface of another individual. X 1.3.

Fig. 4. Clypeaster humilis: the same specimen as in fig. 1, but the Aristotle's lantern has been removed. X 1.3. 
Fig. 5. Clypeaster humilis: Vertical section of the test of a dried specimen. X 1.3.

Fig. 6. Clypeaster Annandalei: lateral view of a jaw. X 3.

Fig. 7. Clypeaster Annandalei: Aristotle's lantern; lateral view, a little oblique of the interradial region. X 1.8 .

Fig. 8. Clypeaster Annandalei: lateral view of the Aristotle's lantern with a portion of the adjacent ventral surface of the test. X 2.3.

Fig. 9. Clypeaster Annandalei: specimen F; dorsal surface.

Fig. 10. Clypeaster amplificatus: apical plate. X 4.2.

Fig. 11. Clypeaster amplificatus: enlarged portion of a petal. X 4.2.

Fig. 12. Clypeaster humilis: Aristotle's lantern, dorsal surface. X 1.3.

\section{PLATE IV}

Fig. 1. Clypeaster destinatus: specimen A; dorsal surface; slightly enlarged.

Fig. 2. Clypeaster destinatus: specimen C; dorsal surface; slightly enlarged.

Fig. 3. Clypeaster destinatus: specimen B; dorsal surface; slightly enlarged.

Fig. 4. Clypeaster destinatus: specimen A; ventral surface; slightly enlarged.

Fig. 5. Clypeaster destinatus: specimen C; ventral surface; slightly enlarged.

Fig. 6. Clypeaster destinatus: specimen E; abnormal; dorsal surface. X 1.3.

Fig. 7. Clypeaster destinatus: ventral surface of the same. X 1.3.

Fig. 8. Clypeaster destinatus: apical system of the same. $\mathrm{X} 4$.

Fig. 9. Echinodiscus auritus: vertical section of the test. X 4.5.

Fig. 10. Echinolampus Alexandri: dorsal surface slightly enlarged.

Fig. 11. Clypeaster destinatus: apical plate. X 4.

Fig. 12. Clypeaster destinatus: enlarged portion of the dorsal surface of the test. X 4 .

Fig. 13. Clypeaster destinatus: specimen A; lateral view, very slightly enlarged.

Fig. 14. Clypeaster destinatus: specimen B; lateral view, very slightly enlarged.

\section{PLATE V}

Fig. 1. Clypeaster rarispinus: specimen whose ventral surface has been removed to show the internal organization. X 2 .

Fig. 2. Clypeaster rarispinius: specimen opened by the dosal sufce. $\mathrm{X} 2$.

Fig. 3. Clypeaster Annandalei: enlarged portion of an iterradius of the dorsal surface. X 4 .

Fig. 4. Clypeaster destinatus: Aristotle's lantern seen from the dorsal surface. X. 1.4.

Fig. 5. Clypeaster destinatus: specimen opened by the ventral surface with the Aristotle's lantern in place. X 1.4.

Fig. 6. Clypeaster destinatus: another specimen whose Aristotle's lantern has been removed. X 1.4 .

Fig. 7. Clypeaster rarispinus: enlarged portion of the dorsal surface. X 6.

Fig. 8. Arachnoides placenta: specimen opened by the ventral surface. X 1.4.

Fig. 9. Arachnoides placenta: specimen opened by the dorsal surface; the gonads cover a large part of the digestive tube. X 1.4.

Fig. 10. Arachnoides placenta: the same specimen whose gonads have been partially removed to expose the digestive tube. X 1.4. 


\section{PLATE VI}

Fig. 1. Clypeaster fervens: dorsal surface. X 1.2.

Fig. 2. Clypeaster fervens: ventral surface. X 1.2.

Fig. 3. Rhapidoclypus reticulatus: dried test whose dorsal surface has been partially removed. X 2.

Fig. 4. Rhapidoclypus reticulatus: specimen in alcohol whose dorsal surface has been in part removed to show the digestive tube. $\mathrm{X} 2$.

Fig. 5. Echinolampas ovatus: dorsal surface. X 1.5.

Fig. 6. Clypeaster fervens: lateral view. X 1.2.

Fig. 7. Clypeaster rarispinus: dorsal surface of a specimen with a slightly elongated test. X 1.7.

Fig. 8. Clypeaster rarispinus: dorsal surface of a specimen nearly as wide as long. X 1.7.

Fig. 9. Clypeaster rarispinus: dorsal surface of another specimen whose radial regions are protuberant. X 1.7.

Fig. 10. Clypeaster rarispinius: Aristotle's lantern seen from the ventral surface. X 2.

Fig. 11. Clypeaster rarispinius: Aristotle's lantern seen from the dorsal surface. X 2.

\section{PLATE VII}

Fig. 1. Clypeaster amplificatus: dorsal surface reduced about a sixth.

Fig. 2. Clypeaster amplificatus: ventral surface: same reduction.

\section{PLATE VIII}

Fig. 1. Peronella Lesueuri: specimen of average size. X 1.8

Fig. 2. Peronella Lesueuri: specimen of large size, very slightly reduced.

Fig. 3. Peronella Lesueuri: enlarged portion of the dorsal surface of a small specimen. X 14 .

Fig. 4. Peronella Lesueuri: enlarged portion of the dorsal surface of another specimen. X 7 .

Fig. 5. Laganum decagonale: enlarged portion of the dorsal surface. X 8 .

Fig. 6. Peronella Lesueuri: radiograph of the specimen in Fig. 2, reduced nearly a half.

Fig. 7. Peronella Lesueuri: ventral surface of a small specimen. X 2.

Fig. 8. Peronella Lesueuri: ventral surface of another specimen. X 2.

Fig. 9. Laganum Joubini: ventral surface of a larger specimen. Natural size.

Fig. 10. Peronella Lesueuri: ventral surface of a small specimen. X 2.

\section{PLATE IX}

Fig. 1. Laganum depressum: specimen opened by the ventral surface. X 1.6.

Fig. 2. Laganum depressum: specimen opened by the dorsal surface. X 1.8.

Fig. 3. Laganum Rullandi: enlarged portion of the dorsal surface. X 8.

Fig. 4. Laganum Bonani: specimen opened by the ventral surface. X 2.

Fig. 5. Peronella macroproctes: specimen A; enlarged portion of the dorsal surface. X 12 .

Fig. 6. Laganum Joubini: dorsal surface of a small specimen slightly enlarged.

Fig. 7. Laganum depressum: ventral surface slightly enlarged.

Fig. 8. Laganum depressum: dorsal surface of the same specimen slightly enlarged.

Fig. 9. Laganum Joubini: dorsal surface of a large specimen. Natural size. 
Fig. 10. Laganum Rullandi: ventral surface. X 2.7.

Fig. 11. Peronella macroproctes: specimen C; dorsal surface. X 4.

Fig. 12. Laganum Joubini: ventral surface of a small specimen. Natural size.

Fig. 13. Laganum Rullandi: dorsal surface. X 2.7.

Fig. 14. Peronella macroproctes: dorsal suface of specimen D. X 4.

\section{PLATE $X$}

Fig. 1. Peronella merguiensis: dorsal surface of the largest specimen (A). X 1.5.

Fig. 2. Peronella merguiensis: ventral surface of the same. X 1.5.

Fig. 3. Peronella merguiensis: smallest specimen B of which one part of the ventral surface has been removed. X. 2.5.

Fig. 4. Peronella merguiensis: apical plate and surrounding region. X 5.

Fig. 5. Laganum retinens: dorsal surface of the largest specimen (A). X 1.7.

Fig. 6. Laganum retinens. Apical plate and surrounding region. X 7.

Fig. 7. Clypeaster Annandalei: Radiograph reduced by more than 2/5.

Fig. 8. Laganum retinens: dorsal surface of specimen C. X 2.

Fig. 9. Laganum, retinens: ventral surface of specimen B from which a portion of the test has been removed. X 2.4.

Fig. 10. Peronella macroproctes: ventral surface of the largest specimen. X 2.

Fig. 11. Peronella macroproctes: dorsal surface of the same. X 4.

Fig. 12. Peronella macroproctes: ventral surface of specimen B. X 4.

Fig. 13. Laganum retinens: ventral surface of specimen A. X 1.7.

Fig. 14. Echinodiscus auritus: radiograph reduced by more than 2/5.

\section{PLATE XI}

Fig. 1. Echinarachnius parma: Individual opened by the dorsal surface; the gonads have been left in place. X 1.4 .

Fig. 2. Echinarachnius parma: Individual opened by the ventral surface. X 1.4.

Fig. 3. Laganum decagonale: individual opened by the dorsal surface. X 2.

Fig. 4. Peronella Lesueuri: specimen opened by the ventral surface. X 2.

Fig. 5. Echinodiscus auritus: specimen opened by the ventral surface. Natural size.

Fig. 6. Echinarachnius parma: specimen opened by the dorsal surface and whose gonads have been removed in part. X 1.4.

\section{PLATE XII}

Fig. 1. Laganum versatile: specimen A; dorsal surface. X 1.5.

Fig. 2. Laganum versatile: same specimen; ventral surface. X 1.5.

Fig. 3. Laganum versatile: specimen $\mathrm{B}$ whose ventral surface has been removed. X 1.5.

Fig. 4. Laganum versatile: specimen A; lateral view. X 1.5.

Fig. 5. Laganum tonganense: dorsal surface. Natural size.

Fig. 6. Echinocyamus sollers: specimen with spines. Ventral surface. X 6.

Fig. 7. Echinocyamus sollers: another specimen; ventral surface X 6 .

Fig. 8. Echinocyamus sollers: specimen lacking spines; ventral surface. X 6 . 
Fig. 9 to 12. Echinocyamus sollers: four specimens seen by the dorsal side. X 6 .

Fig. 13. Echinocyamus sollers: ventral surface. X 6.

Fig. 14. Echinocyamus sollers: specimens whose dorsal surface has been removed. X 6 .

Fig. 15. Fibularia volva: dorsal surface. X 6.2.

Fig. 16. Echinocyamus crispus: dorsal surface of a specimen from Mangalore. X 7.

Fig. 17. Echinocyamus crispus: dorsal surface of another specimen from the same locality. X 7 .

Fig. 18. Echinocyamus sollers: lateral view. X 6.

Fig. 19. Echinocyamus sollers: lateral view of another specimen. X 6.

Fig. 20. Fibularia cribellum: lateral view. X 6.

Fig. 21. Echinocyamus crispus: specimen whose dorsal surface has been removed. X 6 .

\section{PLATE XIII}

All the figures are reproductions of radiographs at natural size; the specimens are seen by the dorsal surface.

Fig. 1. Clypeaster amplificatus.

Fig. 2. Laganum Joudini. The small specimen.

Fig. 3. Laganum depressum.

Fig. 4. Peronella macroproctes.

Fig. 5. Laganum Rullandi.

Fig. 6. Clypeaster fervens.

Fig. 7. Peronella merguiensis.

Fig. 8. Laganum Joudini. The large specimen.

Fig. 9. Laganum tonganense. The small specimen.

\section{PLATE XIV}

Fig. 1. Clypeaster Annandalei: a, valves of large tridactyls, X 90; b, valves of small tridactyls, X 120 ; c, rosette of a tube foot, X 230; d, valve of trifoliate, X 230; e, primary spine, X 35; $\mathrm{f}$, miliary spine, $\mathrm{X} 75$.

Fig. 2. Laganum depressum: a, valves of large tridactyl, X 135; b, valve of large tridactyl, X 180; c, ophiophalous pedicellariae, X 80; d, valve of small tridactyl, X 230.

Fig. 3. Clypeaster destinatus: a, miliary spine, X 120; b, large primry spine, X 35; c, rosette of tube foot, X 230; d, valves of large tricatyls, X 120; e, valves of small tridactyles, X 120; f, valve of ophicephalous, X 120; f, valves of trifoliate, X 230.

Fig. 4. Laganum tonganense: a, valves of large tridactyl, X 135; b, valve of small tridactyl, X 135; c, ophiocephalous pedicellariae, X 80.

Fig. 5. Clypeaster humilis: a, valves of large tridactyl, X 75; b, valves of trifoliate, X 230; c, rosette of a tube foot, X 230; d, valve of small tridactyl, X 125; e, entire large tridactyl, X 75 .

Fig. 6. Laganum Bonani: a, valves of large tridactyl, X 180; b, valves of trifoliate, X 230; c, valves of small tridactyl, X 180; d, entire small didactyl pedicellaria, X 180.

Fig. 7. Laganum Joubini: a, valve of large tridactyl, X 135; b, entire large tridactyl, X 80; c, entire small tridactyl, X 230; d, ophiocephalous, X 80. 
Fig. 8. Echinolampas oriformis: a, valve of small tridactyl, X 235; b, valve of trifoliate, X 230; c, entire large tridactyl, X 100.

Fig. 9. Clypeaster rarispinus: a, valves of large tridactyl, X 110; b, entire large tridactyl, X 75.

\section{PLATE XV}

Fig. 1. Clypeaster fervens: a, primary spines, x 35; b, secondary spines, X 75; c, valves of large tridactyl pedicellariae, X 120; d, valves of small tridactyls, X 120; e, valve of trifoliate, $\mathrm{X} 230$; f, terminal rosette of a tube foot, X 230.

Fig. 2. Laganum rullandi: a, primary spines, X 50; b, miliary spines, X 135.

Fig. 3. Laganum versatile: a, valve of tridactyle pedicellaria (basal part is missing), X 230 .

Fig. 4. Fibularia craniolaris: a, ophiocephalous pedicellariae, X 230; b, miliary spine, X 120; c, distal end of a miliary spine, X 230; d, valve of trifoliate, X 230.

Fig. 5. Peronella Lesueuri: a, valves of tridactyle pedicellariae with shortened head; b, valve of elongated tridactyl; c, valves of trifoliate, X 230.

Fig. 6. Echinocyamus sollers: a, end of a miliary spine, X 120; b, valve of ophiocephaloous pedicellaria, X 230; c, valves of trifoliate, X 230; d, primary spine, X 60 .

Fig. 7. Laganum retinens: a, valve of small tridactyl, X 230; b, valve of large tridactyl, X 120; c, ophiocephalous, X 120; d, valve of trifoliate, X 230.

Fig. 8. Peronellla merguiensis: a, primary spine, X 50; b, miliary spines, X 100; end of a miliary spine, X 230; d, valve of a ophiocephalous pedicellaria and e, of a trifoliate, $X$ 230.

Fig. 9. Echinodiscus bisperforatus: a, valve of bifoliate pedicellaria, X 230; b, valves of small tridactyles, X 175; c, entire bifoliate, X 230; d, entire small tridactyl, X 175.

Fig. 10. Rhaphidoclypus reticulatus: a, valve of small tridactyl, X 120; b, valve of large tridactyl, X 75; c, valve of trifoliate, X 230; d, valve of ophiocephalous, X 120; e, miliary spine, X 120; f, primary spine, $X 75$.

Fig. 11. Peronella macroproctes: a, valve of large tridactyl, X 125; b, ophiocephalous pedicellaria, X 150; c, three valves of bifoliate, X 230; d, valve of small tridactyl, X 150; e, end of miliary spine, X 230; f, primary spine, X 50.

Fig. 12. Echinodiscus auritus: a, miliary spine with its integumentary sheath forming a terminal expansion, X 75; b, valves of large tridactyl, X 60;, c, entire large tridactyl; d, denuded miliary spines, X 60; e, primary spine, X 35; f, valve of trifoliate, X 230; g, ophiocephalous pedicellaria, X 45.

Fig. 13. Laganum decagonale: a, terminal part of a miliary spine, X 230; b, primary spine, X 70; c, isolated valves of small tridactyls, X 230; d, valve of trifoliate, X 230.

Fig. 14. Arachnoides placenta: valves of bifoliate pedicellaria, X 230. 


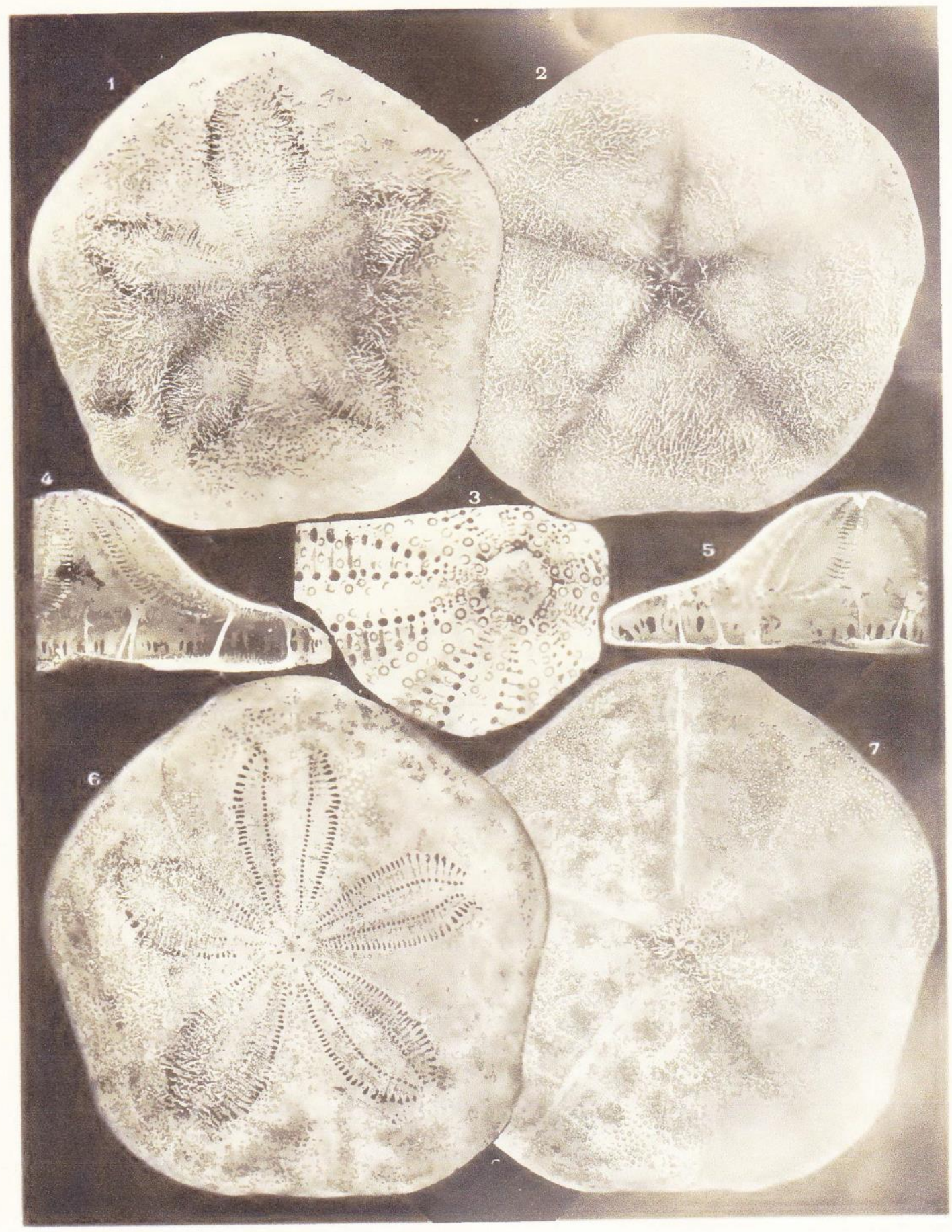




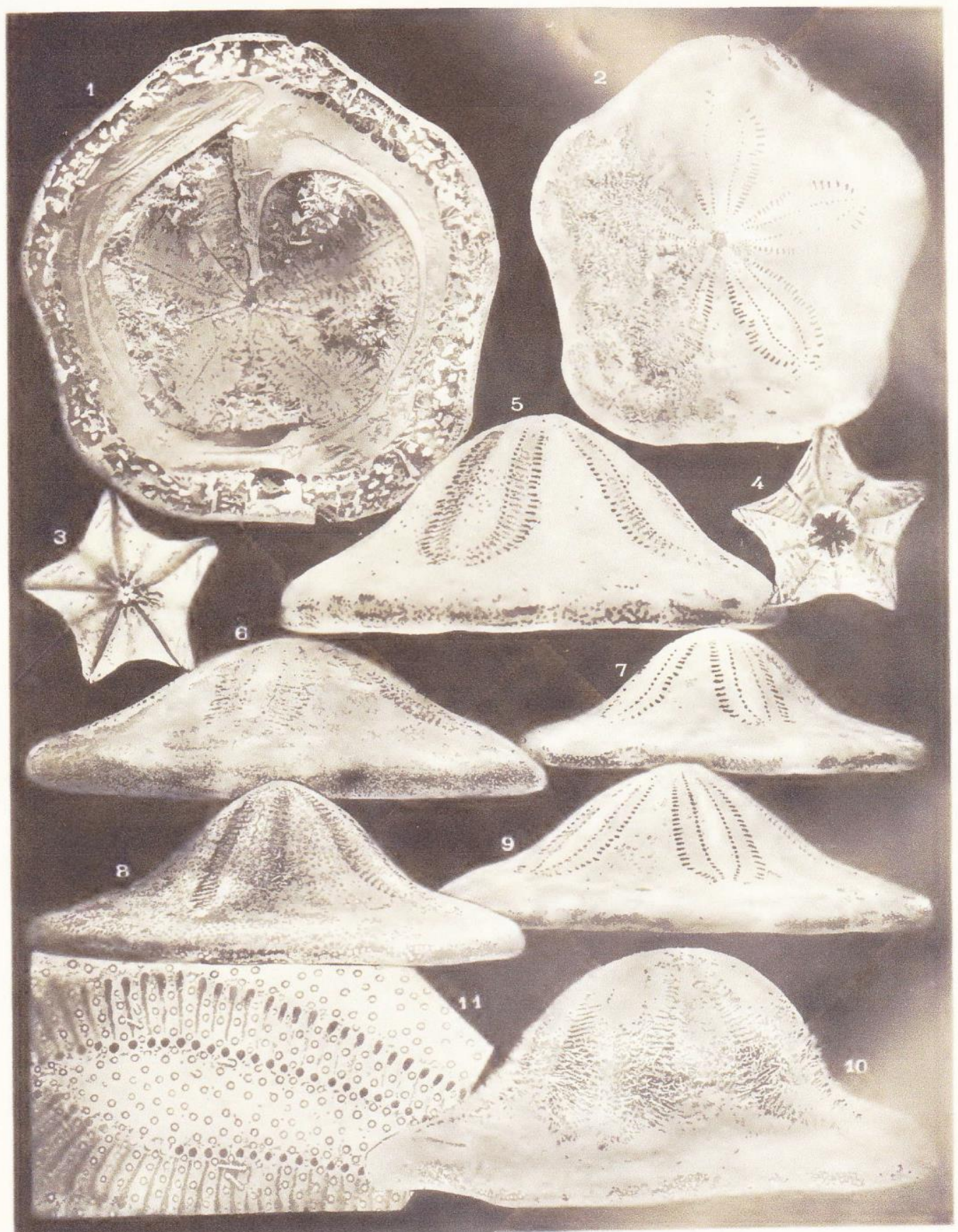

it. Kintiler phot, 


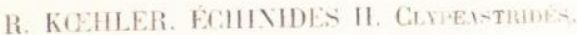

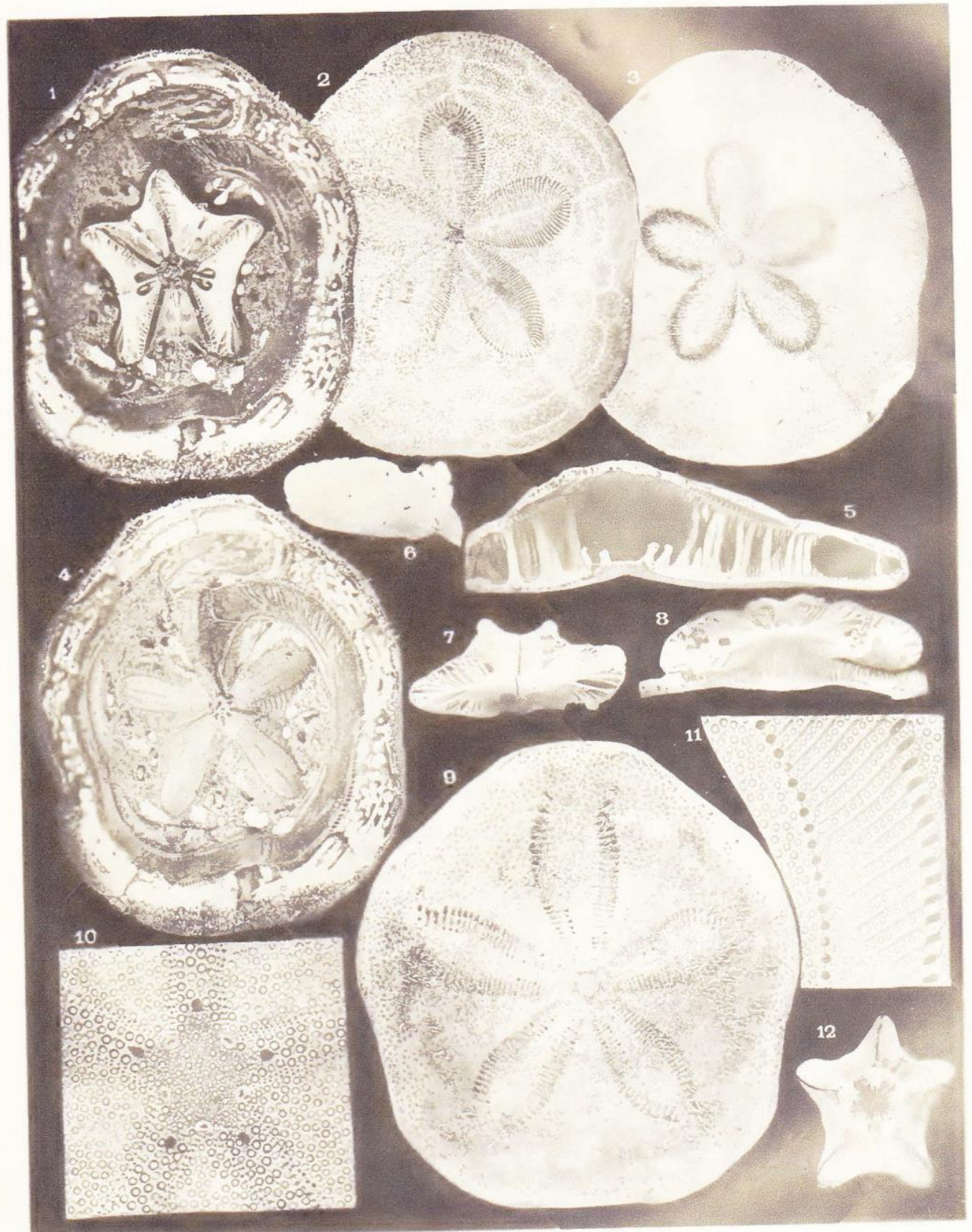




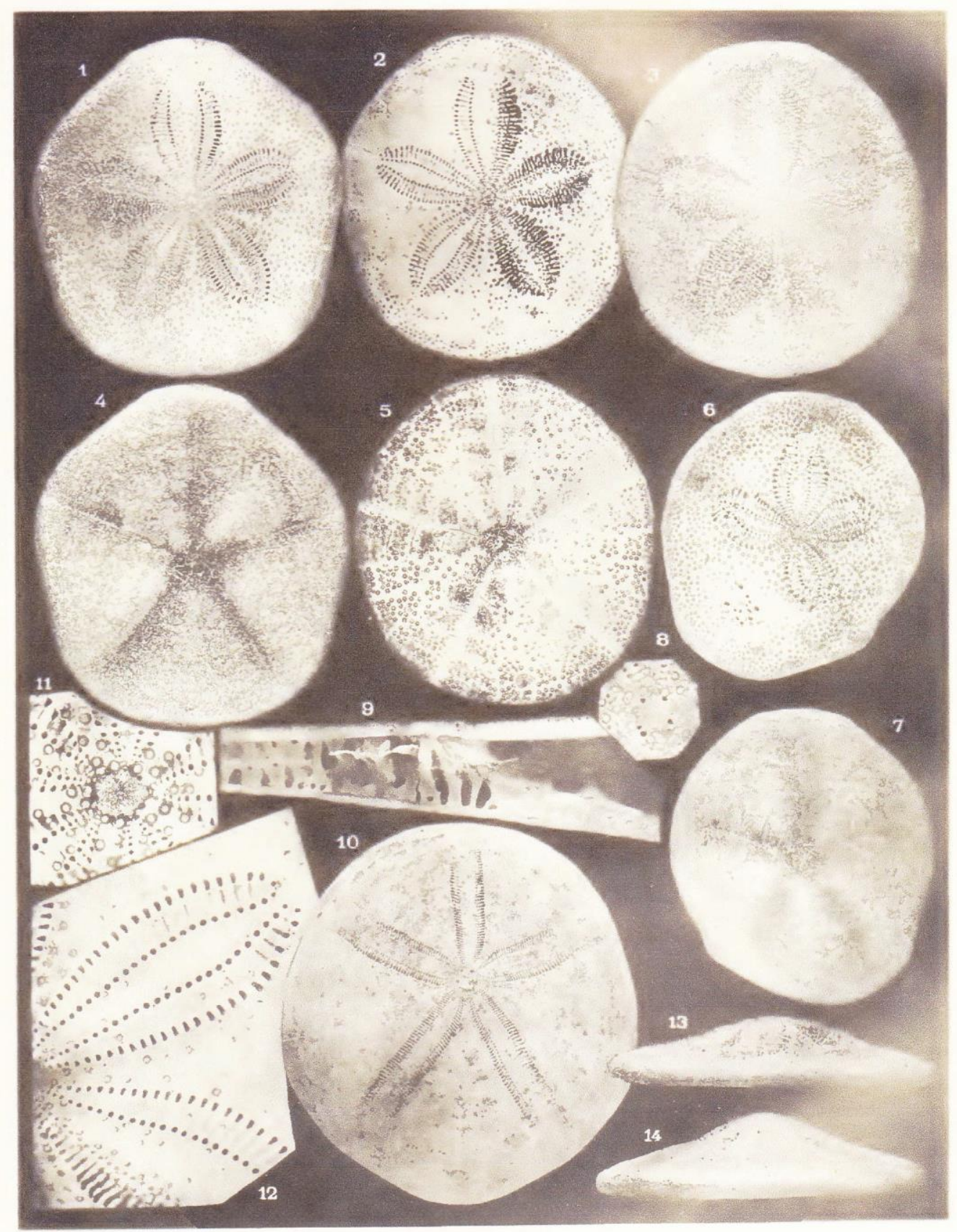




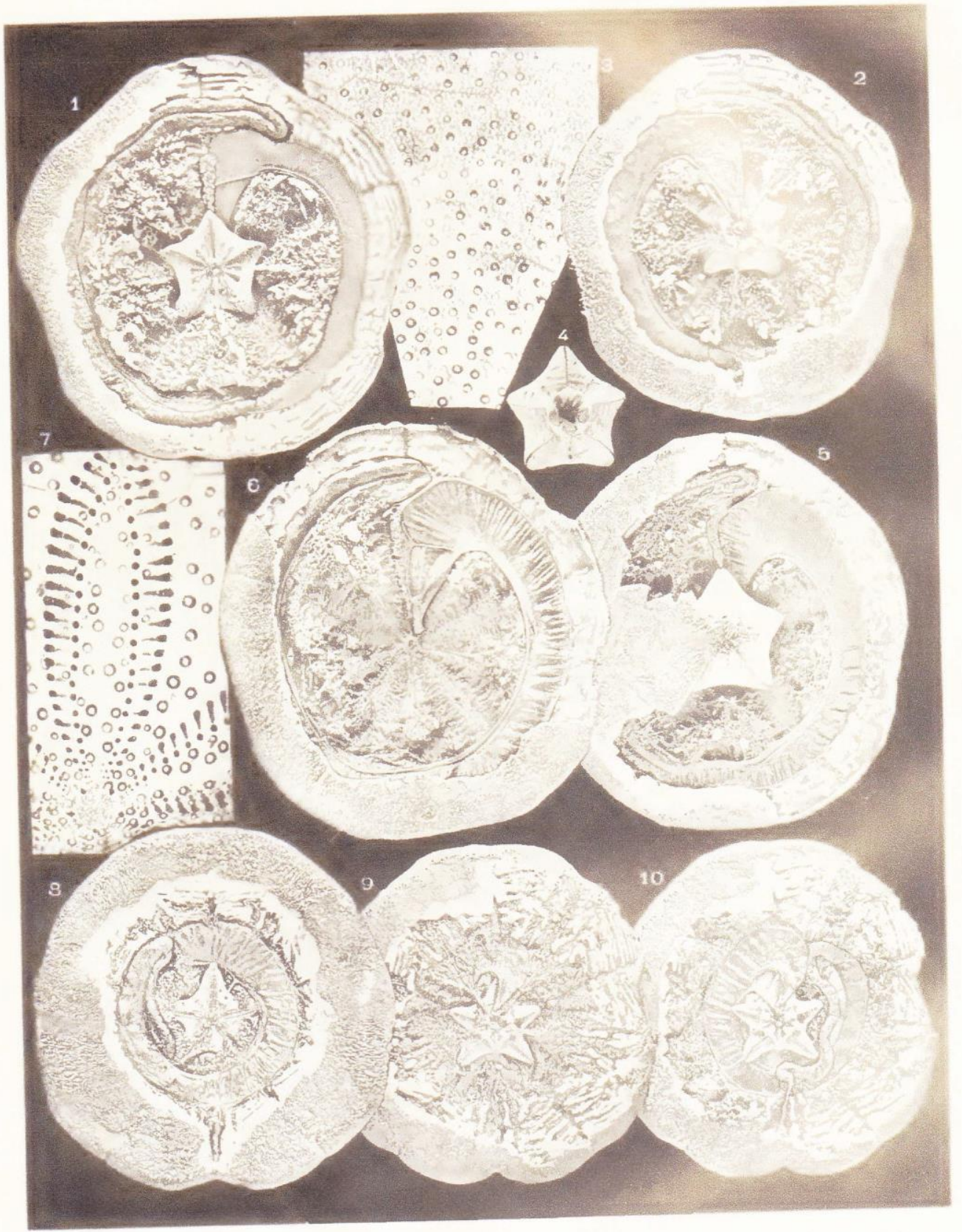

1i. Kintilet phet. 


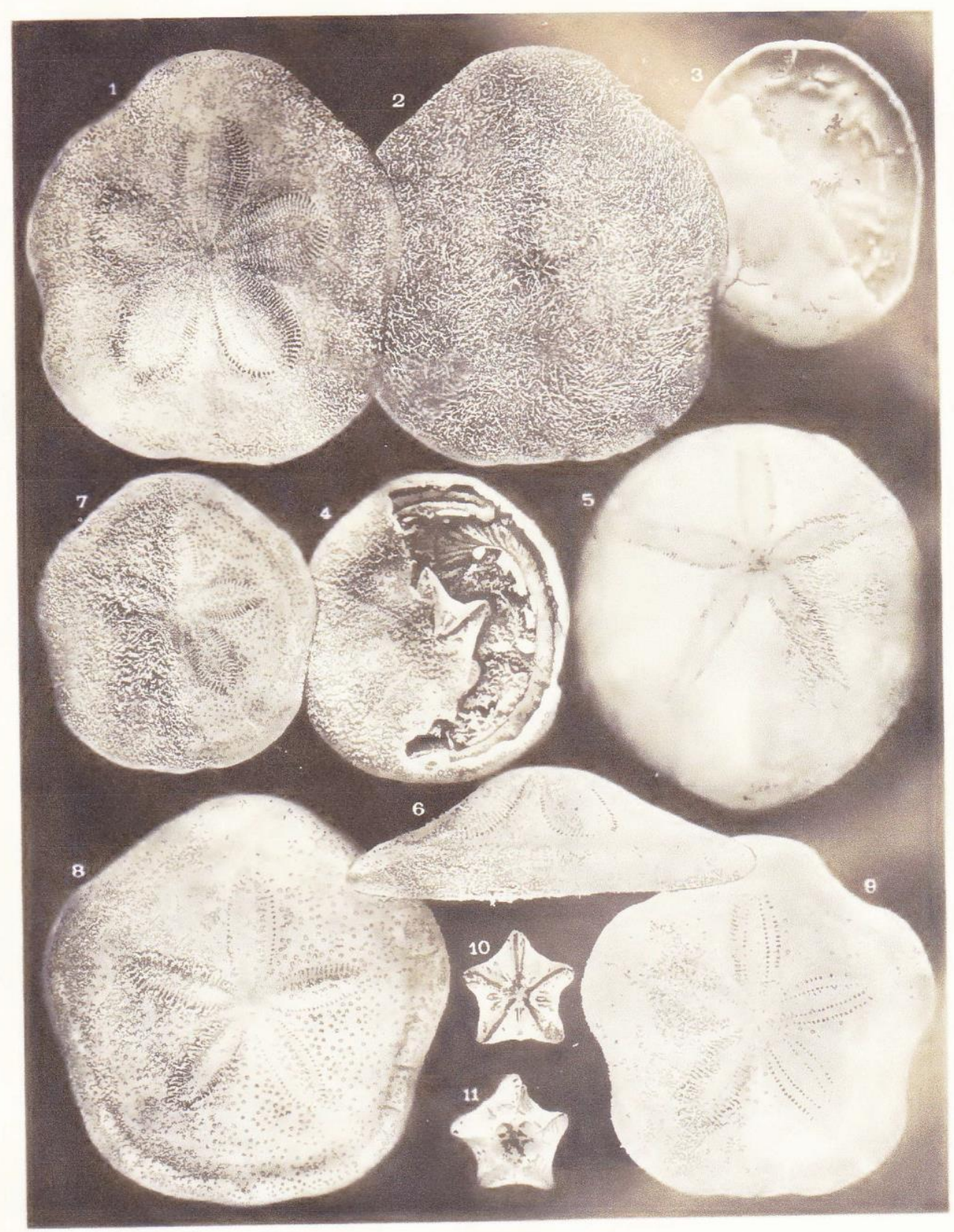

15. Kintater phot

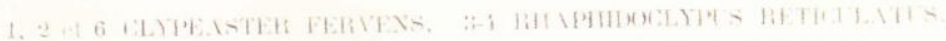

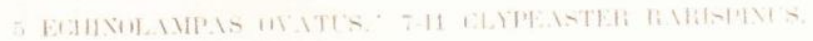




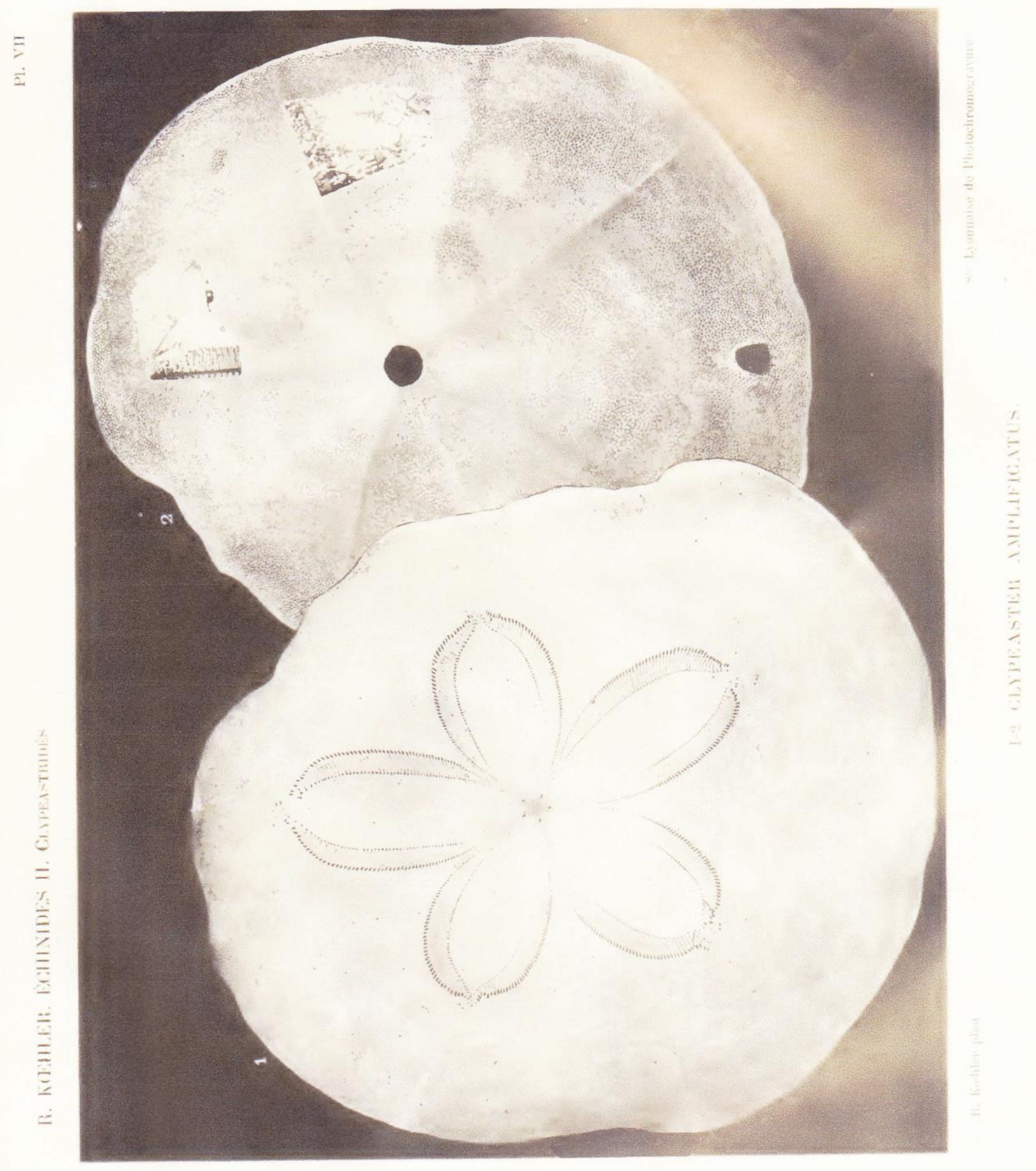




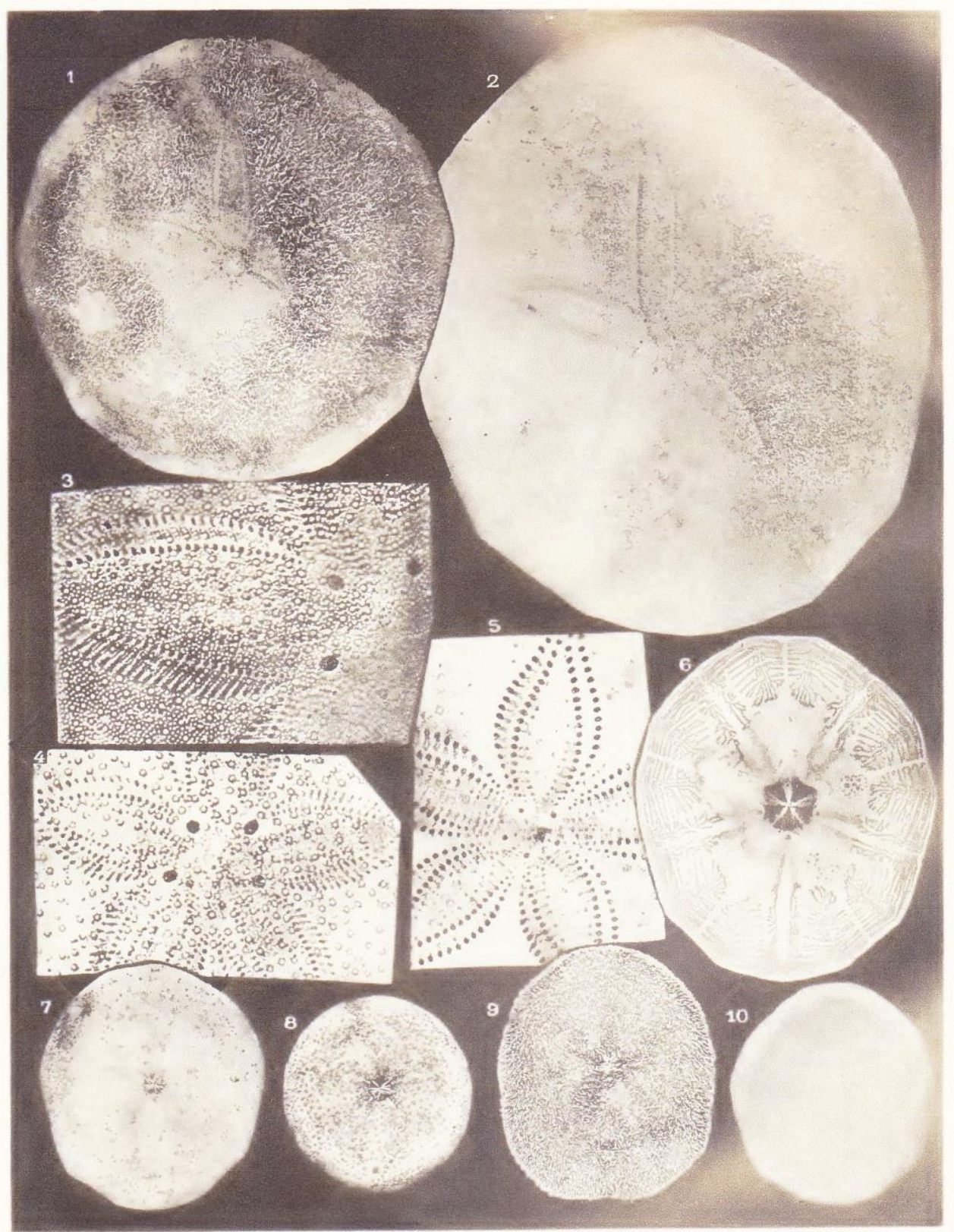

F. Kintiles phinot. 


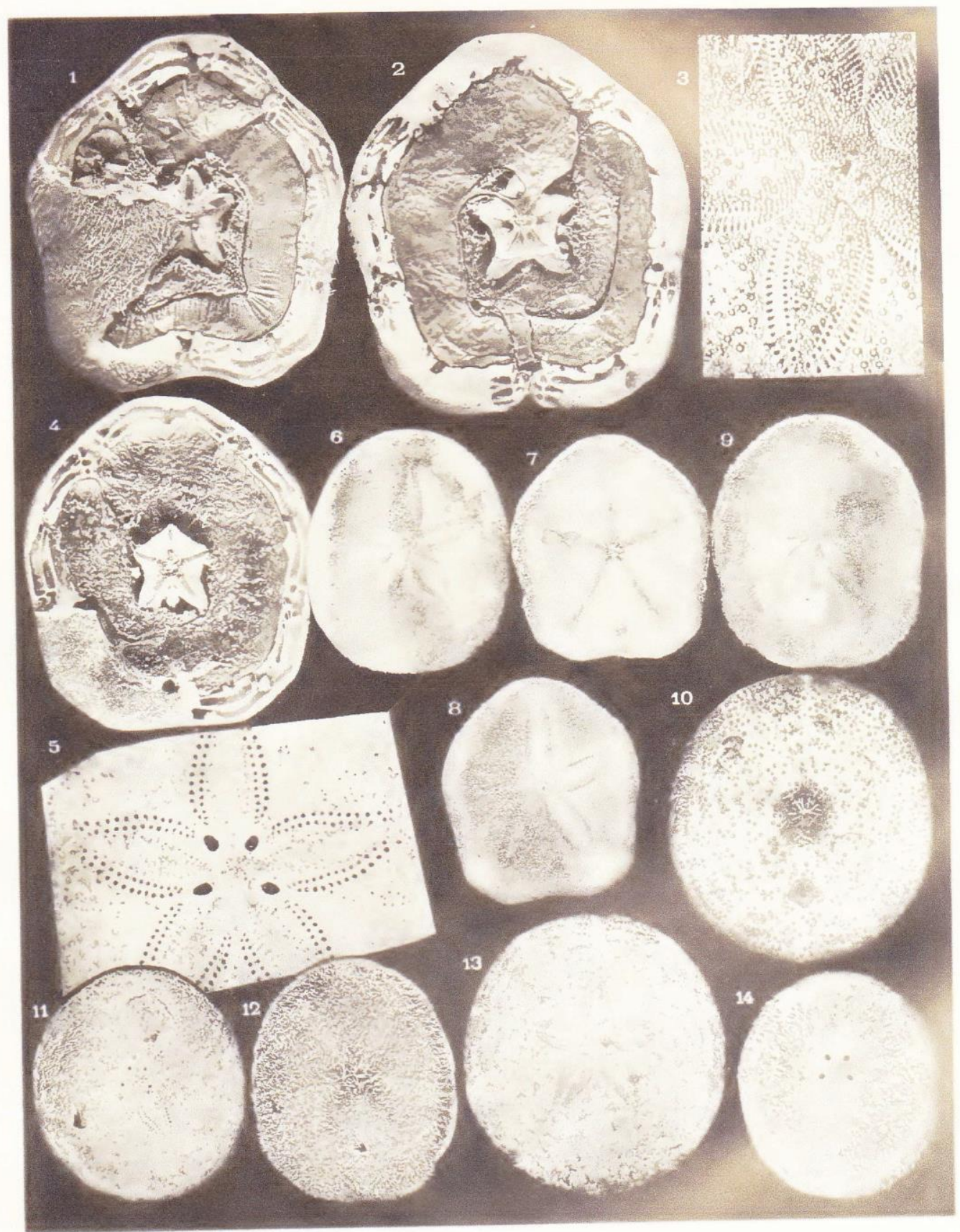




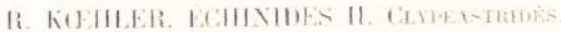

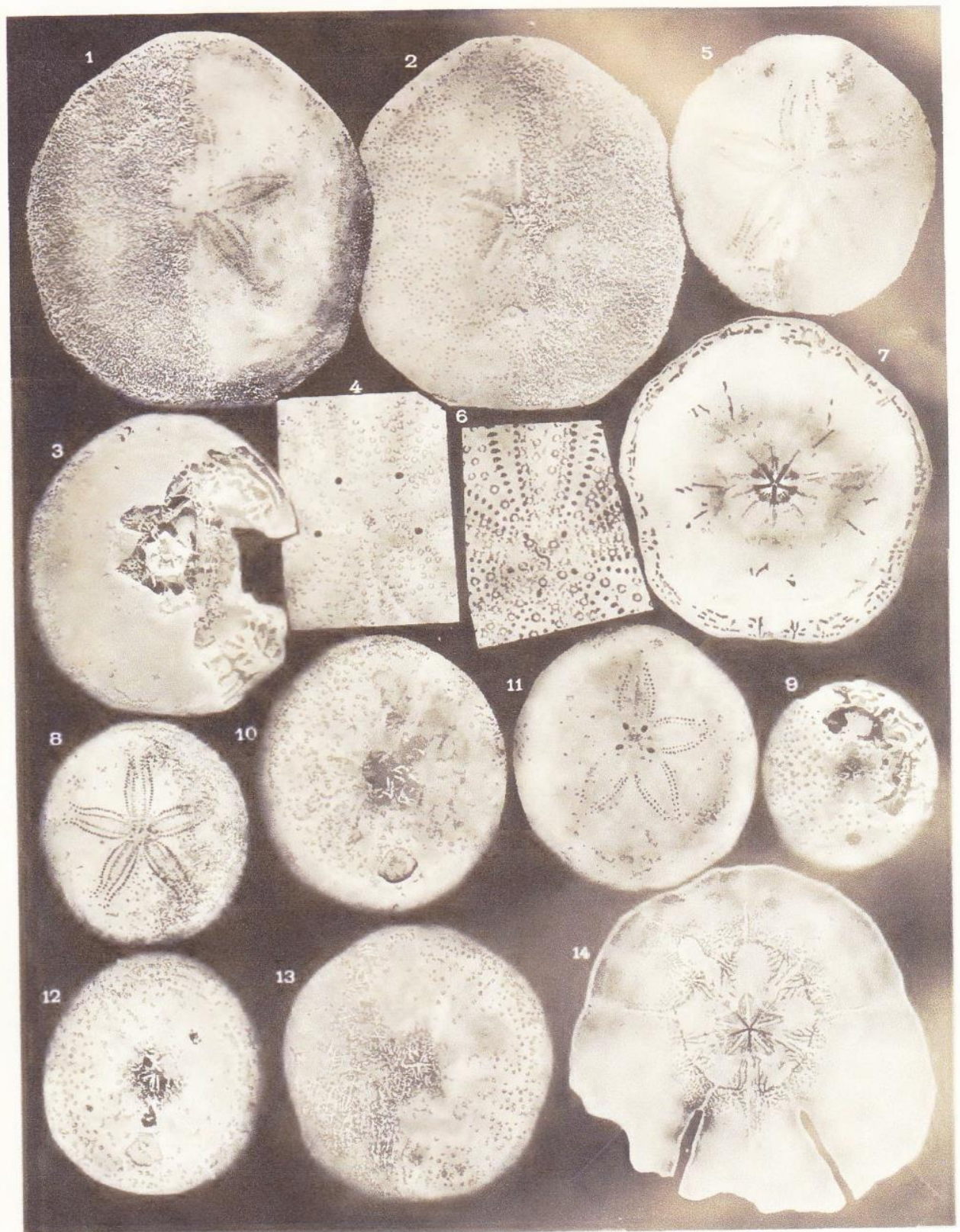

th hiativer th

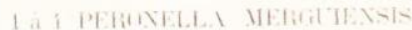

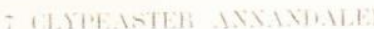

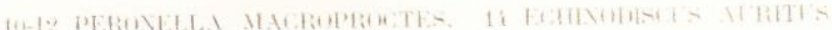




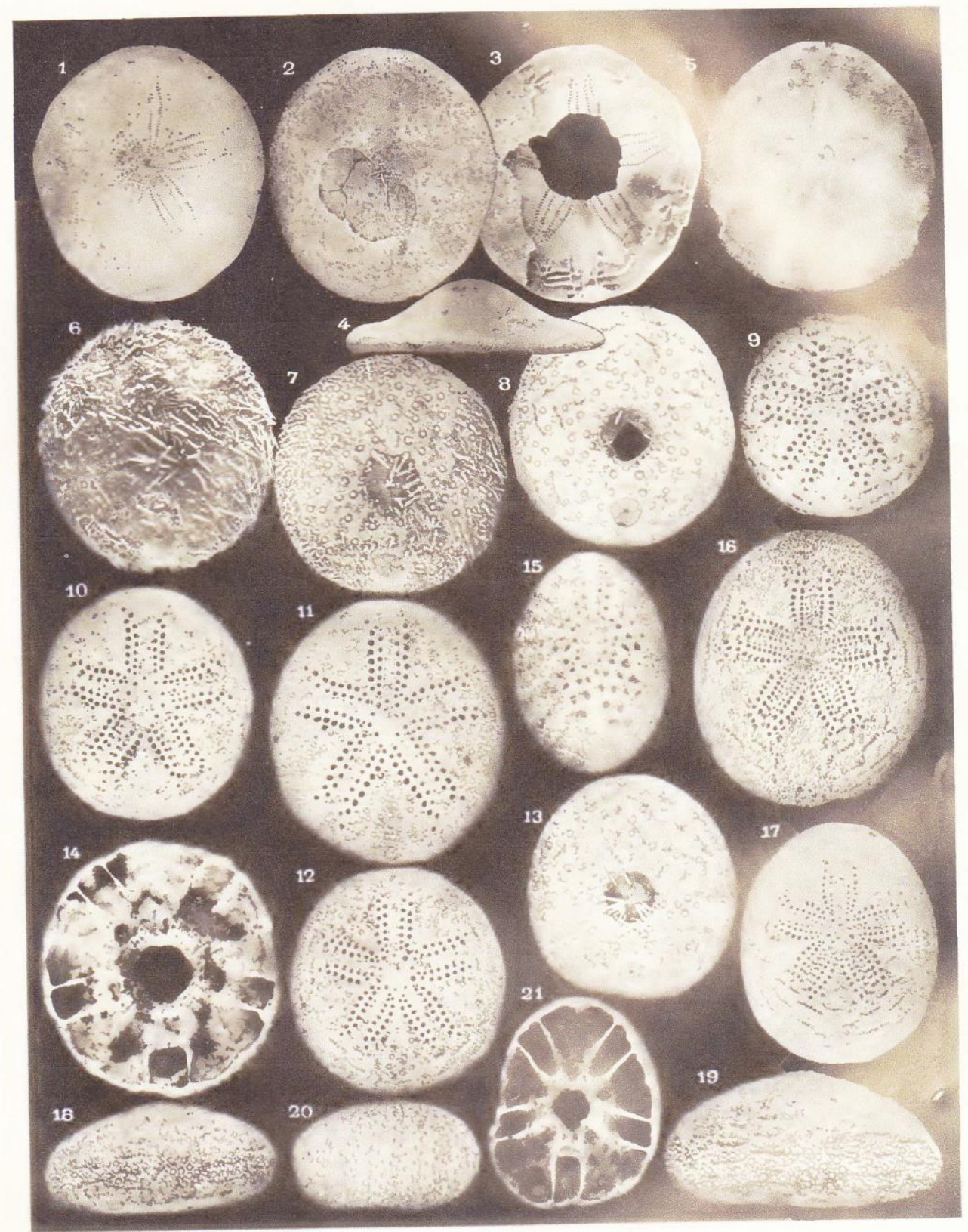

1:. Kiwhter phot

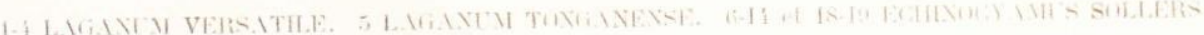

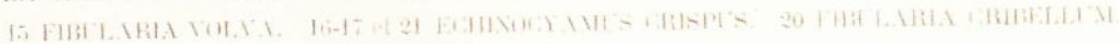




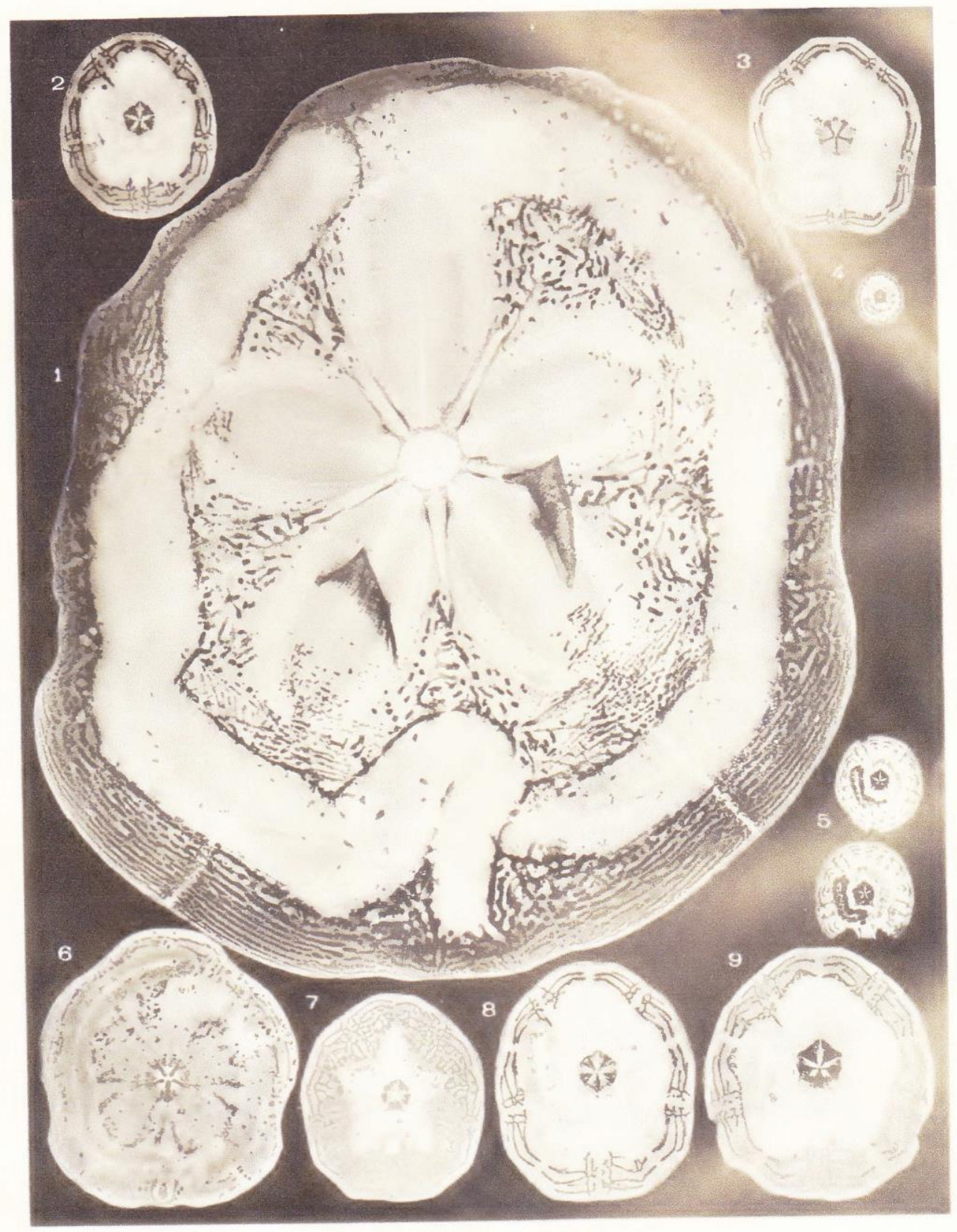

R. Kuthter phot.

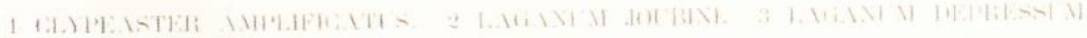

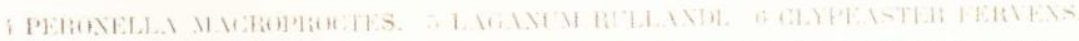

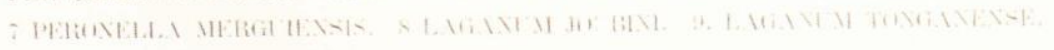




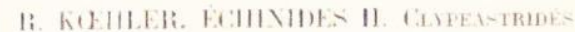

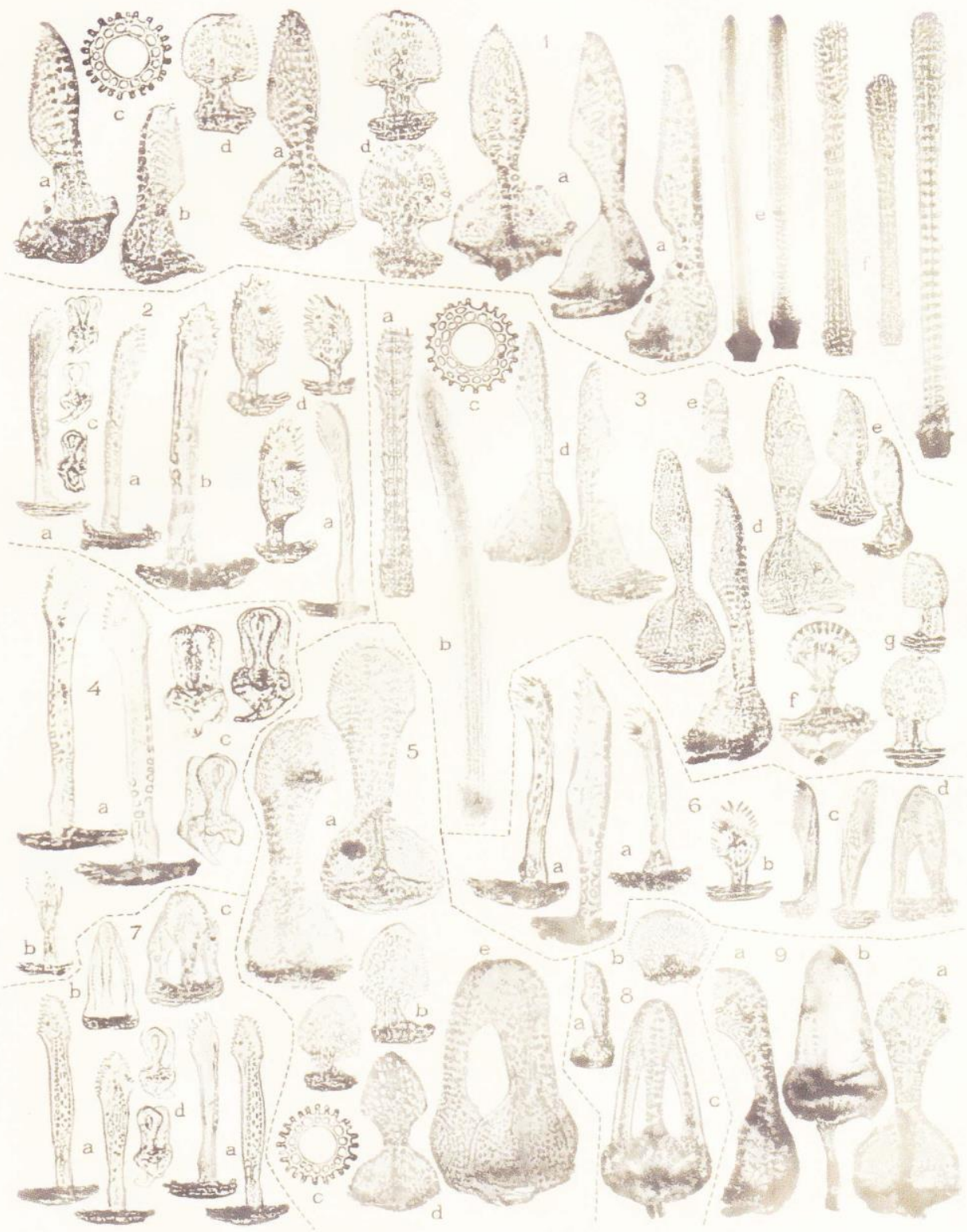

12. hulther phest 


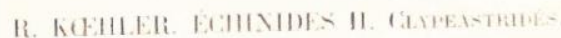

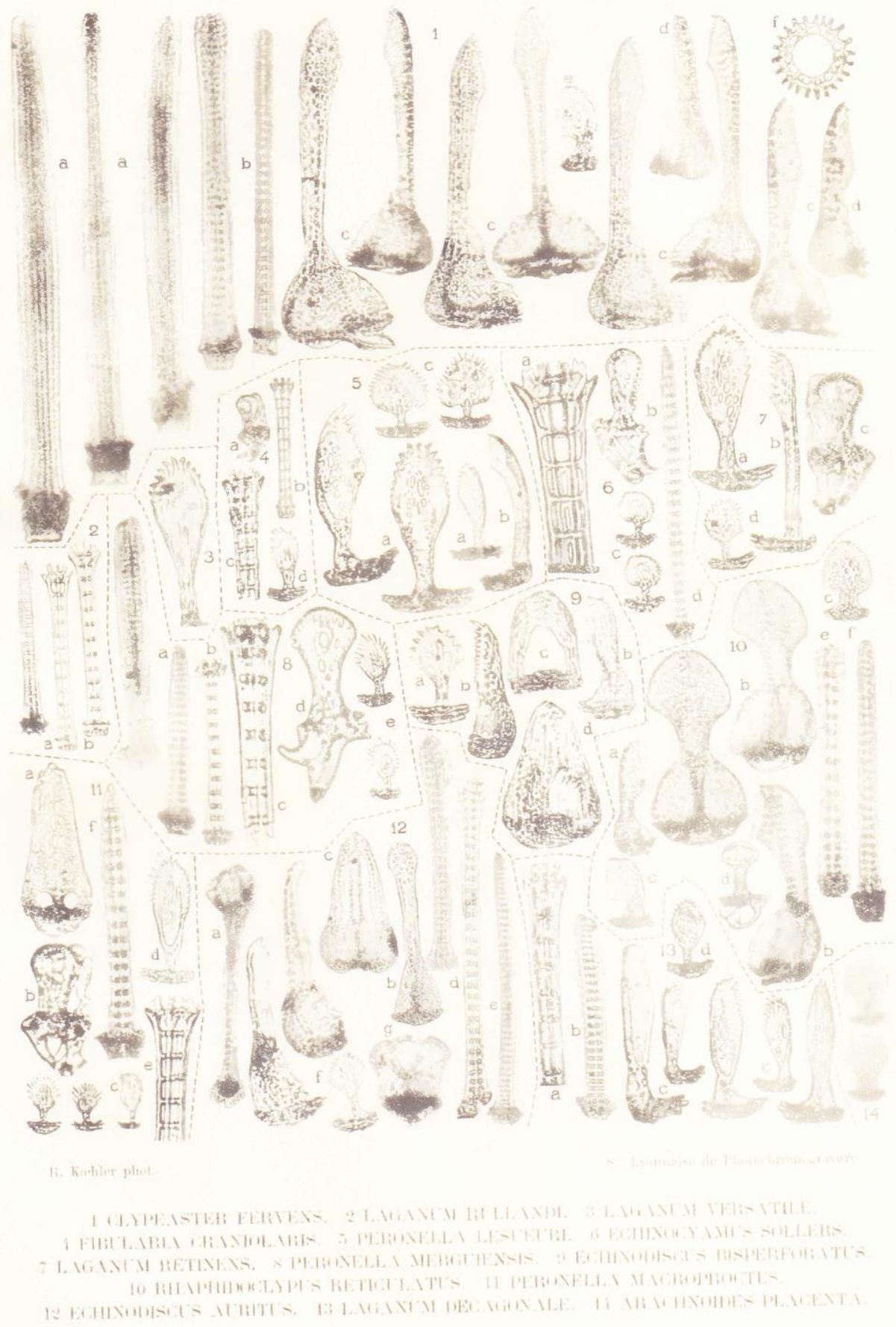

